Article

\title{
Exploring Citizens' Actions in Mitigating Climate Change and Moving toward Urban Circular Economy. A Multilevel Approach
}

\author{
Adriana AnaMaria Davidescu 1,2,*®D, Simona-Andreea Apostu ${ }^{1,3}$ and Andreea Paul ${ }^{4}$ \\ 1 Department of Statistics and Econometrics, Bucharest University of Economic Studies, Romana Square, \\ 15-17 Dorobanți St., Sector 1, 010552 Bucharest, Romania; simona.apostu@csie.ase.ro \\ 2 Labour Market Policies Department, National Scientific Research Institute for Labour and Social Protection, \\ 6-8, Povernei Street, 010643 Bucharest, Romania \\ 3 Institute of National Economy, Romanian Academy House, 13 September 13, 050711 Bucharest, Romania \\ 4 Department of International Economic Relations, Bucharest University of Economic Studies, \\ 15-17 Dorobanti St., Sector 1, 010552 Bucharest, Romania; andreea.paul@inaco.ro \\ * Correspondence: adrianaalexandru@yahoo.com
}

Received: 22 July 2020; Accepted: 3 September 2020; Published: 11 September 2020

\begin{abstract}
Urbanization and climate change are requiring cities to find novel pathways to a sustainable future, and therefore the urban context may accelerate the conversion to a circular economy. In this sense, climate change is a considerable threat to the environment, affecting both human and natural systems, and in this context individuals have a very important role. Therefore, the paper aims to investigate, on the one hand, what determines people to undertake specific actions in fighting climate change and, on the other hand, what determines some people to engage in adopting multiple actions exhibiting extra mitigation behaviour compared to others, paving the way to an urban circular economy. In order to do that, multilevel logistic regression analysis using hierarchical data (individuals grouped in counties), reflecting group variability and group-level characteristics effects on outcomes at individual level has been applied. Special attention was given to modernisation thesis validation, stipulating that citizens from more developed and modernized countries are expected to manifest a higher level of extra mitigation compared to inhabitants of less-modernized nations. The empirical results revealed the positive association of pro-environmental factors, socio-demographic and economic factors with both specific and extra mitigation behaviour in fighting climate change. An important finding of the empirical research highlighted the validation of the modernisation thesis, even if partially, and the reinforcement of the modernisation thesis impact on the extra mitigation behaviour determined by the urban area segmentation. The extra commitment behaviour reflected by citizens' multiple actions in fighting climate change ensures progress to a circular economy through its contribution to waste reduction, eco-shopping increase, on eco-friendly transportation increase or domestic energy reduction. We believe that a shift in citizens' attitude towards climate change is needed, taking into account that a lot must be done" to effectively respond to climate change, paving the way for the circular economy.
\end{abstract}

Keywords: circular economy; urbanization and climate change; multilevel logistic regression; citizens; extra mitigation behavior; EU member states

\section{Introduction}

In the context of urbanization and excessive pollution, on the path to achieving sustainable development, the principles of circular economy become increasingly important and also necessary. The circular economy implies material reducing, reusing, remanufacturing and recycling, but the 
transition is not possible without including environmental considerations, such as climate change. Potential synergies between circular material use, climate change mitigation and the halting of biodiversity loss are increasingly recognized [1].

Urbanization and climate change are determining cities to find novel pathways in order to lead to a sustainable future, therefore the urban context may precipitate the conversion to a circular economy. In this sense, climate change is a considerable danger to the environment, affecting both human and natural systems [2], and in this context individuals have a very important role [3].

Climate change needs to be mitigated, requiring a change in personal behavior, from levels of action or limited action to broader and higher levels of behavioural involvement [4]. A further way of tackling climate change is represented by the adoption of auxiliary actions leading to a higher level of engagement in climate change mitigation going beyond what most people do [5].

Cities represent the link to circular development, the city administrations being able to specify and inform a circular vision and strategy. Cities can provide opportunities for accessing, purchasing, promoting and stimulating circular solutions.

The movement to a circular economy is not easy, particularly for companies in which all the operations are deeply subordinated to the linear approach, production processes must first be transformed from linear to circular [6] and, accordingly, the implications of such a transformation refers to changes of processes, additional investments, modifications in equipment and production, shifts in raw materials, as well as personnel re-training with consequences on extensive value chain.

The current model of wasting resources involves depleting the natural capital of the Earth, generating irrevocable and alarming effects on both environment and climate.

Climate change is a serious environmental challenge, the reduction of greenhouse gas (GHG) emissions representing an important target that can be acquired only by the involvement in actions targeting the increase of resource efficiency, prolonging the lifecycle of buildings and goods, enhancement of recycling and reuse together with a decline in primary raw materials [1].

Therefore, the main objective of the research is two-fold: on the one hand to enhance understanding of the main environmental, socio-demographic and economic determinants of citizens' specific actions to mitigate climate change and, on the other hand, to investigate factors related to a higher level of extra commitment in fighting climate change in an urban context.

Thus, the paper aims to answer to the following main question: "What determines some people engaging in adopting multiple actions exhibiting extra mitigation behaviour compared to others?" Finding a reliable respond to this question will also provide solutions that will help stakeholders to make the transition to an urban circular economy.

More in depth, the research aims also to respond to specific research questions through the results provided by the multilevel approach: what are the main characteristics of pro-environmental behaviour associated to an increased level of engagement in adopting specific actions in fighting climate change as well as an extra mitigation behaviour? What are the main socio-demographic characteristics associated with a higher level of engagement in adopting specific actions in fighting climate change as well as an extra mitigation behaviour? What are the main economic characteristics associated with an increased level of engagement in adopting specific actions in fighting climate change as well as an extra mitigation behaviour? Is extra mitigation behaviour to climate change higher in more modernized developed economies? What is the extent of between-country variation in adopting taking specific actions as well as in developing extra mitigation behaviour in fighting climate change? Can between-country differences in fighting climate change be explained by differences in individual characteristics? Does the effect of modernization thesis on the extra mitigation behavior depends on the segmentation of large town vs. small or medium town?

In order to mitigate climate change and also to pave the way to circular economy, the role of citizens is fundamental and a shift in personal behaviour is required. In combating climate change, the actions need to cover multiple measures and to target the implications of the main actors-local governments, business sector, civic society, environmental organisations and European institutions. 
In the paper, the focus is on the role of citizens, the personal mitigation behaviour referring to voluntary behavioural responses to climate change.

The article makes its contribution to the literature in the following four ways. Firstly, it investigates factors related to specific actions made by citizens to combat climate change, revealing the main individual determinants that could lead citizens to make a certain action by the analysis of 13 self-reported actions, revealing also how the actions taken to combat climate change could support the shift to a circular economy.

Secondly, the study investigates factors related to citizens' profile characteristics leading them to adopt specific actions to address climate change, highlighting the differences among individual actions.

Thirdly, the study explores the individual extra mitigation behaviour in fighting climate change, analysing the individual behaviour in terms of cumulative actions, taking into account that according to Ortega et al. [5], a lot must be done to effectively address climate change. More in depth, the research examines the between-country variations related to both citizens' actions in tackling climate change, as well as an extra engagement level in combating climate change using a staged multi-level logistic regression model based on hierarchical data (individuals within countries). The utility of this category of models have been acknowledged also by Ortega-Egea [5] who mentioned that multilevel models are the most appropriate in tackling environmental researches.

In particular, the research makes a contribution to climate change research by testing the modernization thesis according to which an extra mitigation behavior for climate change is higher in more modernized developed economies, highlighting also how a broader and greater level of commitment can pave the way to a circular economy.

Fourthly, for exploring country discrepancies in both specific and extra mitigation behaviour to fight climate change, the dataset of the recent Eurobarometer 91.3 Rule of law and climate change has been used [7], having the advantage of using the most recent large-scale survey conducted at the end of 2019. In such a way, the study contributes to the research field through an advance of current understanding of climate change extra mitigation behaviour reinforcing also the main implications for supporting the shift to a circular economy. The main results of the research represent a useful tool mainly for policy-makers that need to focus on expanding the engagement level in tackling climate change both among citizens and across countries.

The paper is organized as follows. The Section entitled "Literature review" offers an overview of the most proper studies regarding climate change mitigation and its implications for the transition to a circular economy. Section 3 offers additional information about the data used in the analysis providing also a brief description of the methodology used within the paper. Section 4 is divided into five main sub-sections presents the descriptive profile of the respondents, a brief analysis of climate change mitigation actions among European Union (EU) countries and also the sub-sections of multilevel models results, summary of findings in relation to specific mitigation and extra mitigation behaviour and discussions in relation to the man findings. The paper ends with concluding remarks and also by highlighting limitations and recommendations for further study.

\section{Literature Review}

The circular economy emerged as a response to maximize the reuse of assets and products and minimize their depreciation [8] becoming the driving force of sustainable land development, aiming to maximize resource efficiency together with impact reduction on environment [9].

The circular economy put together four main actions: reduce, reuse and recycle and remanufacture of materials in the processes of production, distribution and consumption [10,11]. The circular economy relies mainly on resource and environmental efficiency, aiming to provide key measures that will assure the transition to a greener and more sustainable economy [12].

Korhonen et al. [13] define the circular economy as an approach aiming to fight against environmental challenges and encourage sustainable development, reducing both the input of virgin materials and waste production by closing the economic and ecological curves of resource courses [14]. 
The circular economy achieve optimal production by simultaneously minimizing the use of natural resources, minimizing waste by reusing production, and minimizing pollution by recycling and restoring industrial unnecessary waste [15].

The circular path is more than just a recycling and environmental issue, it represents a new approach to thinking about how to grow and develop without resorting only to spending resources [16], but reusing them. Reuse supports resource efficiency, reducing air, water and soil pollution during the lifecycle of the product [17]. In this context, circular economy can play the fundamental role of driving force, strongly supporting the attainment of Sustainable Development Goals [18].

There are many definitions for climate change in the literature, but the most prominent has been provided by the Ellen MacArthur Foundation [19], according to which circular economy represents an industrial system designed and intended to be restorative or regenerative, replacing restoration with transition to renewable energy usage. This excludes the use of toxic chemicals, which impair reuse, and eliminate waste $[20,21]$.

The circular economy represents a model of generating and waste, involving the distribution, rental, reusing, repair, reconditioning and recycling of materials and products as long as possible, aiming also to increase the product lifecycle.

Therefore, the circular economy has 3 dimensions:

sustainable food system that can lead to improved efficiency, solving logistical problems and protecting food security in the agricultural sector;

resource management and waste optimization that can improve the waste-recycling process; reducing pollution that has raised awareness about polluted cities and the associated health risks [22].

The circular economy relies on three major principles: waste and pollution reduction, preserve using products and materials; reestablishing natural systems [19].

The transition to a circular economy implies targeted changes implying all three actors: civic society, governments and business sector, with consequences on different subsystems: energy, logistics and financial subsystems and clear guidance and monitoring [23]. The circular economy involves both public actors responsible for sustainable development and planning, as well as businesses seeking economic, social and environmental results and society that should ask itself about its real needs [24].

The urban population is constantly growing, so cities must meet the criteria of sustainability. UN-HABITAT (2011) [25] reported that urban areas generate 70\% of global greenhouse gas emissions and $50 \%$ of global waste [26]. In this sense, measures are being taken in the field of sustainability, cities and communities being encouraged to apply ingenious strategies to address circularity on urban scale [27], reducing the breadth of global waste streams and emissions [28].

The model of circular economy implies reusing, reducing, recycling and remanufacturing [29] (Figure 1), representing sustainable ecological growth by extending the life of products and materials and reducing waste. The path to circular economy should also include environmental considerations, such as climate change [30]. The circular model has many environment, climate, social and economic benefits, one being the mitigation of climate change [1].

In 2019, the World Economic Forum stated that the circular economy could represent an important tool to avoid climate change [31]. Reducing greenhouse gas emissions in the circular economy is reflected by increasing resource efficiency, by raising the life of construction and goods, increasing recycle and reuse, and a complete reduction in using primary raw materials. According to the Committee on Climate Change (CCC), the transition to a circular economy must be a part of climate change. As part of Covid-19 recovery plan that prioritizes the climate crisis, the CCC has urged the governments to hurry the transition to a circular economy, reiterating its call for a ban on biodegradable wastes to landfill by 2025 [32].

A major global challenge is represented by climate change [33], requiring the international community to adopt mitigation strategies having as their main target limiting the average increase 
of global temperature $[34,35]$. Climate change is a major, anthropically caused environmental risk, with important effects for human and natural systems [36].

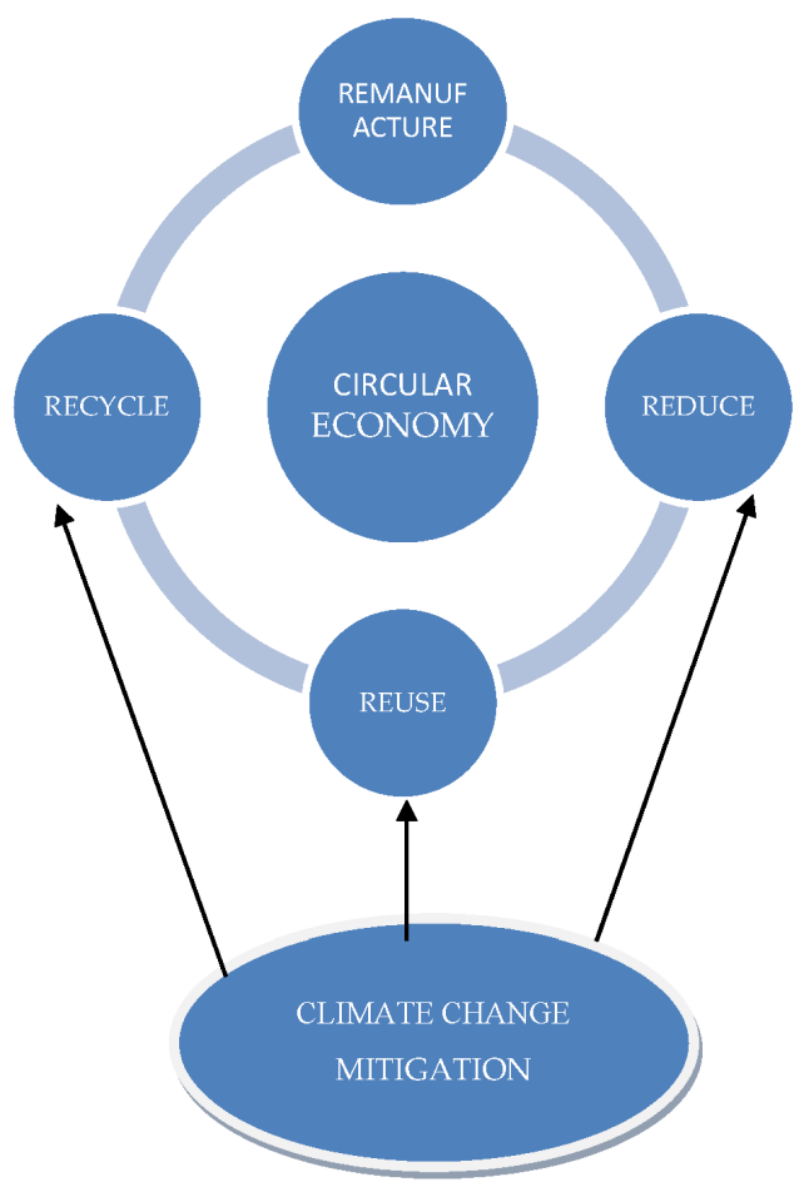

Figure 1. The implications of climate change mitigation on the transition to circular economy. Source Author's contribution.

Under the Framework Convention on Climate Change, climate change is defined as a climate modification attributed to human activity, altering the the global atmosphere composition [37]. According to the Intergovernmental Panel on Climate Change, climate change is defined as any modification regarding climate caused by natural variability or human activity [38].

Climate change is significantly influenced by humans, the main changes occurring in the atmospheric composition. These are caused by emissions associated with energy consumption, urbanism and land-use changes, being very important at local and regional level. Although certain progress have been achieved in the processes of monitoring and exploring climate change, several scientific, technical and institutional obstacles still have to be overcome in order to design, plan for, adapt to and mitigate the impact of climate change [39].

Climate change mitigation calls for cooperation both national governments and consumers, the mitigation effort being concentrated on reducing sources and amplifying greenhouse gas sinks, requiring concerted efforts of both national and international institutions that take quite a long time [40]. One potential solution for urgent measures is the increase in the level of citizens' commitment by adopting voluntary more-sustainable and low-carbon lifestyle alternatives.

Through a higher level of individuals' engagement, a higher level of receptivity and response to change messages, emissions from home using up and personal transportation could be significantly attenuated [41]. 
The most important factor causing climate change is excessive energy consumption, so in order to adopt a new low-carbon paradigm, energy reduction is needed, both on businesses and civil societies [3]. Even if climate change is generally seen as a global issue and municipal governments have their local agenda as an important tool to control greenhouse gas emissions, the mitigation behaviour cannot be improved without the help of state and national policy changes [42].

In this fight against climate change, the contribution of citizens becomes increasingly important [43], they acquiring the role of agents of change in field of environment [44].

Although the anthropogenic cause of climate change is scientifically proven, people consider different causes regarding climate change, such as: natural processes, human activities, determining both risk perception and mitigation behaviour [45].

In industrialized countries, the principal cause of climate change is the lifestyle [41], with high level of carbon emissions, with households responsible for $20 \%$ of total greenhouse gas emissions [46] and over a quarter of the final energy consumed [47]. Therefore, individuals have a very important role in the face of climate change [3], either adapting to potential and unavoidable climate impacts, or decreasing GHG emissions to avoid further damage [48].

The literature is focused on different specific actions undertaken to combat climate change in relation to the transition to a circular economy, grouped in four main categories: eco-friendly transportation referring to: low fuel consumption car, electric car, alternatives to car use, travel carbon footprint considered; domestic energy reduction referring to: insulated home better, low-energy home, energy efficiency households (EFF HH) appliances, switched energy supplier, energy-saving equipment home, installed solar panels home; eco-shopping referring to: food carbon footprint considered; and waste reduction refering to: reduce and separate waste, use less disposable items (Figure 2).

Previous studies targeted very intensively recycling [17,18], reducing the use of the car and adopting another means of transport that supports the environment, [22,49] or explaining involvement in environmental citizenship [19] by various individual factors [12,23-30,50]. The relevance of pro-environmental behavior has proved its stability over time [11,33] being related to ecological behavior [34]. Ortega-Egea et al. [5] analysed the main factors related to an extra mitigation behaviour among individuals, revealing the relevance of gender, age, attitudes, knowledge and political ideology in combating climate change.

Although most people consider climate change and sustainability to be important issues, too few citizens are taking action to stop the growing flow of greenhouse gases and other related issues. This is due to adverse climate infrastructure, and psychological barriers such as: limited knowledge of the issue, ideological conceptions of the world that tend to deter a pro-environmental habit, comparisons with other key people, low costs and time of behavior, discrediting of experts and authorities, perceived risks of change [51].

The models tested in the research propose that environmental factors, socio-demographics and modernisation theory-related factors enhance understanding of citizens' specific actions to mitigate climate change as well as the extra mitigation behavior in fighting climate change in urban context.

The literature review is structured on the four main factors related to climate change mitigation: environmental factors, demographics factors, socio-economic factors and state-level factors. 

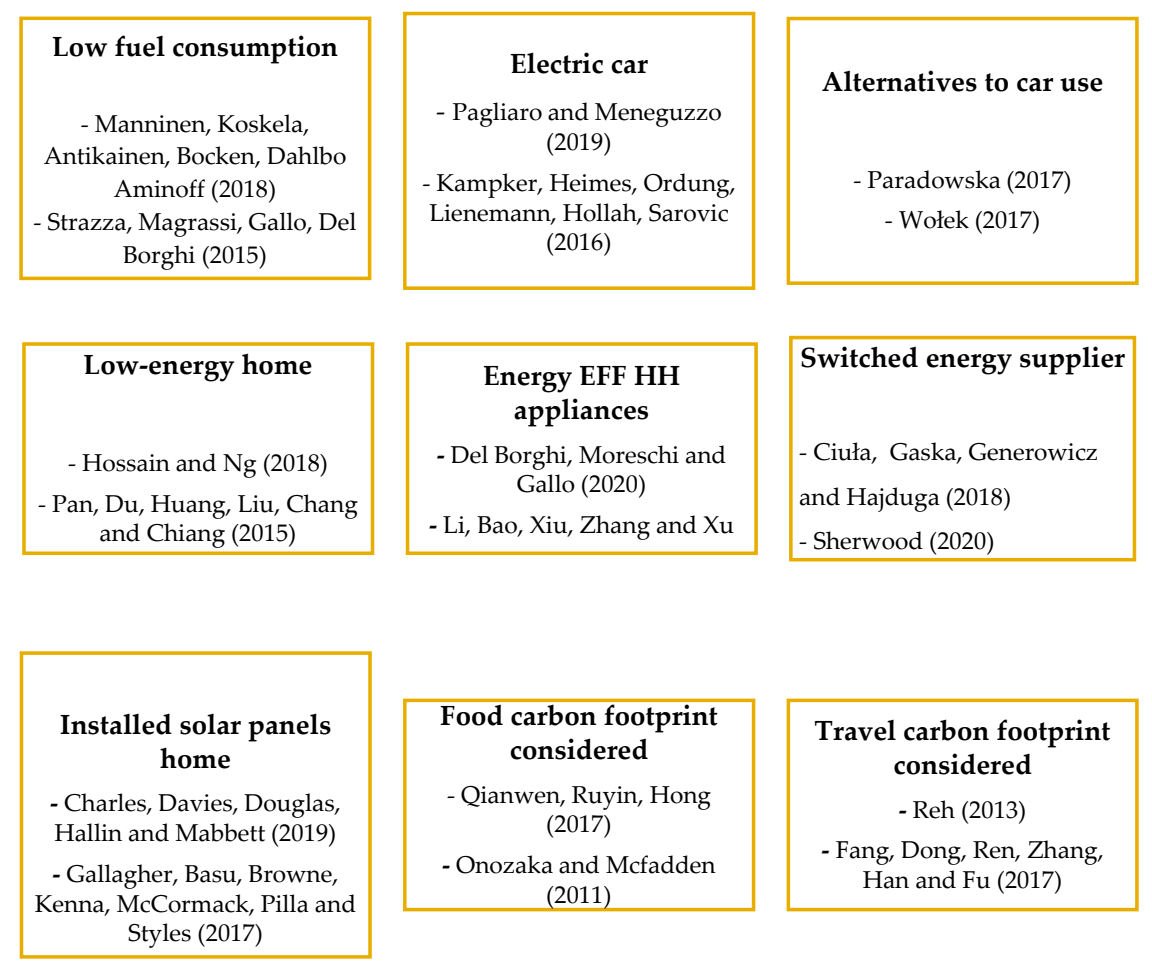

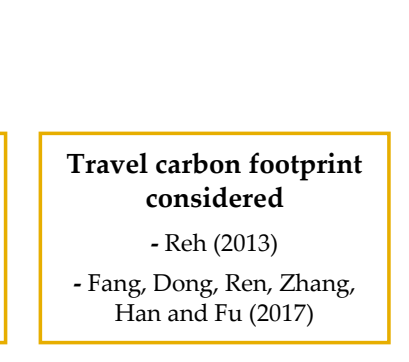

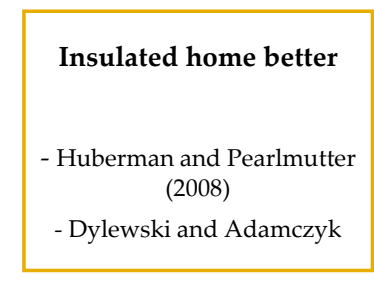

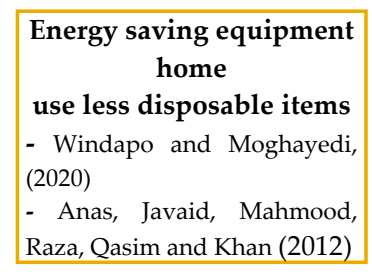

\begin{tabular}{|l|}
\hline \multicolumn{2}{|c|}{ Reduce and separate } \\
waste \\
- Malinauskaite, Jouhara, \\
Czajczyńska, Stanchev, \\
Katsou, Rostkowski, Thorne, \\
Colón, Ponsá, Al-Mansour, \\
Anguilano, Krzyżyńska, \\
López, Vlasopoulos and \\
Spencer (2017) \\
- Veleva, Bodkin and \\
Todorova (2017) \\
\hline
\end{tabular}

Figure 2. An overview of the most relevant studies concerning specific mitigation behaviour and its relation with the circular economy. Source: Author's contribution.

\subsection{Perceived Importance of Climate Change}

The pro-environmental and climate change motivated behavior has been analyzed in the literature [52-63]. The concept of global environmentalism [63-65] emerged as a consequence of environmental degradation, joint with pro-environmental actions in wealthy and developing countries [66,67]. The globalization hypothesis was debated in specialized studies $[67,68]$, with some studies $[51,54,57-59,68,69]$ supporting the country significant differences regarding public environmental concern and protection, including climate change mitigation efforts [62].

People do not take any action to mitigate climate change because they do not believe that climate is changing and, if it does, they deny the involvement of human activity [70-73]. According to Tranter and Booth [74], the proportion of climate sceptics was around one-fifth of the interviewed respondents from the dataset of the 2010 International Social Survey Programme, while according to the World Values Survey, the proportion of sceptics is even lower, the general perception being as "very serious" issue [75,76]. The results of 2017 Pew Global Attitudes and Trends survey [77] revealed that almost $61 \%$ of respondents from 38 countries acknowledged that climate change is a "major threat" in case of their country and only $23 \%$ of them consider climate change a "minor threat".

People's opinion about climate change is influenced by the position of scientists on this issue, the disagreement of scientists on global warming leads to the new indivisibility to global warming and can be reduced for climate policy [78].

Some people do not believe in climate change, in its anthropogenic character and its importance to humans and nature $[67,68,74,79,80]$. They are climate skeptics and represent at most one-fifth of respondents to the 2010 International Social Survey Program [74], being more prevalent in Anglo-American countries, especially in the United States [81,82]; however, they represent a declining minority [83-85]. Therefore, most people consider climate change to be anthropogenic, real, and costly [86]. 


\subsection{Climate Change Perceived Responsibility}

In the context of climate change, responsibility is the obligation of people to achieve their goal of protecting the environment [87]. Regarding how individuals respond to climate change, four typologies can be identified-community, systemic, skeptical and economist; most of them claiming that individuals act based on their perceived responsibility regarding climate change. It is worth mentioning that under these circumstances, behavioural change is seen as an optimal combination of living standards, knowledge of the causes and climate change contributions and harmful emissions intensity, involving actions of individuals as voters and consumers [88].

Responsibility in the case of climate change is also attributed to state institutions, governments and churches taking action so as to reduce dependence on carbon-based energy sources $[89,90]$.

\subsection{The Perceived Importance of Climate Actions}

The perceived importance in the case of climate change is influenced by environmental position and climate change knowledge, the relationship being mediated by risk perception [91].

Bockarjova and Steg [92] highlighted that measures to combat climate change are associated with health, including quitting smoking or promoting exercise, and changing behavior patterns. In this context, Bergantino and Catalano [93] consider that age, sex, employment status and the number of young children significantly influence the psychological profiles of respondents.

For civil societies fighting against climate change it is very important that citizens are well informed and know about this problem [94]. In this regard, informational efforts have been made to encourage public and voluntary involvement in climate change mitigation actions $[95,96]$. Other measures that have led to public awareness and preoccupation about climate change are economic incentives, subsidies and related interventions [97].

\subsubsection{Gender}

Pro-environmental behavior is influenced by gender, with women being more likely to take action to combat climate change $[98,99]$. Women are more likely to work for the environment in response to climate change by reducing waste and saving energy during the day $[55,100]$. Other studies have highlighted the greater concern and involvement of women about the environment compared to men $[98,101,102]$. Ortega-Egea [5] found evidence although weakly that female gender was more inclined to develop an extra mitigation behavior to address climate change.

In some areas, climate policies are insensitive to gender issues and do not take into account the fact that some adaptation actions may be less available for certain groups of women, such as the head of the household [103]. Countries whose development policies aim at the stability of the system by strengthening the status quo, neglects the differentiated vulnerability, adaptability, existing cultural, institutional and political factors of inequality [104].

\subsubsection{Age}

Environmental behavior is most influenced by age, with young people being those most concerned about climate change [105]. Most studies have found that age is inversely correlated with attitudes and concerns about the environment, with young people being more concerned about climate change [3,106,107], perceiving the seriousness of climate change more acutely [108]. Other studies have highlighted the negative, positive or insignificant link between age and environmental behaviour [48,98]. An important result has been obtained by the study of Ortega-Egea [5] indicating an inverted U-shaped relationship between age and individual level of engagement, citizens aged between $45-56$ years old tend to be more inclined to exhibit an extra mitigation by way of acting. 


\subsubsection{Education}

Women, people with a lower level of education, middle-aged, with higher household incomes are more skeptical about the existence of climate change [109]. Many studies have shown a direct correlation between the level of education and environmental behavior $[5,98,110]$, individuals with a high level of education are informed, concerned and involved in pro-environmental activities [98,107,111,112], undertaking actions to mitigate climate change [2,3,41]. Ortega-Egea [5] proved that there is a appositive association between education and extra mitigation behavior.

\subsubsection{Marital Status (Children)}

Marital status is an important characteristic, particularly in the case of women, that affects the social relationships [113]. Gender intersects with marital status, being discursively produced [109,114] and manifested in the concrete actions of women and men [115].

Chant [116] argues that women from households formed exclusively by women face poverty and vulnerability differently to women from mixed households formed by women and men. While women in households formed exclusively by women often have to deal with the problem of limited resources, women from mixed households have less access and control over household assets.

Englert [117] highlighted that unmarried, divorced and widowed women have more freedom to buy land or take action, marital status having an important role, and in the case of married women their actions depend on the nature of their relationship with the husband. The marital status significantly influences climate change initiatives, mainly for women, and this results has been supported by the study of KatrienVan and Holvoet [103].

\subsubsection{Occupation}

Confidence in the environment, awareness of the main implications of climate change, high income, employment and old age have led to support for climate change policy [112]. Employment status has no effect on environmental concern [118], a higher remuneration is associated with an increase in the level of pro-environmental engagement [119].

\subsubsection{Difficulties Paying Bills}

Some people find it difficult to manage risky events related to climate change, lack of cash, credit, land, networks, education, or time to adapt $[120,121]$, leading to a lack of involvement in actions related to environmental protection. Significant linkage between household income and standard socio-demographic characteristics and environmental quality concerns has been demonstrated [122,123].

For this particular case, poor people or migrants tend to be the most vulnerable [124]. Regarding income, the evidence is inconclusive, the actions pro-environment is unrelated to income, according to Domene and Sauri [125] and positively correlated, according to Renwick and Archibald [126].

\subsubsection{Urban Area}

Taking account of the high level of population concentration in cities, these consume three-quarters of global energy consumption and greenhouse gas emissions [127]. That's why cities are fighting to mitigate climate change by implementing low-carbon development strategies [128]. Cities involve wealth and innovation, with resources and tools necessary to combat climate change [129].

Intercultural analyses of climate change and environmental protection behavior have attracted increasing attention recently [52-54], highlighting variations in environmental concerns and public protection at the regional level $[55,58,69,102]$, including efforts to mitigate climate change [60]: coastal or riverine regions are strongly unprotected and thus vulnerable in facing climate change impact [130], which poses a huge pressure on urban infrastructure, the lives of urban citizens and the entire urban system. 
Climate change mitigation is more likely in large cities than smaller cities [131], most often the focus being on energy policy, air quality and GHG emissions.

\subsubsection{Political Ideology}

Another important variable that influences environmental behavior is political ideology [48, $64,88,99,110,112,132]$, and people with left-center political visions are more concerned and have significant environmental attitudes and behavior [96,112,113,133]. Political ideology has clear relationships with beliefs about climate change [134,135], and conservatives and right-wing citizens have low beliefs about climate change [136], being more skeptical on this issue [46]. The explanation is that conservatives have strong tendencies to justify the system, denying issues that threaten the functioning of the system, including climate change [137]. Important results have been provided by the study of Ortega-Egea et al. [5] who have proved that individual having a leftist/liberal political orientation were more likely to engage in extra mitigation behavior compared to right-wing/pro-environmental respondents.

\subsubsection{Political Interest Index}

Citizens' beliefs directly influenced their implication in the public policy and have not been the subject of many researches, as there are few studies in the literature on this connection [138]. Political distrust is more prevalent in countries with more corruption [86]. People who trust politics support environmental protection policies $[72,139,140]$, and countries that register a high level of political trust are more inclined to spend for environmental protection [141]. In developed countries there is a tendency to diminish political trust [142], this being considered the reason for the low involvement of citizens in actions aimed at improving the common good [143]. On environmental issues, people do not trust governments, businesses, industry, and experts, and hold them accountable for controlling environmental risks [36].

According to the results of Fairbrother et al. [86], supported at the level of 23 European countries, higher political trust was related to a higher level of support in adopting fossil fuel taxes among individuals believing in the importance and awareness of climate change.

\subsubsection{Modernisation Theory-Related Factors}

The existent differences in pro-environmental beliefs are for sure related to the existent differences in wealth modernisation level $[54,60,68]$, stating that citizens from richer nations grant a higher level of importance to all environmental targets compared with those from pooper countries. The environmental awareness is positively correlated with wealth [67], and negatively correlated with work $[64,67,68]$ in poorer countries, generally the environment related issues are subjects of public concern. For individuals in rich countries, the general perception is that climate change is a fundamental issue and in consequence it is not ranked as a highly dangerous threat, leading to maladaptation to climate change [144].

Individuals of richer countries have this perception about climate change to be a fundamental issue and consequently this could lead to maladaptation to climate change [144-146].

Since greenhouse gas emissions significantly influence climate change, modernization theory and world economy theory [147] have been investigated, empirical results confirming both theories. The IPCC WGII [148] proved that the main factors of influence in the climate change adaption are the access to economic and natural resources as well as institutions and governance.

Well-being is very important in climate change mitigation, and human need and quality of life interferes with energy and resources usage within society [149-151]. Adua et al. [152] drew attention that the modern communities need to be redesigned if the target is to attenuate the environmental crisis [153] still registering economic growth. Between technological innovations indicators and $\mathrm{CO}_{2}$ emissions was registered a negative relationship, with technological innovation being very important in diminishing human impacts on the environment. 
Digitalization foster climate-friendly urban environments [154] being considered a stepping stone for the global economy [155].

ICTs (Information and Communication Technologies) brings a contribution to climate change mitigation through the access to relevant information, increasing concerns and making possible the enhancing of learning and knowledge [156]. Individuals who exhibit a higher level of information using diverse and multiple sources of information, [157] have also a different level of environmental issues' perception, including climate change.

In order to mitigate and adapt to climate change, digital technologies are very important, with information and communications technologies leading to cities climate action. Involving citizens and making possible their participation in city programs with appealing digital technology are very important for climate action [158]. Exploring similarities in environmental protection and climate change mitigation among Norway's voters, Kullberg and Aardal [159] revealed that those in favor of environmental protection and climate change mitigation possess rather a libertarian way of thinking compared with climate-only supporters who exhibit an authoritarian belief. The governmental policy related to climate change put in the first place mitigation instead of adaptation [160], taking into account on the one hand the main benefits of mitigation [161] as well as other factors such as savings, energy security or the importance of reducing emissions [162-166]. Governments significantly influence environmental issues, and can intervene politically through taxes related to the damage caused to the environment. Thus, polluters pay for each environmentally harmful action, discouraging pollution and encouraging companies to find and implement new technologies and production processes that affect the environment as little as possible $[167,168]$.

Taking into account all these, the present research represents, to our knowledge, the first study exploring the specific mitigation behavior of climate change through the analysis of 13 types of personal actions and their determinants, as well as one of the few studies exploring the extra mitigation behavior determinants in a more comprehensive way.

Acknowledging the important role of personal behaviour in tackling climate change from different perspectives, supporting the shift to a circular economy, the following hypotheses have been formalised in order to highlight the main factors related to the level of citizens' specific mitigation and extra mitigation behaviour:

Hypothesis 1. (H1). An increase in pro-environmental behaviour is associated with a higher level of engagement in adopting specific actions in fighting climate change as well as with a higher level of extra mitigation behaviour, supporting the switch to a circular economy.

Hypothesis 2. (H2). Individuals with the following socio-demographics characteristics (female, from 55-64 age group, married with children, with a higher level of education, self-employed, with a left-center political ideology and a higher level of political interest) are more inclined to engage in specific actions in fighting climate change as well as to exhibit a higher level of extra mitigation behaviour, supporting the transition to a circular economy.

Hypothesis 3. (H3). Citizens from small or medium towns, without facing any difficulties in paying their bills and living in Western Europe or Nordic nations are more likely to engage in specific actions in fighting climate change as well as to exhibit a higher level of extra mitigation behaviour, supporting the transition to a circular economy.

Hypothesis 4. (H4). Citizens from more developed and modernized countries are more likely to exhibit a higher level of extra mitigation behaviour, supporting the transition to a circular economy through the multiple actions undertaken. 


\section{Data and Methodology}

\subsection{Data}

The empirical analysis relied on the cross-national dataset "Eurobarometer 91.3/2019-Rule of law and climate change" [7] aiming to reveal the attitudes and behaviour of European citizens' towards climate change, data collection being between 9 and 26 April 2019. The survey covers the resident population of all European Union member states aged 15 years and over. A multi-stage, random (probability) sample has been used in all countries, and a total of 27,655 individuals were interviewed face-to-face, from which 18,529 individuals were from urban areas. The questionnaire treats among others, the assessment of climate change importance; responsible actors for tackling climate change, detailing here the role of national governments, international institutions, local authorities, environmental agencies, citizens or business sector; the importance of climate change actions leading to innovation; with a detailed presentation of personal actions undertaken to combat climate change, being presented in the reports of European Commission $[169,170]$. The Data Archive for the Social Sciences provides access to the Eurobarometer data [7]. The outcomes of our research have been analysed from two points of view-as individual actions to mitigate climate change as well as extra mitigation behavior through multiple actions taken.

Individual mitigation behavior, was quantified by specific climate change actions taken by individuals in the last six months coded on a binary nominal scale (1-yes, $0-$ no) from a set of 13 self-reported mitigation actions related to four environmental area of personal action:

- eco-friendly transportation refereeing to: low fuel consumption car, electric car, alternatives to car use, travel carbon footprint considered;

- $\quad$ domestic energy reduction refereeing to: insulated home better, low-energy home, energy EFF HH appliances, switched energy supplier, energy saving equipment home, installed solar panels home; - eco-shopping refereeing to: food carbon footprint considered;

- waste reduction refereeing to: reduce and separate waste, use less disposable items.

Multiple actions taken to combat climate change have been considered, building several binary nominal scale variables (1-yes, 0 -no): for at least one action, at least two actions; at least three actions; at least four actions; at least five actions; six actions and more, differencing between common behavior and extra behavior.

As extra mitigation behavior, based on the distribution of the number of actions at individual level, we have considered at least five actions as being a broader and greater level of personal engagement.

Climate change related explanatory variables considered in the analysis were as follows:

Perceived importance of climate change was initially rated on a scale from 1 to 10 , from 1- not at all a serious problem to 10- an extremely serious problem, and this has been transformed into a three point categories variable where 1- not a serious problem, 2- a fairly serious problem and 3- a very serious problem.

Climate change perceived responsibility has been rated on the report of binary nominal scale (1-yes, 0-no) coding the responsibility of national governments, European Union, local authorities, business sector citizens and environmental agencies.

The perceived importance of climate change actions was captured through the statement "Fighting climate change will lead to innovation making companies more competitive" initially rated on four-point scales from 1 to 4 , from 1- totally agree and 4- totally disagree, and then transformed into a dummy variable coded 1 -agree and 0 -disagree.

Individual-level demographics considered in the analysis were as follows:

$\checkmark$ Gender: a dichotomous variable with value 1 for men and 2 for women;

$\checkmark$ Age: initially measured as a continuous variable, was divided into six age categories: value 1 for 15-24, value 2 for 25-34, value 3 for 35-44, value 4 for 45-54, value 5 for 55-64, and value 6 for 65 years and over. 
$\checkmark \quad$ Education is a categorical variable with value 1 for up to 15 years old, value 2 for $16-19$ years old, value 3 for 20 years old or over, value 4 for still studying and value 5 for no full-time education.

$\checkmark \quad$ Marital status (children) is a four category variable with1 for Single without children, 2 for single with children, 3 for multiple marriages without children, 4 multiple marriages with children.

$\checkmark$ Occupation is quantified by 1 for self-employed, value 2 for employed, value 3 for not working.

$\checkmark \quad$ Difficulties of paying bills is quantified by 1 for having difficulties most of the time, value 2 for from time to time and value 3 for almost never/never.

$\checkmark$ Urban area is a categorical variable with value 0 for small or middle sized town and value 1 for large town.

$\checkmark \quad$ Region is quantified 1 for East-Central Europe 2 for Western Europe 3 for Southern Europe and 4 for Nordic Nations Political ideology is an ordinal variable with $1=$ left/liberal; $2=$ centre; and $3=$ right/conservative.

$\checkmark \quad$ Political interest index was rated on four-point scale from value 1-strong, value 2-medium, value 3-low, value 4 -not at all.

Country-level variables. In accordance with the second objective of our research, we aims to investigate what are the main factors leading to an extra commitment in fighting climate change. In this context, the research aims to test the validity of modernization thesis according to which respondents from more developed and modernized nations are more involved in all environmental-related issues, allowing a relevant importance to this matter of combating climate change compared to citizens of less-modernized nations. In order to test this hypothesis, the following variables have been used:

$\checkmark \quad$ GDP per capita in purchasing power standards;

$\checkmark$ Human Development Index (HDI);

$\checkmark$ Happy Planet Index (HPI);

$\checkmark$ Social Progress Index (SPI);

$\checkmark$ Individuals' level of internet skills (\%);

$\checkmark \quad$ Individuals' level of internet access (\%);

$\checkmark$ SGI government effectiveness score;

$\checkmark \quad$ SGI policy performance score;

$\checkmark \quad$ SGI environmental policy protection score.

Definitions and data sources for all variables are provided in Appendix A. All country-level predictors were centred on its sample mean.

The GDP per capita in Purchasing Power Standards (PPS) is used as proxy for the level of economic development and the expected sign is a positive one, respondents from wealthier EU-28 countries are expected to be more active and involved in supporting the process of diminishing this danger of climate change than citizens of poorer nations.

According to the HDI, not the economic growth need to be the benchmark for wealth, pointing out the relevance of investing in people and in developing their capabilities if the objective is the assessment of country development. It is worth to mention how HDI can quantify the way in which two countries with similar Gross National Income (GNI) per capita can register different human development outcomes. Therefore, the expected impact is a positive one, a higher the level of human development of a country, leading to a higher level of engagement in climate change mitigation.

Social progress aims to improve peoples' lives all over the world, offering to responsible bodies the chance for more effective cooperation and an efficient resources use in order to solve pressing social and environmental problems. Through this, both individuals and communities could make their contribution to the progress of their lives, creating the conditions to attain full potential. Under these circumstances, the Social Progress Index (SPI) rigorously measures country performance on many aspects of social and environmental performance, including a component of environmental quality. 
Therefore, a positive sign is expected, a higher level of SPI leads to a higher level of engagement in climate change mitigation.

The Happy Planet Index (HPI) reflects sustainable wellbeing for all individuals, quantifying the process of achieving a long, happy, sustainable lives, and puts together four dimensions: wellbeing, life expectancy, inequality of outcomes and ecological footprint, in order to quantify how citizens of different countries are using environmental resources to lead long, happy lives. Therefore, the expected sign is a positive one, a higher level of the index, a higher level of engagement in mitigating climate change.

Two proxies for digital usage and access have been taken into account-individuals' level of internet skills (individuals who have done at least one internet activity) in urban areas (\%) and individuals' level of internet access in the last 12 months in urban areas (\%); a positive impact being expected. Therefore, a higher level of individuals' internet skills and access is associated with a higher level of personal engagement in tackling climate change.

As governance indicators, we have included three main variables: SGI government effectiveness score, SGI policy performance score, SGI environmental policy protection score.

The first, SGI Government Effectiveness score is one of the SGI Governance indicators and measures the efficient implementation of governmental policies. Therefore, a positive impact is expected, a higher perceived level of government effectiveness being associated with a higher level of engagement in climate change mitigation.

The second one, SGI policy performance score, is another SGI Governance indicators measuring the government efficiency in cultivating sustainable conditions helping to assure well-being an empowerment. Also, a positive impact is expected, and a higher level of trust in government is associated with a higher level of personal mitigation of climate change.

The last one, the SGI environmental policy protection score, measures the level of resources protection and environment quality acquired through environmental policy, a positive impact being expected; a higher level of environmental policy protection being associated with a higher level of citizens' engagement in fighting climate change.

\subsection{Multi-Level Econometric Modelling}

In the process of highlighting the main driving forces of climate change among EU citizens, a multilevel logistic regression (the command in STATA 15 for the estimation of multilevel logistic regression models is xtmelogit) analysis has been used highlighting that the specific and extra mitigation behaviour is influenced by both individual characteristics and country specificities in combating climate change, supporting thus the shift to a circular economy.

The conceptual framework of the main determinants for citizens' engagement level in mitigating climate change is presented in Figure 3.

\section{County level (level 2)}

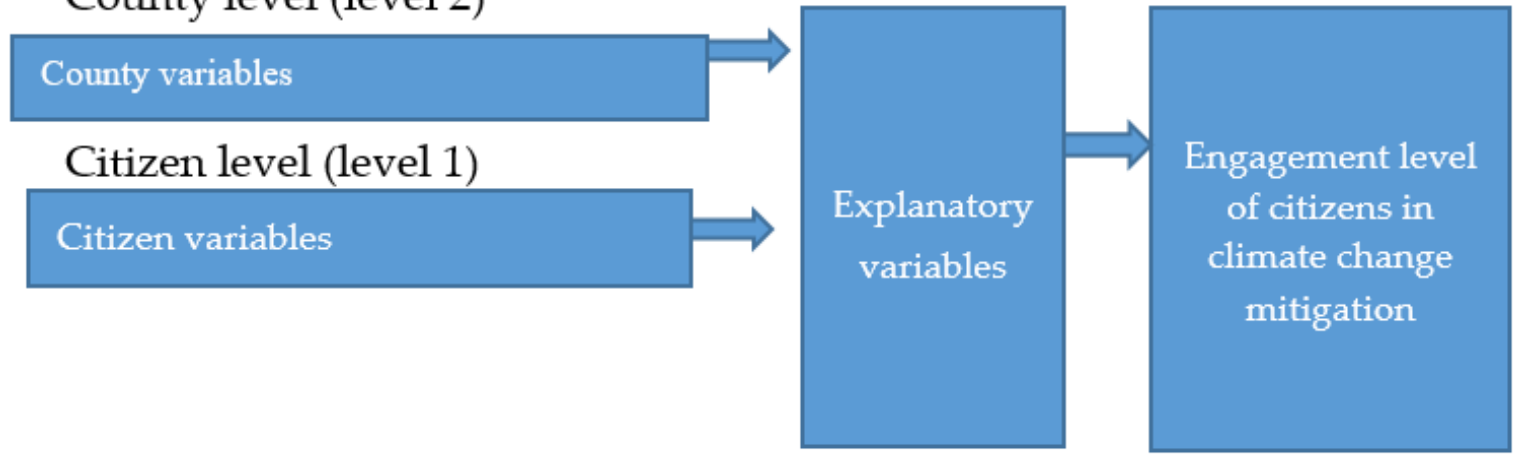

Figure 3. Conceptual framework of the main determinants for citizens' engagement level in mitigating climate change. Source: Author's contribution. 
In order to analyse the between-country variation in the specific and extra mitigation behaviour of climate change, diverse categories of of two-level models were used. The two-level models implies a four-stage methodology.

In the first stage, the appropriateness of the multi-level approach was tested by the estimation of a baseline random intercept model without any explicative variables, the empty two level model with an intercept and country effects (the null model) has the following specification:

$$
\log \left(\frac{\pi_{i j}}{1-\pi_{i j}}\right)=\beta_{0}+u_{0 j}
$$

The intercept $\beta_{0}$ is shared by all countries, while the random effect $u_{0 j}$ is specific to county $\mathrm{j}$ and it follows a normal distribution with variance $\sigma_{u o}^{2}$.

In the second stage, the model additionally assumes the influence of first-level characteristics:

$$
\log \left(\frac{\pi_{i j}}{1-\pi_{i j}}\right)=\beta_{0}+\beta_{1} \cdot X_{i j}+u_{j}
$$

In the third step, the model specification includes simultaneously both individual-related factors as well as country-level variables being formulated as follows [85]:

$$
\log \left(\frac{\pi_{i j}}{1-\pi_{i j}}\right)=\beta_{0}+\beta_{1} \cdot X_{i j}+\beta_{2} \cdot X_{j}+u_{j}
$$

where: $\beta_{0}$ is the overall intercept, $\beta_{1}$ is the cluster specific effect, $\beta_{2}$ is the contextual effect, $X_{i j}$ is the vector containing individual level explanatory variables and their interactions, $X_{j}$ is the vector containing country level explanatory variables and $u_{j}$ is the group (random) effect.

As in any regression model, we can include interaction effects which allow for the possibility that the effect of one explicative variable on the outcome depends on the value of another explanatory variable. An interaction between a level 1 variable and a level 2 variable is called a 'cross-level interaction'. Furthermore, it is worth testing if the effect of contextual country factors on climate change extra mitigation behavior depend on the type of the town (large town vs. small and medium size town). Therefore, in the fourth step, different random intercept models with cross-level interactions have been estimated.

$$
\log \left(\frac{\pi_{i j}}{1-\pi_{i j}}\right)=\beta_{0}+\beta_{1} \cdot X_{i j}+\beta_{2} \cdot X_{j}+\beta_{3} \cdot X_{i j} \cdot X_{2 j}+u_{j}
$$

The general scheme of two level models for citizens' engagement level in combating climate change is displayed in Figure 4. Different specifications of two-level logistic models were estimated in over to overcome the issue of multi-collinearity, as country-level variables could be correlated. 


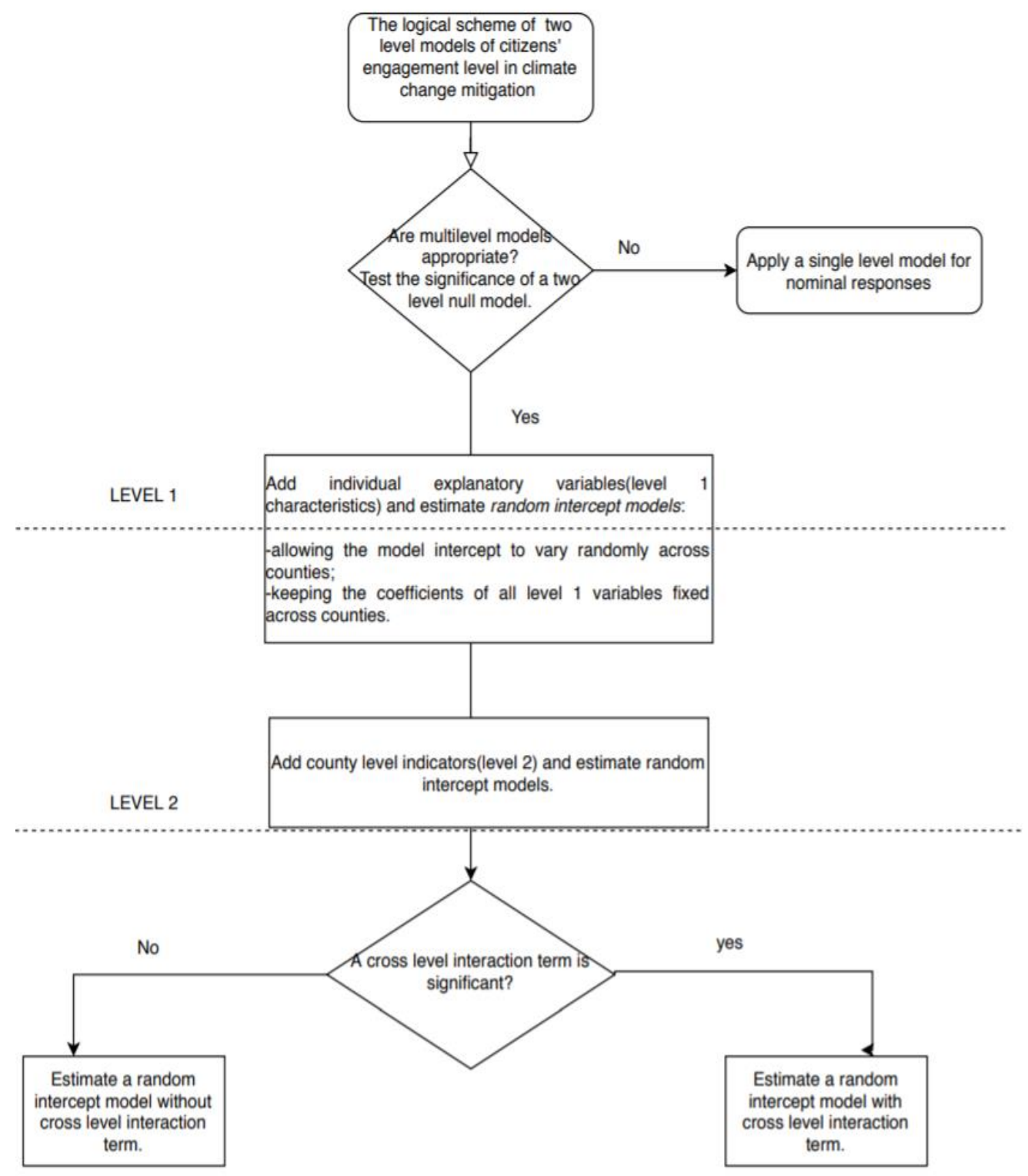

Figure 4. The logical scheme of two-level models for climate change mitigation behaviour. Source: Author's contribution.

\section{Empirical Results and Discussion}

\subsection{Descriptive Profile of Respondents}

From 18,529 individuals from the urban environment, almost $42.7 \%$ of them come from a large town while $57.3 \%$ of respondents live in small and medium-sized towns. Also, 38.66\% of them were citizens of East-Central Europe and only 13.38\% come from Nordic nations.

The sample is well-proportioned in terms of gender, age, education; yet, there was greater involvement of female $(54.3 \%)$, middle-aged (mean age $=51.09$ years), and moderately educated individuals (41.84\% of them finishing school at the age of, at most, 19 years old) and $34.81 \%$ have multiple marriages without children, a centre political orientation (42.08\%). Almost $47.33 \%$ of them were not working, $45.84 \%$ of them were employed and only $6.84 \%$ were self-employed and $66.91 \%$ of respondents declared that never had difficulties in paying bills and only $7.8 \%$ of them declared that most of the time faced this issue.

Almost half of respondents have a medium level of political interest and only $16 \%$ of them were not at all interested in such a topic. 
Asked about the importance of climate change, an overwhelming proportion of $78.71 \%$ of them perceived it as a very serious problem and only $6 \%$ of individuals considered it not a big problem. Also about $88.7 \%$ of citizens agreed with the fact that action on climate change leads to innovation making companies more competitive.

In the descending order of perceived responsibility, most citizens considered national governments responsible for the mitigation of climate change (55.28\%), followed by business and industry $(52.12 \%)$, European Union (49.22\%), citizens (35.41\%), regional and local authorities (33.09\%), and environmental groups (29.04\%). All of these actors have been mentioned only by almost $11 \%$ of the respondents. Asked if they undertook specific actions in fighting climate change in the last six months, almost $63 \%$ of respondents consented to this statement.

\subsection{A Descriptive Analysis of Climate Change Mitigation among European Union (EU) Countries}

The climate change was perceived as a very serious problem by most of the respondents in each country, with an overwhelming proportion of citizens in Malta $(93 \%)$, Greece $(92 \%)$ and Spain $(89.5 \%)$. Only a very small proportion of citizens from every country considered that the climate change is not a serious problem, with two-digit percentages for Finland (11.6\%) and Austria (16\%).

Asked about how the main responsibility of tackling climate change is divided among the main actors in the field, the majority recognised the important role of national governments, EU institutions as well as business and industry. More than half of all respondents from urban areas attributed the main responsibility to national governments $(55.3 \%)$, business and industry $(52.1 \%)$ as well as EU instructions (49.2\%). Just over $30 \%$ of respondents recognised the role of themselves as important drivers in tackling climate change, as well as the contribution of local authorities. Almost $29 \%$ of respondents mentioned environmental groups as being responsible for tackling climate change. What it is interesting to mention is that only $11 \%$ of all respondents attributed the responsibility of combatting climate change to all actors involved.

From all EU member states, 18 countries recognised the importance of national governments' responsibility in combating climate change, the leaders being Sweden $(80.2 \%)$, the Netherlands $(73.6 \%)$, Malta $(73.4 \%)$ and Greece $(67.8 \%)$, while in the vision of the respondents from Sweden $(57 \%)$, Netherlands $(57 \%)$ and Finland $(51 \%)$, citizens were seen as a responsible body in tackling climate change.

More than 4 out of 10 respondents in Sweden and Portugal (47\%, respectively, 43\%), Romania (44\%) and Malta (42\%) assigned the responsibility of combating climate change to regional and local authorities.

An interesting remark is related to the fact that $18 \mathrm{EU}$ countries attributed the responsibility of combatting climate change to all actors involved, with the highest proportions in Portugal (21.6\%), Slovenia (19.7\%) and Luxembourg (19.6\%).

Citizens from the urban areas of more than 22 countries declared that they have personally taken action to fight climate change in the past six months and this is available mostly in the case of Slovenia (86\%), Malta (85\%), Sweden (81\%), Spain and Finland (80\%) and Luxembourg (78\%) compared to only $31 \%$ in Romania, $34 \%$ in Bulgaria and $40 \%$ in Poland (Table A2, Appendix A).

Asked about specific actions in fighting climate change (Figure 5), 73.4\% of respondents declared that they tried to reduce their waste and regularly separate it for recycling, while $62 \%$ of them resorted to reducing consumption of disposable items, these being the most common measures taken to combat climate change. The Energy EFF HH appliances was ranked third in the list of measures taken to mitigate climate change, these three actions being considered as the most common measures taken by more than half of the respondents. 


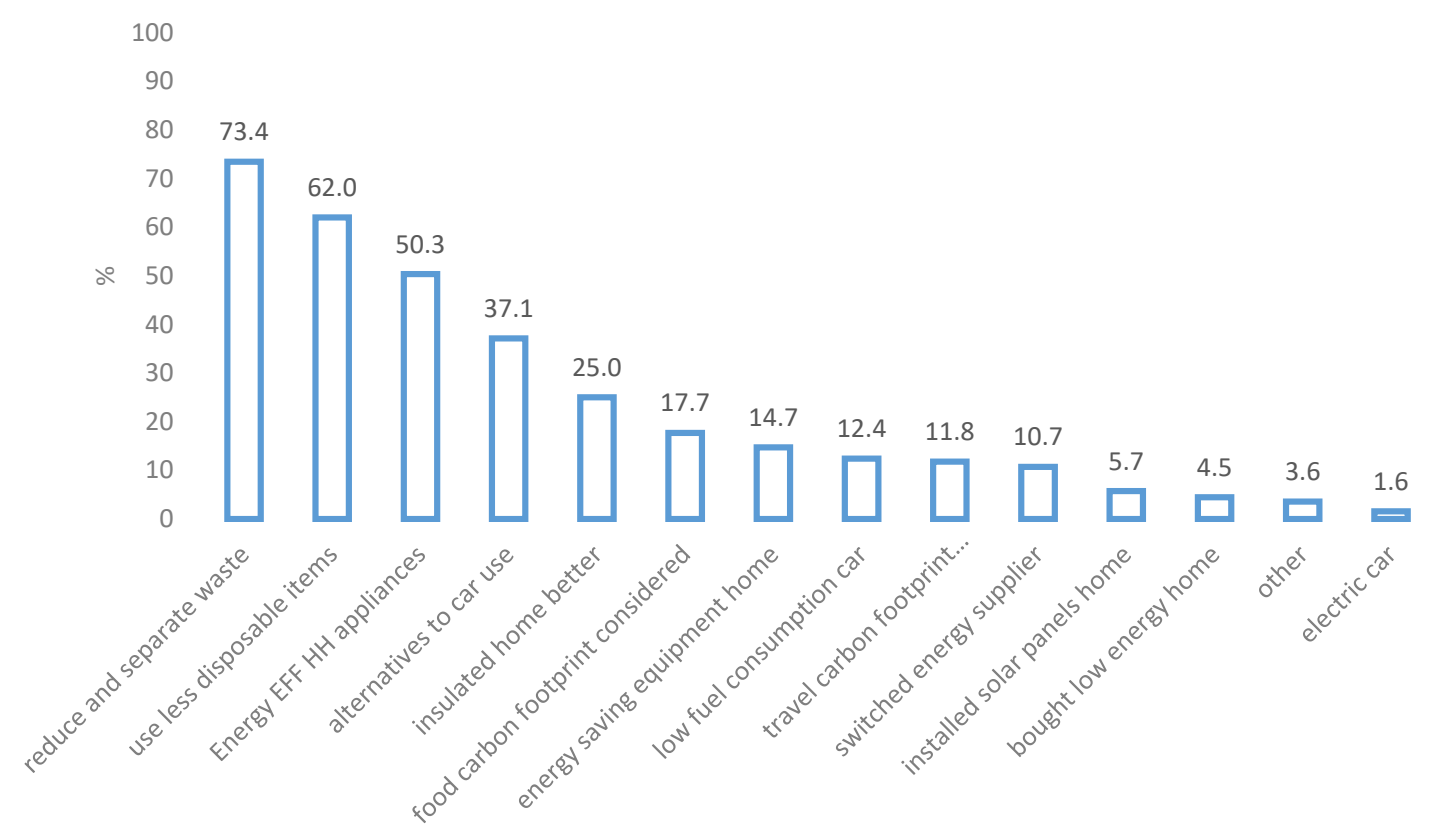

Figure 5. Types of individual action taken to fight climate change. Source: Author's contribution.

In order to combat climate change, about $37 \%$ of the respondents declared using environmentally-friendly alternatives to their private car, while $25 \%$ of them insulated their home better.

A small proportion of citizens, almost one in five (18\%) take into account the carbon footprint of their food purchases and tried to accommodate their shopping accordingly, while an even lower percentage of interviewed citizens (14.7\%) declared that they installed energy-saving equipment home and only $12.4 \%$ of respondents admitted that they have tried to reduce the fuel consumption buying a new car.

The measure of considering the carbon footprint of transport, adapting their holiday accordingly, has been adopted by only $11.8 \%$ of the respondents, while an even lower proportion of individuals claimed that they have switched energy supplier in order to increase the energy share from renewable sources $(10.7 \%)$. Installing solar panels $(6 \%)$, buying a low-energy home $(5 \%)$ or buying an electric car $(1.6 \%)$ are the least undertaken actions among EU citizens.

In all countries, except for two, the majority of respondents declare they try undertook the action of reducing and separating waste. The country recording the highest proportion of reduced and separate waste is Sweden $(91.8 \%)$, followed by Netherlands $(87.8 \%)$, France $(87.7 \%)$ and Luxembourg $(87.5 \%)$, while the majority of respondents declaring to reduce consumption of disposable items were from Netherlands (84.8\%), Sweden (84\%) and Luxembourg (78.2\%).

The energy EFF HH appliances measure taken to reduce energy consumption has been the respondents' choice most in the Netherlands (77.6\%), Germany $(65.6 \%)$ and Latvia $(64.9 \%)$, while regarding the alternatives to car use, the first three countries adopting this measure have been Sweden (67.5\%), the Netherlands (67.1\%) and Germany (55.9\%).

Most respondents considering to insulate their home better in order to reduce their energy consumption were from the Netherlands (39.6\%), Bulgaria (36.8\%) and Denmark (36\%) while Finland and Sweden $(41.3 \%)$ were the countries registering the biggest proportion of urban citizens that considered the carbon footprint of their food purchases.

The share of citizens who bought a new car, thus reducing fuel consumption, was higher in Denmark (27\%), Sweden (20.1\%) and Belgium (18.4\%) while the highest adoption rate of considering travel carbon footprint when planning their holiday have been encountered among citizens from Sweden (41\%) and Finland (26\%).

An important measure for climate change mitigation is switching to an energy supplier, contributing thus to an increase in the energy share from renewable sources. In this regard, Sweden registered an adoption rate of $26.8 \%$, the Netherlands (24.5\%) and Belgium $(22.9 \%)$. 
Urban respondents having installed solar panels in their home are most from Cyprus (24.4\%) and the Netherlands (21.5\%), while $12.7 \%$ of citizens in Netherlands and $12.5 \%$ of citizens in Luxembourg have bought a low-energy home.

Overall, the countries registering the biggest proportion of measures mitigating climate change were Denmark (27\%), Netherlands (20.7\%) and Sweden (20.1\%). The countries registering the lowest proportion of measures mitigating climate change were Greece (4.6\%), Spain (4.4\%), Portugal (4.4\%) and Poland (4.7\%).

Analysing the distribution of the number of individual actions taken to combat climate change it can be highlighted that less than $10 \%$ of EU urban citizens took no measure to mitigate climate change, $25 \%$ took one or two actions, and $50 \%$ took at most three actions.

Only $25 \%$ of the respondents declared that they have taken more than five actions and only $1 \%$ of individuals declared to taken 9 or more actions. In urban areas, EU citizens took, on average 3 measures, the maximum of the measures taken being 13 (Table 1 ).

Table 1. Summary statistics on action to mitigate climate change.

\begin{tabular}{ccccc}
\hline \multicolumn{2}{c}{ Percentiles } & Smallest & \\
\hline $\mathbf{1 \%}$ & 0 & 0 & & \\
$\mathbf{5 \%}$ & 0 & 0 & Obs. & 18.529 \\
$\mathbf{1 0 \%}$ & 1 & 0 & Sum. Of Wgt. & 18.529 \\
$\mathbf{2 5 \%}$ & 2 & 0 & Mean & 3268 \\
$\mathbf{5 0} \%$ & 3 & & Std. Dev. & 2165 \\
& & Largest & & \\
$\mathbf{7 5 \%}$ & 5 & 13 & Variance & 4688 \\
$\mathbf{9 0} \%$ & 6 & 13 & Skewness & 6519 \\
$\mathbf{9 5} \%$ & 7 & 13 & Kurtosis & 3229 \\
$\mathbf{9 9 \%}$ & 9 & 13 & & \\
\hline
\end{tabular}

Regarding the cumulative measures to mitigate climate change, it can be seen that the majority from EU urban areas (91.85) took at least one measure, 77.4\% of EU urban citizens took at least two actions and only $15.4 \%$ of EU urban citizens took six or more actions. The Netherlands is the country whose citizens adopted more than six actions in fighting climate change (52.9\% in case of 6 measures) while at the opposite end there is Poland, with only $1.1 \%$ of citizens adopting six actions in combating climate change.

\subsection{Results of the Estimated Models}

In accordance with our first objective, the research explored the main socio-demographic factors related to specific mitigation behaviour quantified by individual actions untaken to fight climate change, with the estimation process including 13 models, one for each type of climate change individual action.

The empirical results of the null baseline random intercept model, revealed that multilevel approach was appropriated and the log-odds of citizens share declaring having undertaken specific actions to fight climate change in an "average" country was estimated to be $\beta_{0}=0.60$.

The between-country variance of the log-odds of citizens' share taking actions to combat climate change was estimated as 0.455 with a standard error of 0.125 . The significance of the between-region variance was tested using a Wald test, the empirical results (Chi-square test $=1456.74$ with a $p$-value $=0.0099$ ) revealing that there is a significant variation between EU countries in the proportion of those citizens environmentally active taking specific actions in fighting climate change.

Based on the value of between-country variance (0.455), the variance partition coefficient (VPC) was computed to be $12.15 \%$ using the formula: $0.455 /(0.455+3.29)=0.1215$; thus $12.15 \%$ of the residual variation in the propensity of taking actions in mitigating climate change is attributable to unobserved country characteristics), indicating that almost $13 \%$ of the variance in climate change specific mitigation actions can be attributed to differences between countries. 
Figure A1, Appendix A, reports the residual level-2 country effects derived from the null model (with no explanatory characteristics) proving the differences between countries. A country whose confidence interval does not overlap the line at zero (representing the mean log-odds of taking specific actions to climate change mitigation across all states) differs significantly from the EU-28 average at a 95\% confidence level [84].

Romania, Bulgaria and Poland are countries with the lowest probability of taking personal actions in mitigating climate change in the last six months (largest negative values of $u_{j}$ ) for which the confidence intervals do not overlap with 0 , pointing out that a significantly lower probability of participation compared with the EU average has been registered by these countries. At the upper end, Sweden, Slovenia and Malta are the countries with intervals that do not overlap with 0 with the highest response probability (largest positive values of $u_{j}$ ), indicating a significantly higher probability of participating in climate change actions compared with the EU-28 average.

Proving that the multilevel approach is the appropriate one, in the second stage different specifications of the multilevel models with only individual level characteristics were stipulated, with 13 sequential models being estimated, one for each specific action taken by citizens in the mitigation process of climate change, providing new and more detailed perspectives regarding the main determinants of climate change specific mitigation behaviour. The empirical results of random intercept models including individual-level variables are presented in Table A3, Appendix A.

For the first specific climate change action adopted at the same time by most of the citizens, reduce and separate waste, the empirical results pointed out the statistical significance of climate change perceived importance, the perceived responsibility of national governments, European Union, business and industry, citizens and environmental groups, as well as the importance of climate change actions leading to innovation in explaining the specific mitigation behaviour.

Also, most of the socio-demographic variables exhibited statistical significance: gender, age, education, occupation, facing difficulties in paying bills, marital status (children), type of urban area, types of EU region, political interest as well as political ideology.

Analysing the individual characteristics, it can be highlighted that women, from the age groups 45-54 years and 55-64 years, with a high level of education, with multiple marriages with children, usually employees, without difficulties in paying their bills, living in small towns from Western Europe, Southern Europe or Nordic Nations, having a leftist/liberal or centre political orientation and a high level of political interest, were inclined to adopt this specific action in fighting climate change.

The empirical results of the second specific action adopted by the most respondents-use fewer disposable items - revealed that people perceiving the climate change as a serious problem, considering that the responsible bodies in fighting this phenomenon are national governments, the European Union, business sector, local authorities or citizens themselves or acknowledging that the role of climate change actions are more inclined to undertake this action. Analysing the profile of individuals adopting this action, it can be mentioned that women more than 35 years old, with a high level of education, with multiple marriages with children, usually without any problem in paying bills, living in Western Europe and Nordic nations having a leftist/liberal or centre political orientation and a high level of political interest were more inclined to fight climate change using less disposable items.

The empirical results of the third action taken to combat climate change-energy EFF $\mathrm{HH}$ appliances-highlighted that people perceiving climate change as a very serious problem, those considering that the main responsibility in tackling this negative phenomenon rests with national governments, European Union, business sector or themselves, as well as those acknowledging the importance of climate change actions on the path to innovation, were more willing to adopt this action.

The fourth action adopted in combating climate change-alternatives to car use-was more likely to be considered by people perceiving the climate change as a very serious problem, those considering that the main responsibility in tackling this negative phenomenon rests with national governments, European Union, or themselves. Regarding individual characteristics, more educated women, 55 years 
old and over, living usually in large towns, having multiple marriages without children, and without having difficulties in paying bills or living in Western Europe as well as in Nordic nations, having an increased level of political interest and a leftist/liberal political orientation, are more determined to combat climate change by adopting this specific measure.

The fifth action mentioned by the citizens in the climate change mitigation- better insulated home-was more likely to be considered by people perceiving the climate change as a very serious problem, those considering that the main responsibility in tackling this negative phenomenon returns mainly to citizens. Exploring the citizens' profile, it can be highlighted that men, with a higher level of education, from all age categories, usually self-employed, living in small towns, having multiple marriages with or without children, without any difficulties in paying bills and having an increased level of political interest and a right/conservative political orientation.

Concerning the sixth action adopted-food carbon footprint-the empirical results revealed that people perceiving the climate change as a very serious problem, those considering that the main responsibility rests mainly with national governments, regional or local authorities as well as to citizens, or acknowledging the importance of climate change actions on the path to innovation were more likely to take such an action. Highlighting the individual profile, it can be mentioned that women, from the age category 65 years old, more educated, having multiple marriages with our without children, not facing any difficulties in paying bills, living in Western Europe or Nordic nations, having an increased level of political interest or a leftist/liberal political orientation, were more inclined to adopt this action as climate change mitigation measure.

The empirical results of the seventh action—energy saving equipment at home-revealed that citizens considering that the main responsibility returns regional or local authorities, environmental groups or even themselves and living in small towns from Western Europe or Nordic nations, from all age categories, with a higher level of education, usually self-employed, having multiple marriages with or without children, with a very strong political interest and a liberal political orientation, were more inclined to adopt this action.

The eighth action — low fuel consumption car —was taken as climate change mitigation more likely by those citizens perceiving climate change as a very serious problem, attributing the main responsibility of climate change mitigation to citizens, those living in small towns, from countries in Western Europe or Nordic nations, without any difficulties in paying bills, being men, either less than 44 years old or over 65 years, with a higher level of education, usually self-employed, having multiple marriages with our without children, having a medium and strong level of political interest and a liberal political orientation.

The ninth action-travel carbon footprint-was more likely by those citizens perceiving climate change as a very serious problem, attributing the main responsibility of climate change mitigation to citizens, living in large towns, from Western Europe or Nordic nations, not facing any difficulties in paying bills, being women, educated people, usually self-employed, having a medium and strong level of political interest and with a leftist/liberal political orientation.

The empirical results of the tenth action-switched energy supplier-revealed that those citizens perceiving climate change as a very serious problem, considering that the main responsibility rests with citizens, acknowledging the importance of climate change actions on the path to innovation, living in Western Europe or Nordic nations, with a high level of education, usually self-employed, having multiple marriages with our without children, an increased level of political interest, were more inclined to adopt this action in the mitigation process of climate change.

The eleventh action-installed solar panels at home - was a climate change mitigation more likely to be taken by those citizens considering that the main responsibility returns to regional authorities, business sector, living in small towns, from Western and Southern Europe, educated people, from the age category 55-64 years old, usually self-employed, having multiple marriages with our without children and a centre political orientation. 
The twelfth action-bought low-energy home-was a climate change mitigation more likely to be taken by those citizens considering that the main responsibility returns to business sector, living in small towns, from Western Europe, being men, educated people, usually self-employed, not facing any difficulties in paying bills, having multiple marriages with our without children and a very strong political interest.

The last action-electric car-was a climate change mitigation more likely to be taken by those citizens considering that the main responsibility returns to regional and local authorities, living in Western Europe or Nordic nations, educated people, having at most 44 years old or over 65 years old, usually self-employed, having multiple marriages with children and a right/conservative political ideology.

The mitigation actions exhibiting the largest variance at country level among individual characteristics were the following: installed solar panels home $(12.27 \%)$, reduce and separate waste $(10.59 \%)$, switched energy supplier $(9.37 \%)$ and food carbon footprint $(9.12 \%)$.

Going further in our research analysis, in accordance with our second objective and after exploring the main determinants of citizens' decisions to undertake specific individual actions to fight climate change, the research investigated factors that relate to extra behavioural engagement, trying to find what determines some people to be involved in an extra commitment (i.e., do "more") to mitigate climate change as compared to others, testing the validity of modernization thesis. In this context, the modernisation thesis has been tested, stipulating that extra mitigation behaviour is more likely to occur in more modernized developed economies. Therefore, in order to prove this, 12 alternative models have been estimated, for different proxies of modernization thesis including also those models taking into account cross-level interaction terms.

The empirical results of the null baseline random intercept model revealed that the multilevel approach was appropriated and the log-odds of extra personal engagement in mitigation behaviour in an "average" country was estimated to be $\beta_{0}=-1.226$.

The between-country variance of the log-odds of citizens' extra mitigation behaviour was estimated as 0.842 with a standard error of 0.228 . The significance of the between-region variance tested with the Wald test (Chi-square test $=2495.02$ with a $p$-value $=0.00$ ) revealed that there is a significant variation between EU countries in the extra personal engagement in mitigation behaviour.

The variance partition coefficient (VPC), determined using the value of between-country variance is $20.37 \%$, revealing that $20.37 \%$ of the residual variation in the propensity of extra mitigation behaviour is attributable to unobserved country characteristics.

Figure A2, Appendix A reports the residual level-2 country effects derived from the null model (with no explanatory characteristics) proving the differences between countries. A country whose confidence interval does not overlap the line at zero (representing the mean log-odds of taking multiple actions to climate change mitigation across all states) differs significantly from the EU-28 average at the $5 \%$ significance level [83].

Poland, Croatia, Lithuania and Italy are countries with the lowest probability of extra mitigation behaviour (largest negative values of $u_{j}$ ) for which the confidence intervals do not overlap with 0 , indicating that they have significantly lower probability of extra mitigating climate change than the EU average. At the upper end, the Netherlands, Sweden, Denmark and Luxembourg are the countries with intervals that do not overlap with 0 with the highest response probability (largest positive values of $u_{j}$ ), indicating a significantly higher probability of extra mitigation of climate change compared with the EU-28 average.

Stipulating that the multilevel approach is the appropriate one, the research built different specifications of multilevel modelling including both individual level characteristics as well as country-level factors related to modernisation thesis in order to extra mitigate climate change.

Therefore, 12 alternative models have been estimated capturing the main determinants of extra mitigation behaviour among EU citizens, the empirical results being presented in Table A4, Appendix A. 
The empirical results of all alternative models revealed that climate change extra mitigation personal behaviour was more likely to be adopted by citizens perceiving the climate change as is a serious problem, attributing the responsibility of fighting against this phenomenon to national governments, regional or local authorities, business sector or themselves contributing through multiple actions undertaken to the transition to a circular economy.

Also, the importance of climate change actions leading to innovation and making companies more competitive was positively associated in all models with an extra personal engagement in mitigation behaviour.

All tested socio-demographic variables manifested a statistically significant impact on the decision of adopting an extra mitigation personal behaviour, the estimates of individual-level demographics being almost identical in all alternative models.

Female gender, from the age category 55-64 years old exhibited a higher level of extra mitigation habits, the empirical results pointing out the existence of an inverted $U$-shape between age and citizens' extra behavioural engagement in fighting climate change. Also, a positive association has been found between education and the extra mitigation behaviour, with people with a higher level of education being more inclined to adopt multiple actions manifesting a higher level of commitment.

Also, the empirical results revealed that people of a leftist/liberal political orientation and a higher level of political interest displayed an extra behavioural engagement in climate change mitigation, while self-employed people, without any difficulties in paying bills, married with or without children, living in small towns, in Western Europe or Nordic nations were more willing to engage in extra mitigation behaviour.

The modernisation thesis have been only partially supported by the empirical results of models II, IV, V, VI, VIII, IX; a higher level of extra mitigation behaviour being encountered among citizens from countries with a higher level of human development and social progress, a higher proportion of individuals with internet skills and access, and a higher level of policy performance and environmental policy protection.

Therefore, the modernisation thesis was strongly supported by the results of the second model; citizens from countries with a higher level of human development exhibiting also a higher level of extra behavioural engagement to mitigate climate change. A similar result was confirmed by the statistical significance of social progress index; citizens from countries with a higher level of social progress exhibited a higher level of extra engagement to mitigate climate change. Also, the digitalisation hypothesis made its contribution to the validity of the modernisation thesis, with citizens from countries with a higher level of individual internet skills and access being more determined to engage in extra mitigation behaviour.

The modernisation thesis was also supported by the statistical significance of SGI governance indicators; citizens from countries with a higher policy performance as well as those from countries with a higher environmental policy protection were more willing to adopt multiple actions in fighting climate change.

Finally, it can be pointed out that the modernisation thesis was only partially validated, due to the lack of statistical significance of GDP per capita at PPS, a proxy for a country's wealth level; the HPI index a proxy for the level of country sustainable well-being; and the SGI government effectiveness a proxy for the efficient implementation of governmental policies.

Furthermore, it was worth testing if the effect of modernization thesis on the extra behavioral engagement to mitigate climate change, depends on the segmentation large town vs. small or medium town. Therefore, different random intercept models with cross-level interactions have been estimated.

Until now, the models assumed that the contextual effect of the modernization thesis is the same for all citizens regardless of whether they live in big or small cities. In this stage, we have modified this assumption allowing the effect of modernization thesis on the extra mitigation behavior to depend on the country level variables associated with this thesis and also on the urban area type, including in the model the interaction between country level variables and the type of the town in which the citizen is 
living as cross-level interactions terms. Another nine alternative models have been estimated, but given the limited space within the paper, we have decided to present only those exhibiting statistically significant impact on the extra mitigation behavior.

The empirical results of the models X, XI and XII displayed in Table A4, Appendix A revealed that the marginal effect of modernization thesis supported by the statistical significance of HDI, SPI, SGI environmental policy protection score on the level of extra behavioural engagement to mitigate climate change positively and significantly depends on the segmentation large vs. small or medium town.

Therefore, in a country with a higher level of human development, social progress or a higher level of environmental policy protection, citizens living in large towns exhibited a higher level of extra engagement in mitigating climate change compared with those living in small or medium towns.

\subsection{Summary of Findings in Relation to Specific Mitigation and Extra Mitigation Behavior}

In Figure 6, we summarize our overall findings in relation to the main hypotheses tested, providing information on the positive relationship between specific factors and each specific action of combating climate change as well as an extra mitigation behaviour in fighting climate change. It also provides information on the modernisation theory supported by each statistically significant finding, along with clarifying remarks.

Analysing the empirical results of specific mitigation behaviour models, the pro-environmental variables were statistically significant in eight of the specific actions models, stipulating the relevance of pro-environmental attitudes in combating climate change. Therefore, individuals acknowledging the importance of climate change, being aware of their responsibility in fighting this phenomenon together with other institutional bodies, and recognising the importance of climate change actions were found to be more inclined to adopt specific actions in mitigating climate change. Thus, hypothesis $\mathrm{H} 1$ has been partially validated for the specific actions: reduce and separate waste, use disposable items, energy appliances, alternatives to car use, insulated home better, food carbon footprint, low fuel consumption car, switch energy supplier. Also, hypothesis H1 has been fully validated in the case of extra mitigation behaviour, by the positive and statistically significant coefficients of pro-environmental proxies.

Hypothesis $\mathrm{H} 2$ regarding the profile of individuals engaged in specific mitigation behaviour is validated in most of the cases, with the exception of three specific actions. Therefore, females, mostly 55-64 years old, married with children, with a high level of education, self-employed, with a left-or center political ideology and a high level of political interest) were more inclined to adopt the following specific actions as measures to combat climate change: reduce and separate waste, use disposable items, energy appliances, alternatives to car use, food carbon footprint, switch energy supplier, energy-saving equipment home, travel carbon footprint, electric care. For the other specific actions concerning insulated home better, low fuel consumption car and bought a low-energy home, the profile of individuals inclined to adopt these actions is: male, young people (15-24 years old), with high level of education, self-employed, married with or without children, having a right political ideology and a high level of political interest.

Hypothesis $\mathrm{H} 2$ has been fully validated in the case of extra mitigation behaviour, by the positive and statistically significant coefficients of socio-demographic variables.

Hypothesis $\mathrm{H} 3$ has been partially validated by the positive and statistically significant coefficients of the models investigating the following seven specific actions: reduce and separate waste, use disposable items, alternatives to car use, food carbon footprint, low fuel consumption car, travel carbon footprint and bought low-energy home. Therefore, individuals not facing any difficulty in paying bills, living in small or medium towns from Western Europe or Nordic nations are more likely to engage in specific actions in fighting climate change.

Hypothesis $\mathrm{H} 3$ has been fully validated in the case of extra mitigation behaviour by the statistically significant coefficients of economic variables. 
H1: Pro-

environmental

behavior

\section{Specific mitigation} behavior :

-reduce and separate waste - use less disposable items

- energy EFF HH appliances

- alternatives to car use

- insulated home better

- food carbon footprint

- low fuel consumption car

switched energy supplier

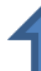

Climate change importance, -Climate change resp onsability, -Importance of climate change actions.

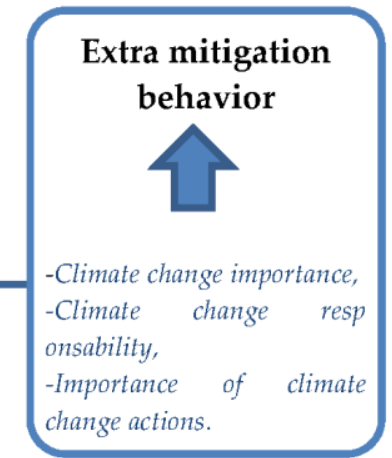

H2: Socio-

demographics

\section{Specific mitigation behavior:}

reduce and separate waste

- use less disposable items

Energy EFF HH appliances

alternatives to car use

- food carbon footprint

- energy saving equipment home

travel carbon footprint

- switched energy supplier

Electric car

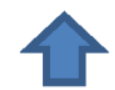

Female, 55-64, higher level of education,

self-employed, MM without and with

children, left, high political interest

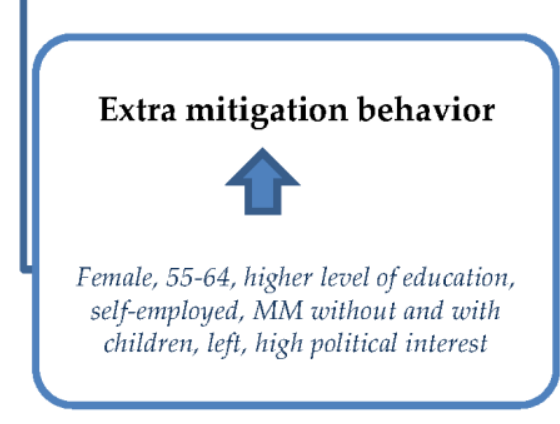

insulated home better - low fuel consumption car

- bought low-energy hom

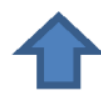

Male, 15-24,high level of education, self-employed MM without and with

children, right political

ideology, high political interest

Figure 6. Summary of findings in relation to specific mitigation and extra mitigation behavior.
H3: Economic

characteristics

Modernisation

theory

\begin{tabular}{|c|c|}
\hline $\begin{array}{l}\begin{array}{c}\text { Specific mitigation } \\
\text { behavior }\end{array} \\
\text { - reduce and separate waste } \\
\text { - use less disposable items } \\
\text { - alternatives to car use } \\
\text { - food carbon footprint } \\
\text { - low fuel consumption car } \\
\text { - travel carbon footprint } \\
\text { - bought low-energy home }\end{array}$ & $\begin{array}{c}\begin{array}{c}\text { Higher level } \\
\text { of Extra } \\
\text { mitigation } \\
\text { behavior }\end{array} \\
\\
\text { - HDI } \\
\text { - SPI } \\
\text { - INTERNET } \\
\text { SKILLS } \\
\text { - INTERNET } \\
\text { ACCESS } \\
\text { - POLICY } \\
\text { PERFORMANCE } \\
\text { INDEX } \\
- \\
\text { ENVIRONMENTA } \\
\text { L POLICY } \\
\text { PROTECTION }\end{array}$ \\
\hline
\end{tabular}

small and medium tow

-region (Western Europe or

Nordic nations) 
In the context of urban environments, it was important to analyse the impact of the segmentation small-medium urban area vs. large urban area on the decision of specific mitigation behaviour in fighting climate change, the empirical results clearly pointing out the statistically significance of urban area coefficients, revealing also that actions such as energy EFF HH appliances, insulated home better, energy-saving equipment home, low fuel consumption car, installed solar panels home, bought low energy home, were more likely to be adopted by citizens from small towns.

Hypothesis $\mathrm{H} 4$ concerning the validation of the modernisation thesis in relation to an extra mitigation behaviour has been only partially supported by the positive and statistically significant coefficients of human development index, social progress index, individuals' level of internet skills and access, SGI policy performance score and SGI environmental policy protection score. Therefore, citizens from more developed and modernized countries are more likely to exhibit a higher level of extra mitigation behaviour.

A related finding acknowledged that the effect of modernization thesis on extra mitigation behaviour depends on the segmentation large town vs. small or medium town, this fact being supported by the positive and highly significant coefficients of cross-level interaction terms between large town and country level variables related to modernisation thesis, revealing that citizens living in large towns in countries with a higher level of human development, a higher level of social progress or a higher level of environmental policy protection, were more likely to exhibit a higher level of extra mitigation behaviour.

\subsection{Discussion}

In order to mitigate climate change and also to pave the way to circular economy, the role of citizens is fundamental and a shift in personal behaviour is highly required. In combating climate change, the actions need to cover multiple measures and to target the implications of the main actors-local governments, business sector, civic society, environmental organisations and European institutions. The present research acknowledges the important role of citizens in tackling climate change, aiming to assess the role of socio-demographic, economic and environmental factors in fighting climate change as well as the validity of the modernisation thesis regarding the extra mitigation behaviour, exploring the between-country variation in both specific and extra mitigation behaviour.

A central question in this study was: what determines some people to engage in adopting specific and extra mitigation behaviour compared to others? The findings revealed that there is a mix of factors that influence both specific and extra mitigation behavior.

Overall, the findings reinforce earlier evidence that pro-environmental behaviour acknowledging the importance of climate change, climate change actions and the main responsibility in tackling this phenomenon are more associated both with a specific mitigation as well as an extra mitigation behaviour $[58,59,62,67,69]$.

The perceived importance of climate change was significantly associated with specific and extra mitigation behaviour. In line with the previous studies [63-67], the findings emphasize the role of perceived importance of climate change on eight types of specific mitigation actions as well as on extra mitigation behavior.

Another driver of specific and extra mitigation behavior was related to the perceived responsibility in tackling this phenomenon, with the empirical results subscribing to studies in literature [87]; if citizens are more aware about their own responsibility and actions in mitigating climate change, this awareness will lead them in the direction of acting and adopting specific or multiple actions in fighting this phenomenon.

In contract with previous studies [91,92], the perceived importance of climate change actions seems not to determine as expected individuals engaging in specific actions, with the empirical results revealing a significant impact only for few specific measures. This is not the case for extra mitigation behavior, in which the increased perceived importance of climate change actions leading to innovation is associated with a higher level of extra mitigation. 
The research strongly supports the idea that-despite empirical evidence from previous environmental studies $[80,98]$ a variety of individual and country-level socio-demographics are significant correlates of specific and extra mitigation behavior in response to climate change.

In line with the work of $[156,158,159,161,168]$, partial validation of modernization thesis have been achieved-a higher level of engagement to mitigate climate change being predominant in countries with a higher level of human development and social progress, a higher proportion of an individual's internet skills and access, a higher level of policy performance and environmental policy protection.

Another important result of our analysis is related to the fact that the effect of modernisation thesis on the extra mitigation behaviour of climate change depends on the type of urban area. Therefore, citizens living in large towns in countries with a higher level of human development, a higher level of social progress or a higher level of environmental policy protection were more likely to exhibit a higher level of extra mitigation behaviour [162].

\subsection{Limitations and Recommendations for Further Study}

The study presents several limitations that should be taken into account for further research. Firstly, the use of Eurobarometer dataset, despite the advantages, restricted the aim of the research questions by not allowing the investigation of other relevant associations of mitigation behaviour. Thus, further research could incorporate additional factors among which the individuals perceptions of self-relevance or the split of environmental activism and citizenship into public/political. Secondly, the research used self-reported data (instead of actual measured mitigation behaviour). Thus, the discrepancy between perceived and objective knowledge (and their relationships) deserves future attention in studies on climate change-motivated behavior. Thirdly, the analysis took into account only environmentally active citizens from urban areas, due to the main purpose of our research regarding specific and extra mitigation behavior. However, the exclusion of the environmentally inactive respondents should be recognised as an important limitation and cautions should be attributed in generalizing the results to non-environmentally active individuals.

Future research could be enlarged by including a broader segment of environmental respondents (the least receptive to the problem of the environment). Fourthly the study focused only on direct associations between factors and extra mitigation behavior. Future research could explore also a potential mediation analysis between different factors in explaining better the mitigation behaviour. Also, in further work, the lagged influence of climate change importance in revealing the determinants of mitigation behaviour could be incorporated and tested. Last but not least, the validation of the modernisation thesis opens the door for exploring also other theses with impacts on climate change mitigation behaviour. In the near future, country differences could be analysed also from the perspective of individualism thesis, long-term orientation or regional discrepancies.

\section{Concluding Remarks}

Taking into account all the findings of our research, the following can be concluded:

1. A shift in personal behaviour is required-from limited or sporadic actions toward exhibiting an extra mitigation behaviour in fighting climate change.

2. Two types of behaviour can be encountered among EU citizens-an individual mitigation behaviour based on singular actions undertaken to combat climate change and an extra mitigation behaviour based on multiple actions taken in fighting climate change.

3. Pro-environmental factors, socio-demographics, economic and country-level factors proved their role in explaining both specific and extra mitigation behaviour through personal engagement.

4. Modernisation thesis substantiated its validity revealing that both specific and extra mitigation behaviour is higher in more modernised countries. 
5. By acknowledging the role of citizens in addressing climate change, and encouraging them to undertake different specific actions and doing more in fighting climate change by adopting multiple actions, we pave the way for a circular economy.

6. Through their contribution to waste reduction, eco-shopping, eco-friendly transportation or domestic energy reduction, citizens ensure the transition to a circular urban economy.

Author Contributions: All authors have been equally contributed to the paper. All authors have read and agreed to the published version of the manuscript.

Funding: This research received no external funding.

Conflicts of Interest: The authors declare no conflict of interest.

\section{Appendix A}

Table A1. Variables explained.

\begin{tabular}{|c|c|c|}
\hline Country-Level Explanatory Variables & Data Source & Expected Sign \\
\hline \multicolumn{3}{|c|}{ The modernisation theory } \\
\hline $\begin{array}{l}\text { Gross Domestic Product (GDP) per capita in } \\
\text { PPS is computed to by the GDP in PPS (current } \\
\text { prices, million purchasing power } \\
\text { standards)/population. }\end{array}$ & $\begin{array}{l}\text { National Ac. Database, Eurostat; } \\
\text { Employment and Unemployment Database, } \\
\text { Eurostat. }\end{array}$ & Positive \\
\hline Human Development Index (HDI) 2019 & $\begin{array}{l}\text { UNDP, Human Development Reports, } \\
\text { http://hdr.undp.org/en/content/human- } \\
\text { development-index-hdi }\end{array}$ & Positive \\
\hline Happy Planet Index (HPI) 2019 & http://happyplanetindex.org/ & Positive \\
\hline Social Progress Index (SPI) 2019 & https://www.socialprogress.org/ & Positive \\
\hline $\begin{array}{l}\text { Individuals' level of internet skills in urban } \\
\text { area (\%) } \\
\text { The share of individuals from urban area who } \\
\text { have used a search engine to find information } \\
\text { (cities, towns and suburbs). }\end{array}$ & $\begin{array}{l}\text { https://appsso.eurostat.ec.europa.eu/nui/ } \\
\text { submitViewTableAction.do }\end{array}$ & Positive \\
\hline $\begin{array}{l}\text { Individuals' level of internet access in urban } \\
\text { area (\%) } \\
\text { The share of individuals from urban area (cities, } \\
\text { towns and suburbs) who have used the internet } \\
\text { in the last } 12 \text { months. }\end{array}$ & $\begin{array}{l}\text { https://appsso.eurostat.ec.europa.eu/nui/ } \\
\text { submitViewTableAction.do }\end{array}$ & Positive \\
\hline $\begin{array}{l}\text { Government Effectiveness Score } 2019 \text { from } \\
\text { SGI Indicators }\end{array}$ & $\begin{array}{l}\text { Sustainable Governance Indicators, } \\
\text { SGI Network, } \\
\text { https: } \\
\text { //www.sgi-network.org/2019/Governance/ } \\
\text { Executive_Capacity/Implementation }\end{array}$ & Positive \\
\hline $\begin{array}{l}\text { Policy performance score } 2019 \text { from } \\
\text { SGI Indicators }\end{array}$ & $\begin{array}{l}\text { Sustainable Governance Indicators, SGI } \\
\text { Network, } \\
\text { https://www.sgi-network.org/2019/Policy_ } \\
\text { Performance }\end{array}$ & Positive \\
\hline $\begin{array}{l}\text { SGI environmental policy protection score } \\
2019 \text { from SGI Indicators }\end{array}$ & $\begin{array}{l}\text { Sustainable Governance Indicators, SGI } \\
\text { Network, } \\
\text { https://www.sgi-network.org/2019/Policy_ } \\
\text { Performance/Environmental_Policies/ } \\
\text { Environment/Environmental_Policy }\end{array}$ & Positive \\
\hline
\end{tabular}


Table A2. Individuals' climate change actions.

\begin{tabular}{|c|c|c|c|c|c|c|c|c|c|c|c|c|c|}
\hline Country ID & $\begin{array}{l}\text { Reduce and } \\
\text { Separate } \\
\text { Waste }\end{array}$ & $\begin{array}{l}\text { Use Less } \\
\text { Disposable } \\
\text { Items }\end{array}$ & $\begin{array}{c}\text { Energy EFF } \\
\text { HH } \\
\text { Appliances }\end{array}$ & $\begin{array}{l}\text { Alternatives } \\
\text { to Car Use }\end{array}$ & $\begin{array}{c}\text { Insulated } \\
\text { Home Better }\end{array}$ & $\begin{array}{l}\text { Food } \\
\text { Carbon } \\
\text { Footprint }\end{array}$ & $\begin{array}{c}\text { Energy } \\
\text { Saving } \\
\text { Equipment } \\
\text { Home }\end{array}$ & $\begin{array}{l}\text { Low Fuel } \\
\text { Consumption } \\
\text { Car }\end{array}$ & $\begin{array}{c}\text { Travel } \\
\text { Carbon } \\
\text { Footprint }\end{array}$ & $\begin{array}{l}\text { Switched } \\
\text { Energy } \\
\text { Supplier }\end{array}$ & $\begin{array}{l}\text { Installed } \\
\text { Solar Panels } \\
\text { Home }\end{array}$ & $\begin{array}{c}\text { Bought } \\
\text { Low-Energy } \\
\text { Home }\end{array}$ & Electric Car \\
\hline FR & 87.7 & 68.0 & 54.5 & 40.4 & 29.9 & 24.4 & 19.6 & 14.8 & 11.1 & 8.8 & 2.4 & 7.5 & 1.2 \\
\hline BE & 72.3 & 61.7 & 51.1 & 42.3 & 32.9 & 26.1 & 15.7 & 18.4 & 13.1 & 22.9 & 9.0 & 9.5 & 3.3 \\
\hline NL & 87.8 & 84.8 & 77.6 & 67.1 & 39.6 & 39.6 & 50.3 & 20.7 & 30.2 & 24.5 & 21.5 & 12.7 & 2.8 \\
\hline DE & 82.3 & 77.4 & 60.1 & 55.9 & 18.3 & 24.8 & 12.2 & 13.4 & 20.9 & 20.5 & 7.0 & 3.4 & 0.5 \\
\hline IT & 66.5 & 41.7 & 40.2 & 21.3 & 14.1 & 4.8 & 7.5 & 9.4 & 4.2 & 10.9 & 5.5 & 3.2 & 2.3 \\
\hline LU & 87.5 & 78.2 & 60.2 & 45.9 & 33.1 & 31.7 & 22.7 & 18.9 & 20.6 & 13.1 & 6.1 & 12.5 & 4.9 \\
\hline DK & 79.8 & 72.8 & 65.6 & 51.7 & 36.0 & 31.6 & 27.4 & 27.0 & 21.4 & 17.3 & 6.6 & 10.6 & 1.6 \\
\hline IE & 73.5 & 60.3 & 36.6 & 39.9 & 30.4 & 25.0 & 19.6 & 14.7 & 11.8 & 14.1 & 6.9 & 8.8 & 2.6 \\
\hline UK & 83.4 & 65.9 & 42.0 & 48.9 & 33.9 & 26.7 & 28.5 & 16.6 & 17.1 & 21.6 & 4.0 & 5.4 & 2.9 \\
\hline GR & 75.7 & 65.2 & 43.4 & 31.2 & 25.7 & 2.1 & 2.7 & 4.6 & 2.8 & 3.0 & 16.9 & 1.7 & 0.5 \\
\hline ES & 85.5 & 62.1 & 39.7 & 33.7 & 17.6 & 10.6 & 17.6 & 4.4 & 3.6 & 4.4 & 1.6 & 2.8 & 0.8 \\
\hline PT & 72.8 & 54.0 & 39.1 & 17.1 & 17.1 & 6.8 & 6.2 & 4.4 & 4.2 & 5.2 & 4.0 & 2.0 & 1.0 \\
\hline FI & 81.5 & 76.2 & 48.4 & 45.8 & 20.9 & 41.3 & 21.3 & 16.6 & 26.0 & 16.1 & 3.4 & 3.4 & 1.9 \\
\hline SE & 91.8 & 84.0 & 59.7 & 67.5 & 16.0 & 41.3 & 15.5 & 20.1 & 40.7 & 26.8 & 3.5 & 2.1 & 2.6 \\
\hline AT & 61.5 & 58.5 & 46.2 & 41.5 & 17.6 & 23.8 & 19.1 & 12.3 & 18.3 & 15.1 & 6.2 & 3.4 & 3.4 \\
\hline$C Y$ & 84.1 & 73.8 & 56.5 & 22.1 & 32.9 & 10.9 & 7.9 & 16.2 & 5.0 & 3.2 & 24.4 & 5.9 & 1.5 \\
\hline $\mathrm{CZ}$ & 76.1 & 54.7 & 53.5 & 29.2 & 20.2 & 8.3 & 8.9 & 11.0 & 5.6 & 4.8 & 4.8 & 1.9 & 1.3 \\
\hline $\mathrm{EE}$ & 75.3 & 64.5 & 50.8 & 32.4 & 35.6 & 11.4 & 11.4 & 13.2 & 3.8 & 2.9 & 1.8 & 4.9 & 0.6 \\
\hline HU & 59.2 & 56.3 & 46.8 & 20.9 & 24.3 & 13.3 & 9.3 & 9.0 & 10.9 & 5.3 & 5.5 & 6.7 & 2.0 \\
\hline LV & 63.1 & 62.1 & 64.9 & 40.8 & 30.6 & 11.8 & 15.7 & 14.8 & 4.3 & 4.8 & 1.2 & 1.5 & 1.2 \\
\hline LT & 79.1 & 51.3 & 51.2 & 22.1 & 17.3 & 6.2 & 8.0 & 6.8 & 3.6 & 0.2 & 0.6 & 1.1 & 0.3 \\
\hline MT & 84.9 & 59.9 & 48.0 & 30.9 & 5.6 & 13.5 & 28.3 & 5.9 & 6.6 & 1.0 & 13.8 & 2.3 & 1.6 \\
\hline PL & 58.3 & 50.0 & 39.4 & 19.8 & 11.9 & 4.0 & 8.3 & 4.7 & 2.9 & 3.2 & 2.3 & 2.9 & 0.5 \\
\hline SK & 71.3 & 54.8 & 36.5 & 28.0 & 25.6 & 5.5 & 9.3 & 8.7 & 2.8 & 4.3 & 3.1 & 0.7 & 1.0 \\
\hline SI & 86.1 & 75.2 & 64.5 & 48.0 & 29.9 & 26.7 & 16.0 & 17.4 & 9.3 & 16.5 & 4.4 & 7.4 & 1.2 \\
\hline BG & 34.1 & 37.7 & 53.2 & 24.8 & 36.8 & 2.4 & 3.3 & 5.7 & 1.9 & 1.7 & 3.7 & 2.7 & 0.5 \\
\hline RO & 35.7 & 37.9 & 38.6 & 22.9 & 25.9 & 4.3 & 6.7 & 5.2 & 4.0 & 3.1 & 2.6 & 1.2 & 1.2 \\
\hline HR & 66.3 & 47.8 & 40.0 & 21.2 & 23.7 & 5.5 & 5.8 & 8.2 & 3.5 & 4.4 & 0.8 & 2.6 & 0.1 \\
\hline EU28 & 73.4 & 62.0 & 50.3 & 37.1 & 25.0 & 17.7 & 14.7 & 12.4 & 11.8 & 10.7 & 5.7 & 4.5 & 1.6 \\
\hline
\end{tabular}


Table A3. Multilevel mixed-effects logistic regression of climate change mitigation actions among European Union (EU) citizens.

\begin{tabular}{|c|c|c|c|c|c|c|c|c|c|c|c|c|c|c|}
\hline & \multicolumn{2}{|c|}{$\begin{array}{c}\text { Reduce And } \\
\text { Separate Waste }\end{array}$} & \multicolumn{2}{|c|}{$\begin{array}{c}\text { Use Fewer } \\
\text { Disposable Items }\end{array}$} & \multicolumn{2}{|c|}{$\begin{array}{l}\text { Energy Efficiency } \\
\text { Households (Eff } \\
\text { Hh) Appliances }\end{array}$} & \multicolumn{2}{|c|}{$\begin{array}{c}\text { Alternatives To Car } \\
\text { Use }\end{array}$} & \multicolumn{2}{|c|}{$\begin{array}{l}\text { Insulated Home } \\
\text { Better }\end{array}$} & \multicolumn{2}{|c|}{$\begin{array}{l}\text { Food Carbon } \\
\text { Footprint }\end{array}$} & \multicolumn{2}{|c|}{$\begin{array}{l}\text { Energy Saving } \\
\text { Equipment Home }\end{array}$} \\
\hline & $\beta$ & $\exp (\beta)$ & $\beta$ & $\exp (\beta)^{1}$ & $\beta$ & $\exp (\beta)$ & $\beta$ & $\exp (\beta)$ & $\beta$ & $\exp (\beta)$ & $\beta$ & $\exp (\beta)$ & $\beta$ & $\exp (\beta)$ \\
\hline \multicolumn{15}{|l|}{ Gender (Men) } \\
\hline Women & $0.23^{* * *}$ & 1.25 & $0.32 * * *$ & 1.38 & $0.14^{* * *}$ & 1.15 & $0.15^{* * *}$ & 1.16 & $-0.09 * *$ & 0.92 & $0.47^{* * *}$ & 1.6 & -0.08 & 0.93 \\
\hline \multicolumn{15}{|l|}{ AGE (15-24 YEARS) } \\
\hline 25-34 Years & $0.2 *$ & 1.22 & 0.1 & 1.11 & $0.46^{* * *}$ & 1.57 & -0.04 & 0.96 & $0.33^{* *}$ & 1.39 & -0.1 & 0.9 & $0.38^{* *}$ & 1.47 \\
\hline 35-44 Years & $0.34^{* * *}$ & 1.41 & 0.21 * & 1.23 & $0.56^{* * *}$ & 1.75 & -0.13 & 0.88 & $0.52^{* * *}$ & 1.69 & -0.2 & 0.82 & $0.52^{* * *}$ & 1.68 \\
\hline 45-54 Years & $0.46^{* * *}$ & 1.59 & $0.2 *$ & 1.22 & $0.62 * * *$ & 1.86 & -0.17 & 0.85 & $0.68^{* * *}$ & 1.98 & -0.21 & 0.81 & $0.46^{* * *}$ & 1.58 \\
\hline 55-64 Years & $0.45^{* * *}$ & 1.56 & $0.22 * *$ & 1.25 & $0.62 * * *$ & 1.85 & $-0.23 * *$ & 0.79 & $0.72 * * *$ & 2.05 & -0.19 & 0.83 & $0.48^{* * *}$ & 1.62 \\
\hline 65 Years and Over & $0.39 * * *$ & 1.48 & $0.19^{*}$ & 1.22 & $0.52 * * *$ & 1.68 & $-0.33^{* * *}$ & 0.72 & $0.82 * * *$ & 2.28 & $-0.27 *$ & 0.77 & $0.48^{* * *}$ & 1.61 \\
\hline \multicolumn{15}{|l|}{$\begin{array}{l}\text { Age When Stopped } \\
\text { Education (1-15) }\end{array}$} \\
\hline 16-19 & $0.25^{* * *}$ & 1.28 & $0.15^{* *}$ & 1.16 & $0.32^{* * *}$ & 1.38 & $0.24^{* * *}$ & 1.27 & $0.24 * * *$ & 1.27 & 0.13 & 1.14 & 0.13 & 1.14 \\
\hline $20+$ & $0.46^{* * *}$ & 1.59 & $0.3^{* * *}$ & 1.35 & $0.5^{* * *}$ & 1.65 & $0.54 * * *$ & 1.72 & $0.4^{* * *}$ & 1.51 & $0.42 * * *$ & 1.52 & $0.26^{* * *}$ & 1.29 \\
\hline Still Studying & $0.32^{* *}$ & 1.38 & 0.3 ** & 1.35 & $0.23 *$ & 1.26 & $0.62 * * *$ & 1.86 & 0.27 & 1.31 & 0.33 ** & 1.4 & 0.19 & 1.21 \\
\hline No Full-Time Education & -0.03 & 0.97 & -0.4 & 0.67 & -0.09 * & 0.92 & $0.46^{* * *}$ & 1.58 & -0.38 & 0.69 & $0.58^{*}$ & 1.79 & $-0.8^{*}$ & 0.45 \\
\hline \multicolumn{15}{|l|}{$\begin{array}{c}\text { Occupation } \\
\text { (Not Working) }\end{array}$} \\
\hline Self-Employed & -0.1 & 0.91 & 0.05 & 1.05 & $0.183^{* *}$ & 1.2 & -0.18 ** & 0.84 & $0.37^{* * *}$ & 1.44 & 0.12 & 1.12 & $0.24 * *$ & 1.27 \\
\hline Employed & $-0.13 * *$ & 0.88 & -0.03 & 0.96 & 0.05 & 1.06 & $-0.13 * *$ & 0.89 & 0.005 & 1.01 & 0.04 & 1.04 & -0.04 & 0.96 \\
\hline \multicolumn{15}{|l|}{$\begin{array}{c}\text { Marital Status } \\
\text { (Single HH without Children) }\end{array}$} \\
\hline Single HH WITH Children & 0.004 & 1.004 & 0.78 & 1.08 & $0.26^{* * *}$ & 1.3 & 0.01 & 1.01 & 0.17 & 1.18 & 0.1 & 1.1 & 0.12 & 1.13 \\
\hline Multiple HH without Children & 0.05 & 1.06 & 0.07 & 1.07 & $0.27 * * *$ & 1.3 & $-0.12 * *$ & 0.89 & $0.49 * * *$ & 1.63 & $0.22 * * *$ & 1.24 & $0.35^{* * *}$ & 1.42 \\
\hline Multiple HH with Children & $0.12 * *$ & 1.13 & $0.11 *$ & 1.11 & $0.41^{* * *}$ & 1.51 & 0.08 & 0.92 & $0.63 * * *$ & 1.89 & $0.17^{* *}$ & 1.18 & $0.39 * * *$ & 1.47 \\
\hline \multicolumn{15}{|l|}{$\begin{array}{l}\text { Difficulties Paying Bills (Most of } \\
\text { the Time }\end{array}$} \\
\hline From Time to Time & $0.31^{* * *}$ & 1.37 & $0.26^{* * *}$ & 1.29 & $0.38^{* * *}$ & 1.47 & -0.03 & 0.97 & 0.23 ** & 1.26 & 0.04 & 1.04 & -0.04 & 0.96 \\
\hline Almost Never & $0.62 * * *$ & 1.86 & $0.47^{* * *}$ & 1.6 & $0.58^{* * *}$ & 1.78 & $0.17^{* *}$ & 1.18 & $0.55^{* * *}$ & 1.74 & $0.21 *$ & 1.23 & 0.12 & 1.13 \\
\hline \multicolumn{15}{|l|}{ Urban Area (Small Town) } \\
\hline Large Town & 0.001 & 1 & -0.003 & 1 & $-0.08^{* *}$ & 0.93 & $0.21 * * *$ & 1.24 & $-0.22 * * *$ & 0.8 & 0.008 & 1.008 & $-0.22 * * *$ & 0.81 \\
\hline \multicolumn{15}{|l|}{ Region(East-Central Europe) } \\
\hline Western Europe & $0.67^{* *}$ & 1.95 & $0.63 * * *$ & 1.88 & 0.07 & 1.07 & $0.76^{* * *}$ & 2.15 & -0.11 & 1.11 & $1.36^{* * *}$ & 3.89 & $0.96^{* * *}$ & 2.6 \\
\hline Southern Europe & $0.68^{* *}$ & 1.97 & 0.24 & 1.2 & -0.14 & 0.87 & -0.05 & 0.95 & $-0.39 *$ & 0.67 & -0.06 & 0.94 & 0.13 & 1.14 \\
\hline Nordic Nations & $0.67^{*}$ & 1.95 & $0.31^{* *}$ & 2.21 & -0.005 & 0.99 & $0.86^{* * *}$ & 2.36 & $-0.48^{*}$ & 0.62 & $1.67^{* * *}$ & 5.27 & $0.76^{* *}$ & 2.15 \\
\hline \multicolumn{15}{|l|}{$\begin{array}{l}\text { Polit. Ideology } \\
\text { (Right) }\end{array}$} \\
\hline Left & $0.26^{* * *}$ & 1.3 & $0.2^{* * *}$ & 1.22 & 0.04 & 1.04 & $0.17^{* * *}$ & 1.18 & -0.11 ** & 0.9 & $0.35^{* * *}$ & 1.42 & $-0.2^{* * *}$ & 0.82 \\
\hline Centre & $0.21 * * *$ & 1.23 & $0.11 * *$ & 1.12 & $0.15^{* * *}$ & 1.16 & 0.06 & 1.06 & 0.07 & 1.07 & 0.05 & 1.05 & -0.05 & 1.07 \\
\hline Political Interest Index (Not at All) & & & & & & & & & & & & & & \\
\hline
\end{tabular}


Table A3. Cont.

\begin{tabular}{|c|c|c|c|c|c|c|c|c|c|c|c|c|c|c|}
\hline & \multicolumn{2}{|c|}{$\begin{array}{l}\text { Reduce And } \\
\text { Separate Waste }\end{array}$} & \multicolumn{2}{|c|}{$\begin{array}{c}\text { Use Fewer } \\
\text { Disposable Items }\end{array}$} & \multicolumn{2}{|c|}{$\begin{array}{l}\text { Energy Efficiency } \\
\text { Households (Eff } \\
\text { Hh) Appliances }\end{array}$} & \multicolumn{2}{|c|}{$\begin{array}{l}\text { Alternatives To Car } \\
\text { Use }\end{array}$} & \multicolumn{2}{|c|}{$\begin{array}{l}\text { Insulated Home } \\
\text { Better }\end{array}$} & \multicolumn{2}{|c|}{$\begin{array}{l}\text { Food Carbon } \\
\text { Footprint }\end{array}$} & \multicolumn{2}{|c|}{$\begin{array}{l}\text { Energy Saving } \\
\text { Equipment Home }\end{array}$} \\
\hline & $\beta$ & $\exp (\beta)$ & $\beta$ & $\exp (\beta)^{1}$ & $\beta$ & $\exp (\beta)$ & $\beta$ & $\exp (\beta)$ & $\beta$ & $\exp (\beta)$ & $\beta$ & $\exp (\beta)$ & $\beta$ & $\exp (\beta)$ \\
\hline Strong & $0.25^{* * *}$ & 1.29 & $0.6^{* * *}$ & 1.82 & $0.55^{* * *}$ & 1.74 & $0.63 * * *$ & 1.88 & $0.52 * * *$ & 1.69 & $0.88^{* * *}$ & 2.4 & $0.23 * * *$ & 1.26 \\
\hline Medium & $0.34^{* * *}$ & 1.4 & $0.41^{* * *}$ & 1.51 & $0.39 * * *$ & 1.47 & $0.37 * * *$ & 1.45 & $0.32 * * *$ & 1.37 & $0.42 * * *$ & 1.52 & -0.007 & 0.99 \\
\hline Low & $0.33 * * *$ & 1.39 & $0.31 * * *$ & 1.37 & $0.3^{* * * *}$ & 1.34 & $0.34^{* * *}$ & 1.41 & $0.16^{*}$ & 1.17 & $0.17^{*}$ & 1.18 & -0.14 & 0.87 \\
\hline \multicolumn{15}{|l|}{$\begin{array}{c}\text { Climate Change } \\
\text { Importance (Not a Serious } \\
\text { Problem) }\end{array}$} \\
\hline A Fairly Serious Problem & $0.17^{*}$ & 1.19 & $0.21 * *$ & 1.23 & 0.1 & 1.1 & 0.13 & 1.14 & 0.64 & 1.26 & 0.16 & 1.17 & -0.07 & 0.94 \\
\hline A Very Serious Problem & $0.7^{* * *}$ & 2.02 & $0.81^{* * *}$ & 2.24 & $0.53 * * *$ & 1.7 & $0.65^{* * *}$ & 1.92 & $0.18 *$ & 1.19 & $0.76^{* * *}$ & 2.13 & 0.0001 & 1 \\
\hline \multicolumn{15}{|l|}{ Climate Change Resp. (No) } \\
\hline National Gov. & $0.15^{* * *}$ & 1.16 & $0.18^{* * *}$ & 1.19 & $0.17^{* * *}$ & 1.18 & $0.09^{* *}$ & 1.09 & 0.07 & 1.07 & $-0.1^{*}$ & 0.9 & 0.04 & 1.04 \\
\hline European Union & $0.16^{* * *}$ & 1.17 & $0.79 *$ & 1.08 & $0.14^{* * *}$ & 1.15 & $0.09^{* *}$ & 1.09 & 0.004 & 1.004 & 0.05 & 1.05 & -0.03 & 0.97 \\
\hline Regional/Local Authorities & $-\underset{* * *}{-0.00089}$ & 1 & $0.86^{*}$ & 1.09 & $0.77^{*}$ & 1.08 & -0.05 & 0.95 & 0.07 & 1.07 & $0.28^{* * *}$ & 1.18 & $0.13 * *$ & 1.14 \\
\hline Business and Industry & $0.33^{* * *}$ & 1.4 & $0.17^{* * *}$ & 1.19 & $0.24^{* * *}$ & 1.27 & 0.04 & 1.04 & 0.06 & 1.06 & 0.05 & 1.05 & -0.005 & 1 \\
\hline Citizens & 0.21 *** & 1.24 & $0.26^{* * *}$ & 1.3 & $0.16^{* * *}$ & 1.18 & $0.42 * * *$ & 1.53 & $0.14^{* * *}$ & 1.15 & $0.28^{* * *}$ & 1.32 & $0.17^{* * *}$ & 1.19 \\
\hline Env. Groups & -0.09 * & 0.92 & -0.002 & 1 & -0.07 & 0.94 & 0.07 & 1.08 & -0.07 & 0.93 & 0.05 & 1.05 & $0.13^{* *}$ & 1.14 \\
\hline \multicolumn{15}{|l|}{$\begin{array}{l}\text { Action on Climate Change will } \\
\text { Lead to Innovation (No) }\end{array}$} \\
\hline Yes & $0.28^{* * *}$ & 1.32 & $0.25^{* * *}$ & 1.29 & $0.25^{* * *}$ & 1.28 & 0.07 & 1.07 & 0.01 & 1.01 & 0.13 & 1.14 & 0.01 & 1.01 \\
\hline Constant & -2.04 & 0.13 & -2.34 & 0.1 & -2.95 & 0.05 & -2.5 & 0.08 & -3.17 & 0.04 & -4.52 & 0.01 & -3.07 & 0.05 \\
\hline Observations & 13714 & & 13714 & & 13714 & & 13714 & & 13714 & & 13714 & & 13714 & \\
\hline No. of Groups & 28 & & 28 & & 28 & & 28 & & 28 & & 28 & & 28 & \\
\hline Log Likelihood & -6726.7 & & -7989.75 & & 8712.85 & & -8225.35 & & -7411.39 & & -5765.97 & & -5634.83 & \\
\hline Wald Chi ${ }^{2}$ & $\underset{* * *}{673.63}$ & & $\underset{* * *}{791.48}$ & & $\underset{* * *}{891.36}$ & & $\underset{* * *}{792.21}$ & & 607.97 & & $\underset{* * *}{696.91}$ & & $\underset{* * *}{245.83}$ & \\
\hline \multicolumn{15}{|c|}{ Random Part Identity: Country } \\
\hline Variance (Constant) & 0.39 & & 0.22 & & 0.19 & & 0.12 & & 0.2 & & 0.33 & & 0.3 & \\
\hline $\begin{array}{l}\text { (Intercept Variance) } \\
\text { (Standard Error) }\end{array}$ & 0.11 & & 0.06 & & 0.05 & & 0.04 & & 0.06 & & 0.1 & & 0.09 & \\
\hline Variance at Country Level ${ }^{2}(\%)$ & $10.59 \%$ & & $6.26 \%$ & & $4.53 \%$ & & $3.40 \%$ & & $5.73 \%$ & & $9.12 \%$ & & $8.36 \%$ & \\
\hline \multirow[t]{3}{*}{ LR Test } & $\underset{* * *}{624.95}$ & & 344.68 & & 372.26 & & $\underset{* * *}{248.94}$ & & 311.61 & & 246.27 & & 401.07 & \\
\hline & \multicolumn{2}{|c|}{$\begin{array}{c}\text { Low Fuel } \\
\text { Consumption Car }\end{array}$} & \multicolumn{2}{|c|}{$\begin{array}{l}\text { Travel Carbon } \\
\text { Footprint }\end{array}$} & \multicolumn{3}{|c|}{$\begin{array}{l}\text { Switched Energy } \\
\text { Supplier }\end{array}$} & \multicolumn{2}{|c|}{$\begin{array}{c}\text { Installed Solar panels } \\
\text { Home }\end{array}$} & \multicolumn{3}{|c|}{$\begin{array}{c}\text { Bought Low-Energy } \\
\text { Home }\end{array}$} & \multicolumn{2}{|c|}{ Electric car } \\
\hline & $\beta$ & $\exp (\beta)$ & $\beta$ & $\exp (\beta)$ & $\beta$ & & $\exp (\beta)$ & $\beta$ & $\exp (\beta)$ & $\beta$ & $\exp (\beta$ & & $\beta$ & $\exp (\beta)$ \\
\hline \multicolumn{15}{|l|}{ Gender (Men) } \\
\hline Women & $-0.23 * * *$ & 0.8 & $0.2 * * *$ & 1.23 & -0.0 & & 1 & -0.07 & 0.93 & $-0.17^{* *}$ & 0.84 & & -0.11 & 0.9 \\
\hline \multicolumn{15}{|l|}{ Age (15-24 Years) } \\
\hline 25-34 Years & $-0.27 *$ & 0.76 & 01 & 1.1 & 0.23 & & 1.26 & -0.006 & 0.99 & 0.12 & 1.13 & & $-0.7^{*}$ & 0.5 \\
\hline 35-44 Years & $-0.35 * *$ & 0.7 & 0.23 & 1.26 & 0.3 & & 1.35 & 0.16 & 1.18 & 0.16 & 1.17 & & $-0.62 *$ & 0.54 \\
\hline
\end{tabular}


Table A3. Cont.

\begin{tabular}{|c|c|c|c|c|c|c|c|c|c|c|c|c|}
\hline & \multicolumn{2}{|c|}{$\begin{array}{c}\text { Low Fuel } \\
\text { Consumption Car }\end{array}$} & \multicolumn{2}{|c|}{$\begin{array}{l}\text { Travel Carbon } \\
\text { Footprint }\end{array}$} & \multicolumn{2}{|c|}{$\begin{array}{l}\text { Switched Energy } \\
\text { Supplier }\end{array}$} & \multicolumn{2}{|c|}{$\begin{array}{c}\text { Installed Solar panels } \\
\text { Home }\end{array}$} & \multicolumn{2}{|c|}{$\begin{array}{c}\text { Bought Low-Energy } \\
\text { Home }\end{array}$} & \multicolumn{2}{|c|}{ Electric car } \\
\hline & $\beta$ & $\exp (\beta)$ & $\beta$ & $\exp (\beta)$ & $\beta$ & $\exp (\beta)$ & $\beta$ & $\exp (\beta)$ & $\beta$ & $\exp (\beta)$ & $\beta$ & $\exp (\beta)$ \\
\hline 45-54 Years & -0.005 & 0.99 & 0.14 & 1.15 & 0.24 & 1.27 & 0.23 & 1.26 & -0.1 & 0.9 & -0.34 & 0.71 \\
\hline 55-64 Years & -0.16 & 0.85 & 0.07 & 1.07 & 0.26 & 1.29 & 0.5 & 1.64 & -0.08 & 0.92 & -0.32 & 0.73 \\
\hline 65 Years and Over & -0.27 & 0.77 & 0.02 & 1.02 & 0.18 & 1.2 & $0.33^{* *}$ & 1.38 & -0.08 & 0.93 & $-0.74^{*}$ & 0.48 \\
\hline \multicolumn{13}{|l|}{$\begin{array}{l}\text { Age When Stopped } \\
\text { Education (1-15) }\end{array}$} \\
\hline $16-19$ & 0.17 & 1.19 & 0.05 & 1.05 & 0.06 & 1.06 & $0.36^{* *}$ & 1.43 & 0.06 & 1.06 & 0.14 & 1.15 \\
\hline $20+$ & $0.39^{* * *}$ & 1.47 & $0.46^{* * *}$ & 1.59 & $0.31^{* * *}$ & 1.37 & $0.69^{* * *}$ & 1.98 & 0.31 * & 1.36 & 0.48 & 1.61 \\
\hline Still Studying & -0.32 & 0.72 & $0.55^{* * *}$ & 1.73 & 0.05 & 1.05 & $0.7^{* *}$ & 2 & 0.45 & 1.56 & 0.26 & 1.3 \\
\hline No Full-Time Education & -0.52 & 0.6 & 0.57 & 1.78 & $0.7^{*}$ & 2.01 & 0.3 & 1.35 & -0.42 & 0.66 & 0.52 & 1.67 \\
\hline \multicolumn{13}{|l|}{$\begin{array}{c}\text { Occupation } \\
\text { (Not Working) }\end{array}$} \\
\hline Self-Employed & $0.31^{* * *}$ & 1.36 & 0.46 & 1.58 & $0.18 *$ & 1.2 & $0.3^{* *}$ & 1.35 & $0.32 *$ & 1.38 & $0.97^{* * *}$ & 2.63 \\
\hline Employed & 0.02 & 1.02 & $0.02^{* * *}$ & 1.02 & -0.11 & 0.89 & -0.13 & 0.88 & 0.1 & 1.11 & $0.38^{*}$ & 1.46 \\
\hline \multicolumn{13}{|l|}{$\begin{array}{c}\text { Marital Status } \\
\text { (Single HH without } \\
\text { Children) }\end{array}$} \\
\hline Single HH with Children & $0.25 *$ & 1.29 & -0.04 & 0.97 & $0.28^{* *}$ & 1.32 & 0.22 & 1.25 & $0.36 *$ & 1.43 & -0.24 & 0.78 \\
\hline $\begin{array}{l}\text { Multiple HH Without } \\
\text { Children }\end{array}$ & $0.6^{* * *}$ & 1.82 & 0.08 & 1.08 & $0.3^{* * *}$ & 1.35 & $0.37^{* * *}$ & 1.45 & $0.31^{* * *}$ & 1.36 & 0.25 & 1.28 \\
\hline Multiple HH with Children & $0.71^{* * *}$ & 2.04 & 0.08 & 1.08 & $0.49^{* * *}$ & 1.63 & $0.62 * * *$ & 1.86 & $0.56^{* * *}$ & 1.75 & $0.56^{* * *}$ & 1.75 \\
\hline \multicolumn{13}{|l|}{$\begin{array}{l}\text { Difficulties Paying Bills } \\
\text { (Most of the Time) }\end{array}$} \\
\hline From Time to Time & 0.19 & 1.21 & $0.34 * *$ & 1.4 & -0.16 & 0.85 & -0.1 & 0.91 & -0.06 & 0.94 & -0.12 & 0.89 \\
\hline Almost Never & $0.67^{* * *}$ & 1.95 & $0.36^{* *}$ & 1.43 & -0.02 & 0.97 & 0.17 & 1.18 & $0.36 *$ & 1.44 & 0.23 & 1.26 \\
\hline \multicolumn{13}{|l|}{ Urban Area (Small Town) } \\
\hline Large Town & $-0.12 * *$ & 0.89 & $0.14^{* * *}$ & 1.15 & 0.05 & 1.05 & $-0.27 * * *$ & 0.76 & $-0.21 * *$ & 0.81 & 0.07 & 1.07 \\
\hline \multicolumn{13}{|l|}{$\begin{array}{c}\text { Region (East-Central } \\
\text { Europe) }\end{array}$} \\
\hline Western Europe & $0.53 * * *$ & 1.71 & $1.33^{* * *}$ & 3.78 & $1.53 * * *$ & 4.61 & $0.9^{* * *}$ & 2.46 & $0.94 * * *$ & 2.57 & $0.94^{* * *}$ & 2.55 \\
\hline Southern Europe & -0.2 & 0.82 & -0.1 & 0.91 & 0.12 & 1.13 & $1.4^{* * *}$ & 4.02 & 0.21 & 1.23 & 0.37 & 1.45 \\
\hline Nordic Nations & $0.69 * * *$ & 1.98 & $1.84^{* * *}$ & 6.32 & $1.56^{* * *}$ & 4.74 & 0.16 & 1.18 & 0.28 & 1.32 & $0.6^{*}$ & 1.82 \\
\hline \multicolumn{13}{|l|}{$\begin{array}{l}\text { Polit. Ideology } \\
\text { (Right) }\end{array}$} \\
\hline Left & $-0.22 * * *$ & 0.8 & $0.59^{* * *}$ & 1.81 & 0.09 & 1.09 & -0.09 & 0.92 & -0.09 & 0.92 & $-0.39 * *$ & 0.68 \\
\hline Center & -0.09 & 0.91 & $0.34^{* * *}$ & 1.41 & 0.01 & 1.02 & -0.16 & 0.85 & 0.07 & 1.07 & $-0.38 *$ & 0.68 \\
\hline \multicolumn{13}{|l|}{$\begin{array}{l}\text { Political Interest Index } \\
\text { (Not at All) }\end{array}$} \\
\hline Strong & $0.44^{* * *}$ & 1.55 & 0.76 & 2.14 & $0.66^{* * *}$ & 1.93 & 0.19 & 1.21 & $0.32 * *$ & 1.37 & -0.1 & 0.91 \\
\hline Medium & $0.25^{* * *}$ & 1.28 & 0.27 & 1.3 & $0.37^{* * *}$ & 1.45 & 0.01 & 1.01 & 0.05 & 1.05 & -0.31 & 0.73 \\
\hline Low & 0.17 & 1.19 & 0.11 & 1.12 & $0.32 * * *$ & 1.38 & -0.06 & 0.94 & -0.06 & 0.94 & -0.13 & 0.88 \\
\hline
\end{tabular}


Table A3. Cont.

\begin{tabular}{|c|c|c|c|c|c|c|c|c|c|c|c|c|}
\hline & \multicolumn{2}{|c|}{$\begin{array}{c}\text { Low Fuel } \\
\text { Consumption Car }\end{array}$} & \multicolumn{2}{|c|}{$\begin{array}{l}\text { Travel Carbon } \\
\text { Footprint }\end{array}$} & \multicolumn{2}{|c|}{$\begin{array}{l}\text { Switched Energy } \\
\text { Supplier }\end{array}$} & \multicolumn{2}{|c|}{$\begin{array}{c}\text { Installed Solar panels } \\
\text { Home }\end{array}$} & \multicolumn{2}{|c|}{$\begin{array}{c}\text { Bought Low-Energy } \\
\text { Home }\end{array}$} & \multicolumn{2}{|c|}{ Electric car } \\
\hline & $\beta$ & $\exp (\beta)$ & $\beta$ & $\exp (\beta)$ & $\beta$ & $\exp (\beta)$ & $\beta$ & $\exp (\beta)$ & $\beta$ & $\exp (\beta)$ & $\beta$ & $\exp (\beta)$ \\
\hline \multicolumn{13}{|l|}{$\begin{array}{c}\text { Climate Change } \\
\text { Importance (not a Serious } \\
\text { Problem) }\end{array}$} \\
\hline A Fairly Serious Problem & 0.12 & 1.13 & 0.5 & 1.64 & -0.01 & 0.99 & -0.17 & 0.84 & 0.21 & 1.23 & -0.12 & 0.89 \\
\hline A very Serious Problem & $0.3^{* *}$ & 1.35 & 0.93 & 2.54 & $0.26 * *$ & 1.3 & -0.06 & 0.95 & 0.2 & 1.22 & 0.07 & 1.07 \\
\hline \multicolumn{13}{|l|}{ Climate Change Resp. (No) } \\
\hline National Gov. & -0.06 & 0.94 & -0.07 & 0.93 & 0.09 & 1.1 & 0.13 & 1.14 & 0.06 & 1.06 & -0.14 & 0.87 \\
\hline European Union & 0.06 & 1.06 & 0.05 & 1.05 & 0.05 & 0.05 & 0.09 & 1.1 & -0.04 & 0.96 & -0.04 & 0.97 \\
\hline Regional/Local Authorities & -0.04 & 0.96 & 0.009 & 1.01 & 0.05 & 1.05 & 0.15 & 1.16 & 0.07 & 1.07 & $0.36^{* *}$ & 1.44 \\
\hline Business and Industry & 0.02 & 1.02 & -0.14 & 0.99 & -0.03 & 0.97 & -0.17 & 0.85 & $-0.21 * *$ & 0.81 & 0.006 & 1.01 \\
\hline Citizens & $0.19 * * *$ & 1.21 & $0.38^{* * *}$ & 0.99 & $-0.18^{* * *}$ & 1.2 & 0.22 & 1.25 & 0.11 & 1.12 & 0.07 & 1.07 \\
\hline Env. Groups & 0.06 & 1.06 & 0.1 & 1.1 & 0.1 & 1.1 & 0.38 & 1.04 & 0.3 & 1.03 & 0.06 & 1.07 \\
\hline \multicolumn{13}{|l|}{$\begin{array}{l}\text { Action on Climate Change } \\
\text { will Lead to Innovation } \\
\text { (no) }\end{array}$} \\
\hline Yes & -0.05 & 0.95 & 0.09 & 1.09 & $0.22 * *$ & 1.25 & 0.03 & 1.03 & 0.05 & 1.05 & -0.19 & 0.83 \\
\hline Constant & -3.52 & 0.03 & -5.61 & 0.004 & -4.68 & 0.01 & -4.64 & 0.01 & -4.43 & 0.01 & -4.62 & 0.01 \\
\hline Observations & 13714 & & 13714 & & 13714 & & 13714 & & 13714 & & 13714 & \\
\hline No. of Groups & 28 & & 28 & & 28 & & 28 & & 28 & & 28 & \\
\hline Log likelihood & -5127.18 & & -4582.28 & & -4585.54 & & -2917.55 & & -2576.41 & & -1144.6 & \\
\hline Wald Chi ${ }^{2}$ & $424.58^{* * *}$ & & $572.44 * * *$ & & $279.46^{* * *}$ & & $190.72 * * *$ & & 135 *** & & $107.2^{* * *}$ & \\
\hline \multicolumn{13}{|c|}{ Random Part Identity: Country } \\
\hline Variance (Constant) & 0.14 & & 0.16 & & 0.34 & & 0.46 & & 0.27 & & 0.16 & \\
\hline $\begin{array}{l}\text { (Intercept Variance) } \\
\text { (Standard Error) }\end{array}$ & 0.05 & & 0.05 & & 0.11 & & 0.14 & & 0.09 & & 0.08 & \\
\hline $\begin{array}{c}\text { Variance at Country } \\
\text { Level }^{1}(\%)\end{array}$ & $4.08 \%$ & & $4.64 \%$ & & $9.37 \%$ & & $12.27 \%$ & & $7.58 \%$ & & $4.64 \%$ & \\
\hline LR Test & $87.13^{* * *}$ & & $147.19^{* * *}$ & & 180.31 & & 213.54 & & 111.08 & & 12.8 & \\
\hline
\end{tabular}

Note: All coefficients are compared to the benchmark category, shown in brackets. All country level indicators were centred to the sample mean. For the sample of 18,529 respondents.

${ }_{* * *} p<0.01,{ }^{* *} p<0.05,{ }^{*} p<0.1$. ${ }^{1}$ Odds ratio. ${ }^{2}$ Variance partition coefficient: measures the proportion of the total residual variance that is due to between-group variation. 
Table A4. Multilevel mixed-effects logistic regression of climate change mitigation cumulative actions in EU.

\begin{tabular}{|c|c|c|c|c|c|c|c|c|c|c|c|c|}
\hline & \multicolumn{2}{|c|}{ Model I } & \multicolumn{2}{|c|}{ Model II } & \multicolumn{2}{|c|}{ Model III } & \multicolumn{2}{|c|}{ Model IV } & \multicolumn{2}{|c|}{ Model V } & \multicolumn{2}{|c|}{ Model VI } \\
\hline & $\beta$ & $\exp (\beta)^{1}$ & $\beta$ & $\exp (\beta)$ & $\beta$ & $\exp (\beta)$ & $\beta$ & $\exp (\beta)$ & $\beta$ & $\exp (\beta)$ & $\beta$ & $\exp (\beta)$ \\
\hline \multicolumn{13}{|l|}{ Gender (men) } \\
\hline Women & $0.21^{* * *}$ & 1.23 & $0.21^{* * *}$ & 1.23 & $0.21^{* * *}$ & 1.23 & $0.21^{* * *}$ & 1.23 & $0.21^{* * *}$ & 1.23 & $0.21^{* * *}$ & 1.23 \\
\hline \multicolumn{13}{|l|}{ Age (15-24 years) } \\
\hline 25-34 years & $0.36^{* * *}$ & 1.43 & $0.35^{* * *}$ & 1.42 & $0.35^{* * *}$ & 1.43 & $0.35^{* * *}$ & 1.43 & $0.35^{* * *}$ & 1.43 & $0.36^{* * *}$ & 1.42 \\
\hline $35-44$ years & $0.37^{* * *}$ & 1.45 & $0.37^{* * *}$ & 1.45 & $0.37^{* * *}$ & 1.45 & $0.37^{* * *}$ & 1.45 & $0.37^{* * *}$ & 1.45 & $0.37^{* * *}$ & 1.45 \\
\hline $45-54$ years & $0.46^{* * *}$ & 1.58 & $0.46^{* * *}$ & 1.58 & $0.46^{* * *}$ & 1.58 & $0.46^{* * *}$ & 1.58 & $0.46^{* * *}$ & 1.58 & $0.46^{* * *}$ & 1.58 \\
\hline 55-64 years & $0.49^{* * *}$ & 1.63 & $0.49^{* * *}$ & 1.63 & $0.5^{* * *}$ & 1.63 & $0.49^{* * *}$ & 1.63 & $0.49^{* * *}$ & 1.63 & $0.49^{* * *}$ & 1.64 \\
\hline 65 years and over & $0.45^{* * *}$ & 1.57 & $0.45^{* * *}$ & 1.57 & $0.45^{* * *}$ & 1.57 & $0.45^{* * *}$ & 1.57 & $0.45^{* * *}$ & 1.57 & $0.45^{* * *}$ & 1.57 \\
\hline \multicolumn{13}{|l|}{$\begin{array}{l}\text { Age when stopped } \\
\text { Education (1-15) }\end{array}$} \\
\hline $16-19$ & $0.31^{* * *}$ & 1.36 & $0.31^{* * *}$ & 1.36 & $0.31^{* * *}$ & 1.36 & $0.31^{* * *}$ & 1.36 & $0.31 * * *$ & 1.36 & $0.31^{* * *}$ & 1.36 \\
\hline $20+$ & $0.7^{* * *}$ & 2.02 & $0.7^{* * *}$ & 2.02 & $0.7^{* * *}$ & 2.02 & $0.7 * * *$ & 2.02 & $0.7^{* * *}$ & 2.03 & $0.7 * * *$ & 2.02 \\
\hline Still studying & $0.49^{* * *}$ & 1.64 & $0.49^{* * *}$ & 1.63 & $0.49^{* * *}$ & 1.63 & $0.49^{* * *}$ & 1.63 & $0.49^{* * *}$ & 1.64 & $0.5 * * *$ & 1.64 \\
\hline No full-time education & 0.12 & 1.12 & 0.12 & 1.13 & 0.12 & 1.12 & 0.12 & 1.12 & 0.12 & 1.12 & 0.12 & 1.12 \\
\hline \multicolumn{13}{|l|}{$\begin{array}{l}\text { Occupation } \\
\text { (not working) }\end{array}$} \\
\hline Self-employed & $0.29^{* * *}$ & 1.34 & $0.29 * * *$ & 1.34 & $0.29 * * *$ & 1.34 & $0.29^{* * *}$ & 1.34 & $0.3^{* * * *}$ & 1.34 & $0.29 * * *$ & 1.35 \\
\hline Employed & -0.07 & 0.93 & -0.07 & 0.93 & -0.07 & 0.93 & -0.07 & 0.93 & -0.07 & 0.93 & -0.07 & 0.94 \\
\hline \multicolumn{13}{|l|}{$\begin{array}{l}\text { Marital status } \\
\text { (single HH without children) }\end{array}$} \\
\hline Single HH with children & $0.28^{* * *}$ & 1.33 & $0.28^{* * *}$ & 1.33 & $0.28 * * *$ & 1.33 & $0.28 * * *$ & 1.33 & $0.28^{* * *}$ & 1.33 & $0.28^{* * *}$ & 1.33 \\
\hline Multiple HH without children & $0.35^{* * *}$ & 1.42 & $0.35^{* * *}$ & 1.42 & $0.35^{* * *}$ & 1.42 & $0.35^{* * *}$ & 1.42 & $0.35^{* * *}$ & 1.42 & $0.35^{* * *}$ & 1.42 \\
\hline Multiple HH with children & $0.53^{* * *}$ & 1.7 & $0.53^{* * *}$ & 1.7 & $0.53 * * *$ & 1.7 & $0.53^{* * *}$ & 1.7 & $0.53 * * *$ & 1.7 & $0.53^{* * *}$ & 1.7 \\
\hline \multicolumn{13}{|l|}{$\begin{array}{l}\text { Difficulties paying bills (most of } \\
\text { the time }\end{array}$} \\
\hline From time to time & $0.3^{* * *}$ & 1.34 & $0.3^{* * *}$ & 1.34 & $0.3^{* * *}$ & 1.35 & $0.3^{* * *}$ & 1.35 & $0.3^{* * *}$ & 1.34 & $0.3^{* * *}$ & 1.34 \\
\hline Almost never & $0.7^{* *}$ & 2.01 & $0.7^{* * * *}$ & 2.01 & $0.7^{* * *}$ & 2.02 & $0.7^{* * * *}$ & 2.01 & $0.7^{* * * *}$ & 2 & 0.7 ** & 1.99 \\
\hline \multicolumn{13}{|l|}{ Urban area (small town) } \\
\hline Large town & $-0.11^{* *}$ & 0.89 & $-0.11^{* *}$ & 0.89 & $-0.11 * *$ & 0.89 & $-0.11 * *$ & 0.89 & -0.11 & 0.89 & $-0.11^{* *}$ & 0.89 \\
\hline \multicolumn{13}{|l|}{ Region (East-Central Europe) } \\
\hline Western Europe & $1.14^{* * *}$ & 3.11 & 0.69 * & 2 & $0.71^{*}$ & 3.95 & $0.71 *$ & 2.03 & $0.87^{* * *}$ & 2.38 & $0.72 * * *$ & 2.05 \\
\hline Southern Europe & 0.26 & 1.3 & 0.13 & 1.14 & -0.07 & 1.42 & -0.07 & 0.94 & $0.58^{* *}$ & 1.78 & $0.45^{* *}$ & 1.57 \\
\hline Nordic nations & $1.21^{* * *}$ & 3.35 & 0.57 & 1.76 & 0.55 & 4.13 & 0.55 & 1.73 & 0.5 & 1.65 & 0.38 & 1.47 \\
\hline \multicolumn{13}{|l|}{$\begin{array}{l}\text { Polit. ideology } \\
\text { (right) }\end{array}$} \\
\hline Left & $0.21 * * *$ & 1.23 & $0.21 * * *$ & 1.23 & $0.21 * * *$ & 1.24 & $0.21 * * *$ & 1.23 & $0.21 * * *$ & 1.23 & $0.21 * * *$ & 1.23 \\
\hline Centre & $0.1^{*}$ & 1.11 & $1^{*}$ & 1.1 & $0.1^{*}$ & 1.11 & $0.1^{*}$ & 1.11 & $0.1^{*}$ & 1.11 & $0.1^{*}$ & 1.11 \\
\hline \multicolumn{13}{|l|}{ Political interest index (not at all) } \\
\hline Strong & $0.9^{* * *}$ & 2.45 & $0.9^{* * *}$ & 2.45 & $0.9^{* * *}$ & 2.45 & $0.9^{* * * *}$ & 2.46 & $0.9 * * *$ & 2.45 & $0.9^{* * * *}$ & 2.45 \\
\hline Medium & $0.46^{* * *}$ & 1.59 & $0.46^{* * *}$ & 1.59 & $0.47^{* * *}$ & 1.59 & $0.47^{* * *}$ & 1.59 & $0.46^{* * *}$ & 1.59 & $0.47^{* * *}$ & 1.59 \\
\hline Low & $0.32 * * *$ & 1.38 & $0.32 * * *$ & 1.38 & $0.32^{* * *}$ & 1.38 & $0.32^{* * *}$ & 1.38 & $0.32^{* * *}$ & 1.38 & $0.32^{* * *}$ & 1.38 \\
\hline
\end{tabular}


Table A4. Cont.

\begin{tabular}{|c|c|c|c|c|c|c|c|c|c|c|c|c|}
\hline & \multicolumn{2}{|c|}{ Model I } & \multicolumn{2}{|c|}{ Model II } & \multicolumn{2}{|c|}{ Model III } & \multicolumn{2}{|c|}{ Model IV } & \multicolumn{2}{|c|}{ Model V } & \multicolumn{2}{|c|}{ Model VI } \\
\hline & $\beta$ & $\exp (\beta)^{1}$ & $\beta$ & $\exp (\beta)$ & $\beta$ & $\exp (\beta)$ & $\beta$ & $\exp (\beta)$ & $\beta$ & $\exp (\beta)$ & $\beta$ & $\exp (\beta)$ \\
\hline \multicolumn{13}{|l|}{$\begin{array}{l}\text { Climate change } \\
\text { Importance (not a } \\
\text { serious problem) }\end{array}$} \\
\hline A fairly serious problem & $0.21 *$ & 1.23 & $0.21 *$ & 1.23 & $0.21 *$ & 1.23 & $0.21 *$ & 1.23 & $0.21 *$ & 1.23 & 0.21 * & 1.23 \\
\hline A very serious problem & $0.86^{* * *}$ & 2.37 & $0.86^{* * *}$ & 2.37 & $0.86^{* * *}$ & 2.37 & $0.86^{* * *}$ & 2.37 & $0.86^{* * *}$ & 2.37 & $0.86^{* * *}$ & 2.37 \\
\hline \multicolumn{13}{|l|}{ Climate change resp. (no) } \\
\hline National gov. & $0.13 * *$ & 1.13 & $0.12 * *$ & 1.13 & $0.13 * *$ & 1.13 & $0.13 * *$ & 1.13 & $0.12 * *$ & 1.13 & $0.12 * *$ & 1.13 \\
\hline European Union & 0.04 & 1.04 & 0.04 & 1.04 & 0.04 & 1.04 & 0.04 & 1.04 & 0.04 & 1.04 & 0.04 & 1.04 \\
\hline Regional/local authorities & 0.11 ** & 1.12 & $0.11 * *$ & 1.12 & $0.11^{* *}$ & 1.12 & 0.11 ** & 1.12 & $0.11^{* *}$ & 1.12 & $0.11^{* *}$ & 1.12 \\
\hline Business and industry & $0.16^{* * *}$ & 1.17 & $0.16^{* * *}$ & 1.17 & $0.16^{* * *}$ & 1.17 & $0.16^{* * *}$ & 1.17 & $0.16^{* * *}$ & 1.17 & $0.16^{* * *}$ & 1.17 \\
\hline Citizens & $0.38^{* * *}$ & 1.46 & $0.38^{* * *}$ & 1.46 & 0.38 & 1.46 & $0.38^{* * *}$ & 1.46 & $0.38^{* * *}$ & 1.46 & $0.38^{* * *}$ & 1.46 \\
\hline Env. groups & -0.07 & 0.93 & -0.07 & 0.93 & -0.07 & 0.93 & -0.07 & 0.93 & -0.07 & 0.93 & -0.07 & 0.93 \\
\hline \multicolumn{13}{|l|}{$\begin{array}{l}\text { Action on climate change will } \\
\text { lead to innovation (no) }\end{array}$} \\
\hline Yes & $0.16^{* *}$ & 1.18 & $0.16^{* *}$ & 1.18 & $0.16^{* *}$ & 1.18 & $0.16^{* *}$ & 1.18 & 0.16 & 1.18 & $0.16^{* *}$ & 1.18 \\
\hline GDP/capita & $8.43 * 10^{-6}$ & 1 & & & & & & & & & & \\
\hline HDI & & & $10.27^{* *}$ & $28,935.8$ & & & & & & & & \\
\hline HPI & & & & & -0.014 & 0.99 & & & & & & \\
\hline SPI & & & & & & & $0.09 * *$ & 1.09 & & & & \\
\hline Internet skills & & & & & & & & & $0.04 * *$ & 1.04 & & \\
\hline Internet access & & & & & & & & & & & $0.82 * * *$ & 1.09 \\
\hline \multicolumn{13}{|l|}{ Government effectiveness index } \\
\hline \multirow{2}{*}{\multicolumn{13}{|c|}{ Policy performance index }} \\
\hline \multicolumn{4}{|l|}{ Environment } & & & & & & & & & \\
\hline \multirow{2}{*}{\multicolumn{13}{|c|}{ Large town ${ }^{*} \mathrm{HDI}$}} \\
\hline & & & & & & & & & & & & Large town *SPI \\
\hline \multicolumn{13}{|l|}{ Large town *environment } \\
\hline Constant & -5.2 & 0.006 & -4.96 & 0.007 & -4.92 & 0.005 & -4.92 & 0.5 & -5.09 & 0.006 & -11.77 & $7.7 * 10^{-7}$ \\
\hline Observations & 13,714 & & 13,714 & & 13,714 & & 13,714 & & 13,714 & & 13,714 & \\
\hline No. of groups & 28 & & 28 & & 28 & & 28 & & 28 & & 28 & \\
\hline Log likelihood & -6803.1 & & -6801.51 & & -6803.15 & & -6801.55 & & -6800.54 & & -6798.35 & \\
\hline \multirow[t]{2}{*}{ Wald $\mathrm{Chi}^{2}$} & $1030.58^{* * *}$ & & 1038.71 & & 1030.28 & & 1038.65 & & 1043.86 & & $1057.57^{* * *}$ & \\
\hline & \multicolumn{12}{|c|}{ RANDOM PART IDENTITY: COUNTRY } \\
\hline Variance (constant) & 0.28 & & 0.25 & & 0.28 & & 0.25 & & 0.23 & & 0.19 & \\
\hline $\begin{array}{l}\text { (Intercept variance) } \\
\text { (standard error) }\end{array}$ & 0.08 & & 0.07 & & 0.08 & & 0.07 & & 0.07 & & 0.06 & \\
\hline Variance at country level ${ }^{2}(\%)$ & $7.84 \%$ & & $7.06 \%$ & & $7.84 \%$ & & $7.06 \%$ & & $6.53 \%$ & & $5.46 \%$ & \\
\hline LR test & $369.54^{* * *}$ & & $338.71^{* * *}$ & & $370.31 * * *$ & & $309.61^{* * *}$ & & $259.76^{* * *}$ & & $229.46^{* * *}$ & \\
\hline Gender (men) & & & & & & & & & & & & \\
\hline Women & $0.21 * * *$ & 1.23 & $0.21 * * *$ & 1.23 & $0.21^{* * *}$ & 1.23 & $0.2 * * *$ & 1.23 & $0.2^{* * *}$ & 1.23 & $0.2 * * *$ & 1.23 \\
\hline
\end{tabular}


Table A4. Cont.

\begin{tabular}{|c|c|c|c|c|c|c|c|c|c|c|c|c|}
\hline & \multicolumn{2}{|c|}{ Model I } & \multicolumn{2}{|c|}{ Model II } & \multicolumn{2}{|c|}{ Model III } & \multicolumn{2}{|c|}{ Model IV } & \multicolumn{2}{|c|}{ Model V } & \multicolumn{2}{|c|}{ Model VI } \\
\hline & $\beta$ & $\exp (\beta)^{1}$ & $\beta$ & $\exp (\beta)$ & $\beta$ & $\exp (\beta)$ & $\beta$ & $\exp (\beta)$ & $\beta$ & $\exp (\beta)$ & $\beta$ & $\exp (\beta)$ \\
\hline \multicolumn{13}{|l|}{ Age (15-24 years) } \\
\hline 25-34 years & $0.36^{* * *}$ & 1.43 & $0.35^{* * *}$ & 1.43 & $0.35^{* * *}$ & 1.43 & $0.35^{* * *}$ & 1.43 & $0.35^{* * *}$ & 1.42 & $0.36^{* * *}$ & 1.43 \\
\hline $35-44$ years & $0.37 * * *$ & 1.45 & $0.37^{* * *}$ & 1.45 & $0.37^{* * *}$ & 1.45 & $0.37^{* * *}$ & 1.45 & $0.37 * * *$ & 1.45 & $0.38^{* * *}$ & 1.46 \\
\hline 45-54 years & $0.46^{* * *}$ & 1.58 & $0.46^{* * *}$ & 1.58 & $0.46^{* * *}$ & 1.58 & $0.46^{* * *}$ & 1.58 & $0.46^{* * *}$ & 1.58 & $0.46^{* * *}$ & 1.58 \\
\hline 55-64 years & $0.49 * * *$ & 1.63 & $0.49^{* * *}$ & 1.63 & $0.49 * * *$ & 1.63 & $0.49^{* * *}$ & 1.63 & $0.49^{* * *}$ & 1.63 & $0.5^{* * *}$ & 1.64 \\
\hline 65 years and over & $0.45^{* * *}$ & 1.57 & $0.45^{* * *}$ & 1.57 & $0.45^{* * *}$ & 1.57 & $0.45^{* * *}$ & 1.57 & $0.45^{* * *}$ & 1.57 & $0.45^{* * *}$ & 1.57 \\
\hline \multicolumn{13}{|l|}{$\begin{array}{l}\text { Age when stopped } \\
\text { Education (1-15) }\end{array}$} \\
\hline $16-19$ & $0.31 * * *$ & 1.36 & $0.31 * * *$ & 1.36 & $0.31 * * *$ & 1.36 & $0.31^{* * *}$ & 1.36 & $0.31^{* * *}$ & 1.36 & $0.31 * * *$ & 1.37 \\
\hline $20+$ & $0.7^{* * *}$ & 2.02 & $0.7^{* * *}$ & 2.02 & $0.7^{* * *}$ & 2.02 & $0.7^{* * *}$ & 2.02 & $0.7^{* * *}$ & 2.01 & $0.7^{* * * *}$ & 2.02 \\
\hline Still studying & $0.5^{* * *}$ & 1.63 & $0.49^{* * *}$ & 1.64 & $0.49^{* * *}$ & 1.64 & $0.49^{* * *}$ & 1.63 & $0.49^{* * *}$ & 1.63 & $0.49^{* * *}$ & 1.64 \\
\hline No full-time education & 0.12 & 1.13 & 0.12 & 1.12 & 0.12 & 1.12 & 0.12 & 1.13 & 0.12 & 1.13 & 0.12 & 1.13 \\
\hline \multicolumn{13}{|l|}{$\begin{array}{l}\text { Occupation } \\
\text { (not working) }\end{array}$} \\
\hline Self-employed & $0.29^{* * *}$ & 1.34 & $0.29^{* * *}$ & 1.34 & $0.29^{* * *}$ & 1.34 & $0.29 * * *$ & 1.34 & $0.29^{* * *}$ & 1.33 & $0.29^{* * *}$ & 1.33 \\
\hline Employed & -0.07 & 0.93 & -0.07 & 0.93 & -0.07 & 0.93 & -0.07 & 0.93 & -0.07 & 0.93 & -0.07 & 0.93 \\
\hline \multicolumn{13}{|l|}{$\begin{array}{l}\text { Marital status } \\
\text { (single HH without children) }\end{array}$} \\
\hline Single HH with children & $0.28 * * *$ & 1.33 & $0.28^{* * *}$ & 1.33 & $0.28^{* * *}$ & 1.33 & $0.28^{* * *}$ & 1.33 & $0.28^{* * *}$ & 1.33 & $0.28 * * *$ & 1.33 \\
\hline Multiple HH without children & $0.35^{* * *}$ & 1.42 & $0.34^{* * *}$ & 1.42 & $0.35^{* * *}$ & 1.42 & $0.35^{* * *}$ & 1.42 & $0.35 * * *$ & 1.42 & $0.35^{* * *}$ & 1.42 \\
\hline Multiple HH with children & 0.53 *** & 1.7 & $0.53^{* * *}$ & 1.7 & $0.53 * * *$ & 1.7 & $0.53 * * *$ & 1.7 & $0.53 * * *$ & 1.7 & $0.53^{* * *}$ & 1.7 \\
\hline \multicolumn{13}{|l|}{$\begin{array}{l}\text { Difficulties paying bills (most of } \\
\text { the time) }\end{array}$} \\
\hline From time to time & $0.3^{* * *}$ & 1.34 & $0.29^{* * *}$ & 1.34 & $0.3^{* * *}$ & 1.34 & $0.3^{* * *}$ & 1.35 & $0.3^{* * *}$ & 1.35 & $0.3 * * *$ & 1.35 \\
\hline Almost never) & $0.7^{* *}$ & 2.02 & 0.7 ** & 2 & $0.7^{* *}$ & 2.02 & 0.7 ** & 2.02 & $0.7^{* *}$ & 2.02 & $0.7^{* *}$ & 2.02 \\
\hline \multicolumn{13}{|l|}{ Urban area (small town) } \\
\hline Large town & $-0.11^{* *}$ & 0.89 & $-0.11 * *$ & 0.89 & $-0.11 * *$ & 0.89 & $-0.14^{* *}$ & 0.87 & $-0.14^{* *}$ & 0.87 & $-0.13 * *$ & 0.88 \\
\hline \multicolumn{13}{|l|}{ Region (East-Central Europe) } \\
\hline Western Europe & $1.38^{* * *}$ & 4 & $0.91 * * *$ & 2.49 & $1.25^{* * *}$ & 3.49 & $0.69^{*}$ & 2 & $0.71 *$ & 2.04 & $1.25^{* * *}$ & $3.5^{* * *}$ \\
\hline Southern Europe & 0.28 & 1.33 & $0.43 *$ & 1.54 & $0.51 *$ & 1.67 & 0.13 & 1.13 & -0.06 & 0.94 & $0.52 *$ & $1.68 *$ \\
\hline Nordic nations & 1.46 ** & 4.3 & $0.51^{* *}$ & 1.67 & $0.96^{* *}$ & 2.61 & 0.57 & 1.77 & 0.55 & 1.75 & $0.97^{* *}$ & $2.65^{* *}$ \\
\hline \multicolumn{13}{|l|}{$\begin{array}{l}\text { Polit. ideology } \\
\text { (right) }\end{array}$} \\
\hline Left & $0.21 * * *$ & 1.23 & $0.21 * * *$ & 1.23 & $0.21 * * *$ & 1.23 & $0.21 * * *$ & 1.23 & $0.21 * * *$ & 1.23 & $0.21 * * *$ & 1.24 \\
\hline Centre & $0.1^{*}$ & 1.11 & $0.1 *$ & 1.1 & $0.1 *$ & 1.1 & $0.1 *$ & 1.1 & $0.1^{*}$ & 1.1 & $0.1 *$ & 1.11 \\
\hline \multicolumn{13}{|l|}{ Political interest index (not at all) } \\
\hline Strong & $0.9^{* * * *}$ & 2.45 & $0.9^{* * * *}$ & 2.46 & $0.9^{* * *}$ & 2.45 & $0.89^{* * *}$ & 2.45 & $0.9^{* * * *}$ & 2.45 & $0.9^{* * *}$ & 2.45 \\
\hline Medium & $0.46^{* * *}$ & 1.59 & $0.47^{* * *}$ & 1.59 & $0.46^{* * *}$ & 1.59 & $0.46^{* * *}$ & 1.59 & $0.46^{* * *}$ & 1.59 & $0.46^{* * *}$ & 1.59 \\
\hline Low & $0.32 * * *$ & 1.38 & $0.32 * * *$ & 1.38 & $0.32 * * *$ & 1.38 & $0.32 * * *$ & 1.38 & $0.32^{* * *}$ & 1.38 & $0.32 * * *$ & 1.38 \\
\hline \multicolumn{13}{|l|}{$\begin{array}{l}\text { Climate change } \\
\text { Importance (not a } \\
\text { serious problem) }\end{array}$} \\
\hline A fairly serious problem & $0.21 *$ & 1.23 & $0.21 *$ & 1.23 & $0.21^{*}$ & 1.23 & $0.2 *$ & 1.23 & $0.2 *$ & 1.23 & $0.21 *$ & 1.23 \\
\hline A very serious problem & $0.86^{* * *}$ & 2.37 & $0.86^{* * *}$ & 2.36 & $0.86^{* * *}$ & 2.37 & $0.85^{* * *}$ & 2.36 & $0.85^{* * *}$ & 2.36 & $0.86^{* * *}$ & 2.37 \\
\hline
\end{tabular}


Table A4. Cont.

\begin{tabular}{|c|c|c|c|c|c|c|c|c|c|c|c|c|}
\hline & \multicolumn{2}{|c|}{ Model I } & \multicolumn{2}{|c|}{ Model II } & \multicolumn{2}{|c|}{ Model III } & \multicolumn{2}{|c|}{ Model IV } & \multicolumn{2}{|c|}{ Model V } & \multicolumn{2}{|c|}{ Model VI } \\
\hline & $\beta$ & $\exp (\beta)^{1}$ & $\beta$ & $\exp (\beta)$ & $\beta$ & $\exp (\beta)$ & $\beta$ & $\exp (\beta)$ & $\beta$ & $\exp (\beta)$ & $\beta$ & $\overline{\exp (\beta)}$ \\
\hline \multicolumn{13}{|l|}{ Climate change resp. (no) } \\
\hline National gov. & $0.13^{* *}$ & 1.13 & $0.12 * *$ & 1.13 & $0.13^{* *}$ & 1.13 & 0.13 ** & 1.13 & $0.13 * *$ & 1.13 & $0.13^{* *}$ & 1.13 \\
\hline European Union & 0.04 & 1.04 & 0.04 & 1.04 & 0.04 & 1.04 & 0.04 & 1.04 & 0.04 & 1.04 & 0.04 & 1.04 \\
\hline Regional/local authorities & $0.11^{* *}$ & 1.12 & $0.11^{* *}$ & 1.12 & $0.11^{* *}$ & 1.12 & $0.11^{* *}$ & 1.12 & $0.11^{* *}$ & 1.12 & $0.11^{* *}$ & 1.12 \\
\hline Business and industry & $0.16^{* * *}$ & 1.17 & $0.16^{* * *}$ & 1.17 & $0.16^{* * *}$ & 1.17 & $0.16^{* * *}$ & 1.17 & $0.16^{* * *}$ & 1.16 & $0.16^{* * *}$ & 1.16 \\
\hline Citizens & $0.38 * * *$ & 1.46 & $0.38^{* * *}$ & 1.46 & $0.38^{* * *}$ & 1.46 & $0.38^{* * *}$ & 1.47 & $0.38^{* * *}$ & 1.47 & $0.38^{* * *}$ & 1.46 \\
\hline Env. groups & -0.07 & 0.93 & -0.07 & 0.93 & -0.07 & 0.93 & -0.07 & 0.94 & -0.07 & 0.94 & -0.07 & 0.93 \\
\hline \multicolumn{13}{|l|}{$\begin{array}{l}\text { Action on climate change will } \\
\text { lead to innovation (no) }\end{array}$} \\
\hline Yes & $0.16^{* *}$ & 1.18 & $0.16 * *$ & 1.18 & $0.16 * *$ & 1.18 & 0.17 & 1.18 & 0.17 & 1.18 & 0.16 & 1.18 \\
\hline \multicolumn{13}{|l|}{ GDP/capita } \\
\hline HDI & & & & & & & $9.31 *$ & 11040.3 & & & & \\
\hline HPI & & & & & & & & & & & & \\
\hline SPI & & & & & & & & & $0.08 *$ & 1.08 & & \\
\hline \multicolumn{13}{|l|}{ Internet skills } \\
\hline \multicolumn{13}{|l|}{ Internet access } \\
\hline Government effectiveness index & -0.05 & 0.95 & & & & & & & & & & \\
\hline Policy performance index & & & $0.43 * *$ & 1.54 & & & & & & & & \\
\hline Environment & & & & & 0.23 * & 1.26 & & & & & 0.2 & 1.22 \\
\hline Large town *HDI & & & & & & & $2.16^{*}$ & 8.67 & & & & \\
\hline Large town *SPI & & & & & & & & & $0.02 *$ & 1.02 & & \\
\hline Large town *environment & & & & & & & & & & & $0.08 *$ & 1.08 \\
\hline Constant & -5.09 & 0.006 & -5.07 & 0.006 & -5.24 & -0.005 & -4.95 & -0.007 & -4.91 & 0.007 & -5.24 & 0.005 \\
\hline Observations & 13,714 & & 13,714 & & 13,714 & & 13,714 & & 13,714 & & 13,714 & \\
\hline No. Of groups & 28 & & 28 & & 28 & & 28 & & 28 & & 28 & \\
\hline Log likelihood & -6803.27 & & -6800.65 & & -6801.78 & & -6801.05 & & -6799.86 & & -6800.17 & \\
\hline Wald Chi ${ }^{2}$ & $1029.72 * * *$ & & $1043.3^{* * *}$ & & $1037.06^{* * *}$ & & $1040.85^{* * *}$ & & $1041.26^{* * *}$ & & $1039.57^{* * *}$ & \\
\hline \multicolumn{13}{|c|}{ Random part identity: country } \\
\hline Variance (constant) & 0.29 & & 0.23 & & 0.26 & & 0.25 & & 0.25 & & 0.25 & \\
\hline $\begin{array}{l}\text { (Intercept variance) } \\
\text { (standard error) }\end{array}$ & 0.08 & & 0.07 & & 0.07 & & 0.07 & & 0.07 & & 0.25 & \\
\hline Variance at country level (\%) & $8.1 \%$ & & $6.53 \%$ & & $7.32 \%$ & & $7.06 \%$ & & $7.06 \%$ & & $7.06 \%$ & \\
\hline LR test & $369.51^{* * *}$ & & $296.61^{* * *}$ & & $338.27^{* * *}$ & & $340.07^{* * *}$ & & $310.78^{* * *}$ & & $337.01^{* * *}$ & \\
\hline
\end{tabular}

${ }^{1}$ Odds ratio. ${ }^{2}$ Variance partition coefficient: measures the proportion of the total residual variance that is due to between-group variation. ${ }^{* * *} p<0.01,{ }^{* *} p<0.05,{ }^{*} p<0.1$. 


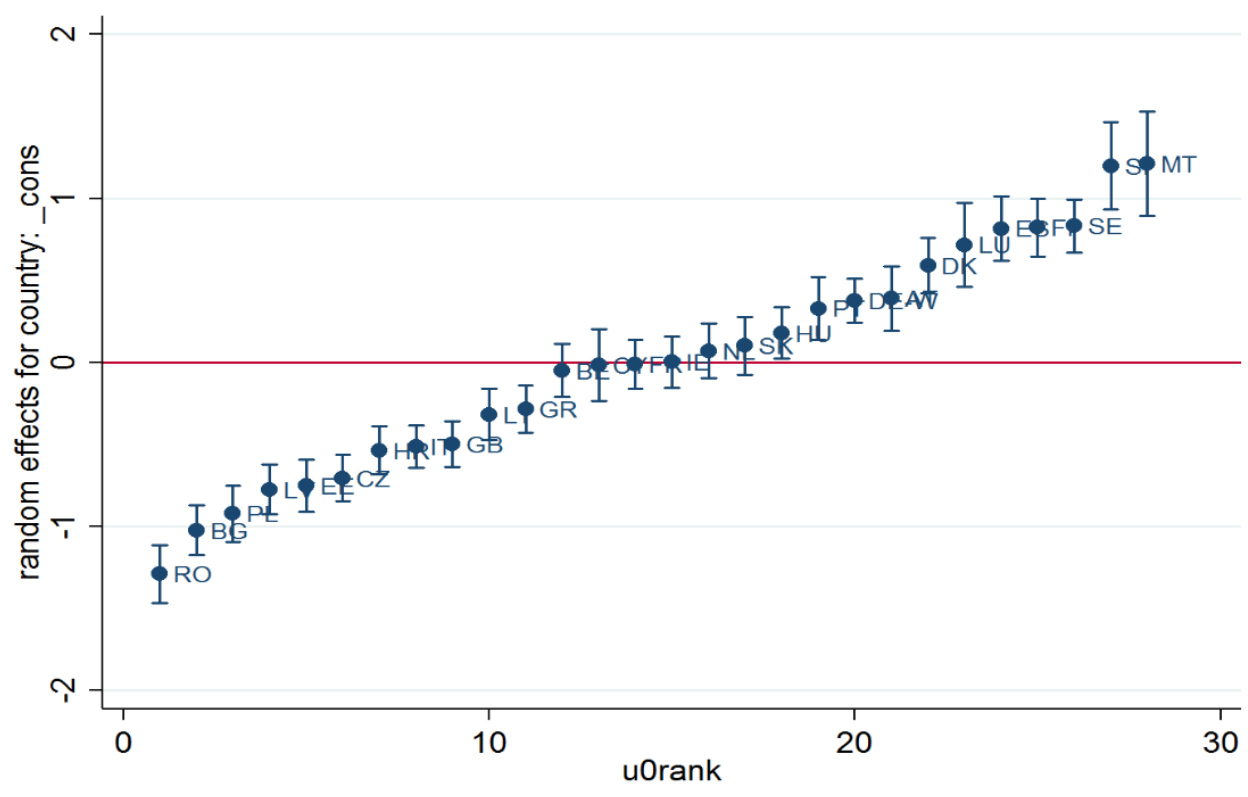

Figure A1. Country-level effects of null model for the decision to undertake climate change individual actions. Source: Author's contribution.

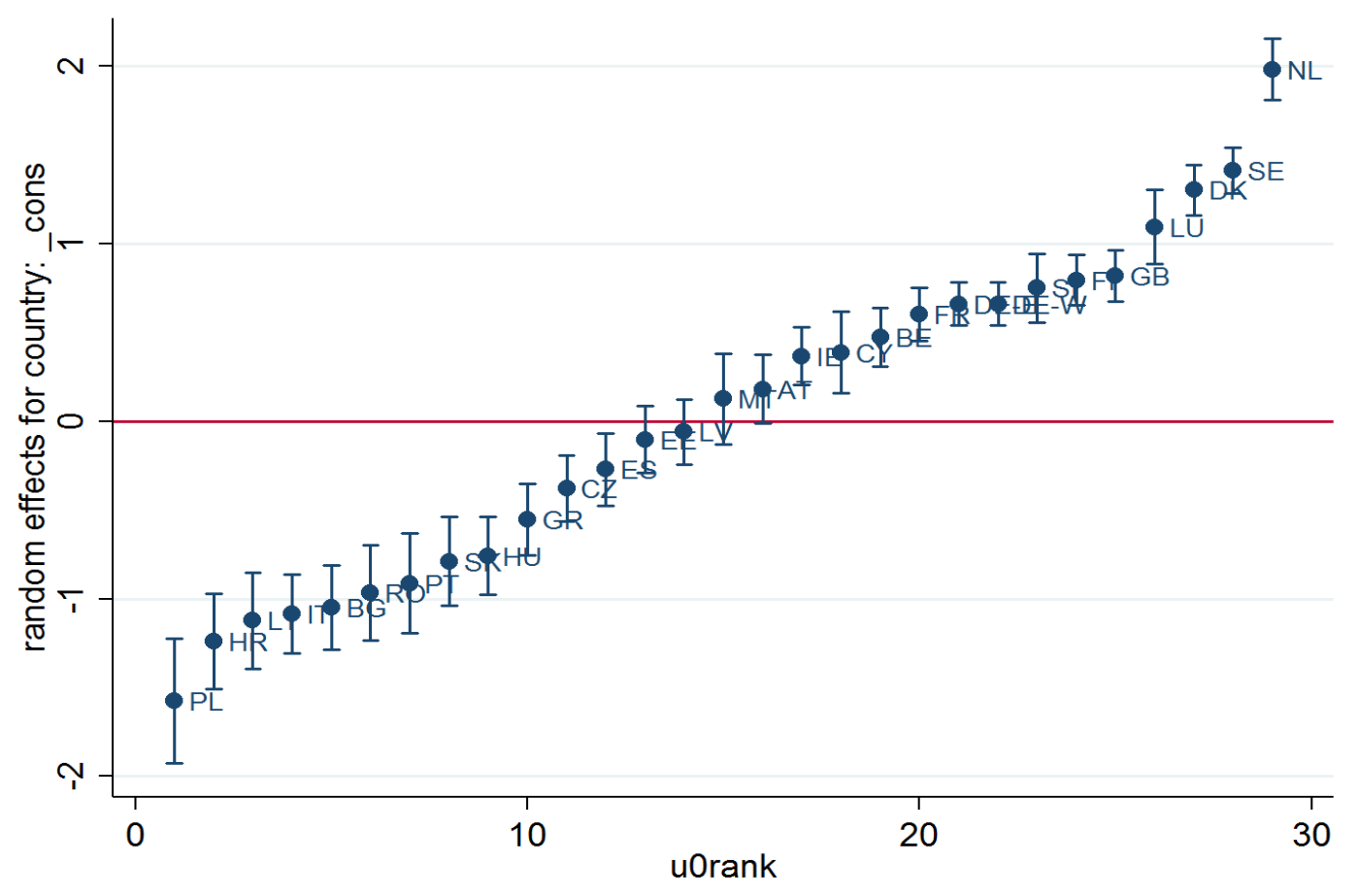

Figure A2. Country-level effects of null model of extra mitigation behaviour. Source: Author's contribution.

\section{References}

1. European Investment Bank. The EIB Circular Economy Guide. Supporting the Circular Transition. Available online: https://www.eib.org/attachments/thematic/circular_economy_guide_en.pdf (accessed on 8 April 2020).

2. Whitmarsh, L. Scepticism and uncertainty about climate change: Dimensions, determinants and change over time. Glob. Environ. Chang. 2011, 21, 690-700. [CrossRef]

3. Whitmarsh, L.; Seyfang, G.; O'Neill, S. Public engagement with carbon and climate change: To what extent is the public 'carbon capable'? Glob. Environ. Chang. 2011, 21, 56-65. [CrossRef] 
4. Thøgersen, J.; Crompton, T. Simple and painless? The limitations of spillover in environmental campaigning. J. Consum. Pol. 2009, 32, 141-163. [CrossRef]

5. Ortega-Egea, J.M.; García-de-Frutos, N.; Antolín-López, R. Why do some people do "more" to mitigate climate change than others? Exploring heterogeneity in psycho-social associations. PLoS ONE 2014, 9, e106645. [CrossRef]

6. Zamfir, A.M.; Mocanu, C.; Grigorescu, A. Circular Economy and decision models among European SMEs. Sustainability 2017, 9, 1507. [CrossRef]

7. GESIS Data Archive for the Social Sciences. Available online: https://www.gesis.org/index.php?id=12376 (accessed on 8 May 2020).

8. Breure, A.M.; Lijzen, J.P.A.; Maring, L. Soil and land management in a circular economy. Sci. Total Environ. 2018, 624, 1125-1130. [CrossRef]

9. Shao, W.C.; Dong, Y.W. Study on the feasibility of improving the indoor air quality from the perspective of circular economy by activation of biological calcium. In Proceedings of the 2019 IEEE International Conference on Architecture, Construction, Environment and Hydraulics (ICACEH), Xiamen, China, 20-22 December 2019; pp. 133-136.

10. Blomsma, F.; Brennan, G. The emergence of circular economy: A new framing around prolonging resource productivity. J. Ind. Ecol. 2017, 21, 603-614. [CrossRef]

11. Naustdalslid, J. Circular economy in China-The environmental dimension of the harmonious society. Int. J. Sustain. Dev. World Ecol. 2017, 21, 303-313. [CrossRef]

12. Ma, S.; Hu, S.; Chen, D.; Zhu, B. A case study of a phosphorus chemical firm's application of resource efficiency and eco-efficiency in industrial metabolism under circular economy. J. Clean. Prod. 2015, 87, 839-849. [CrossRef]

13. Korhonen, J.; Honkasalo, A.; Seppala, J. Circular Economy: The Concept and its Limitations. Ecol. Econ. 2018, 143, 37-46. [CrossRef]

14. Haas, W.; Krausmann, F.; Wiedenhofer, D.Y.; Heinz, M. How circular is the global economy? An assessment of material flows, waste production, and recycling in the European Union and the world in 2005. J. Ind. Ecol. 2015, 19, 765-777. [CrossRef]

15. Wu, H.; Shi, Y.; Xia, Q.; Zhu, W. Effectiveness of the policy of circular economy in China: A DEA-based analysis for the period of 11th five-year-plan. Resour. Conserv. Recycl. 2014, 83, 163-175. [CrossRef]

16. Esposito, M.; Tse, T.; Soufani, K. Is the circular economy a new fast-expanding market? Thunderbird Int. Bus. Rev. 2015, 49, 630-631. [CrossRef]

17. Castellani, V.; Sala, S.; Mirabella, N. Beyond the throwaway society: A life cycle-based assessment of the environmental benefit of reuse. Integr. Environ. Assess. Manag. 2015, 11, 373-382. [CrossRef]

18. Keesstra, S.D.; Bouma, J.; Wallinga, J.; Tittonell, P.; Smith, P.; Cerdà, A.; Montanarella, L.; Quinton, J.N.; Pachepsky, Y.; Van der Putten, W.H.; et al. The significance of soils and soil science towards realization of the United Nations Sustainable Development Goals. Soil 2016, 2, 111-128. [CrossRef]

19. Ellen MacArthur Foundation. What Is a Circular Economy? Available online: https://www. ellenmacarthurfoundation.org/circular-economy/concept (accessed on 12 April 2020).

20. Schut, E.; Crielaard, M.; Mesman, M. Economy in the Dutch Construction Sector: A Perspective for the Market and Government. Available online: http://www.rivm.nl/dsresource?objectid=806b288e-3ae9-47f1a28f-7c208f884b36\&type=org\&disposition=inline (accessed on 11 June 2020).

21. Geissdoerfer, M.; Savaget, P.; Bocken, N.M.P.; Hultink, E.J. The circular economy - a new sustainability paradigm. J. Clean. Prod. 2017, 22, 757-768. [CrossRef]

22. Open Data and the Circular Economy. Available online: https://www.europeandataportal.eu/en/highlights/ open-data-and-circular-economy (accessed on 12 April 2020).

23. Van Buren, N.; Demmers, M.; Van der Heijden, R.; Witlox, F. Towards a Circular Economy: The Role of Dutch Logistics Industries and Governments. Sustainability 2016, 8, 647. [CrossRef]

24. The Circular Economy Foundation. Circular Economy. Towards and Eco-Efficient Europe. Available online: http://economiacircular.org/EN/?page_id=62 (accessed on 21 April 2020).

25. UN-HABITAT. Global Report on Human Settlements 2011: Cities and Climate Change. Available online: https://unhabitat.org/global-report-on-human-settlements-2011-cities-and-climate-change (accessed on 18 April 2020). 
26. Camaren, P.; Swilling, M. Sustainable Resource Efficient Cities: Making it Happen. Nairobi: United Nations Environment Programme. Available online: https://www.academia.edu/12776947/Sustainable_Resource_ Efficient_Cities_Making_it_Happen (accessed on 15 April 2020).

27. Leipold, S.; Petit-Boix, A. The circular economy and the bio-based sector - perspectives of European and German stakeholders. J. Clean. Prod. 2018, 201, 1125-1137. [CrossRef]

28. Liang, S.; Zhang, T. Data acquisition for applying input-output tables in Chinese cities. J. Ind. Ecol. 2011, 15, 825-835. [CrossRef]

29. Mihai, M.; Manea, D.; Titan, E.; Vasile, V. Correlations in the European Circular Economy. Econ. Comput. Econ. Cybern. Stud. Res. 2018, 52, 61-78.

30. Vercalsteren, A.; Christis, M.; Van Hoof, V. Indicators for a Circular Economy. Available online: https: //vlaanderen-circulair.be/en/summa-ce-centre/publications/indicators-for-a-circular-economy (accessed on 10 April 2020).

31. Circular Economy Could Prevent Climate Change. Available online: https://www.therecycler.com/posts/ circular-economy-could-prevent-climate-change (accessed on 12 May 2020).

32. Rutherford, O. Transition to Circular Economy must Be Part of Climate Strategy, Says CCC. Available online: https://resource.co/article/transition-circular-economy-must-be-part-climate-strategy-says-ccc (accessed on 22 May 2020).

33. Intergovernmental Panel on Climate Change (IPCC). AR4 Climate Change 2007: Synthesis Report. Available online: https://www.ipcc.ch/report/ar4/syr (accessed on 17 May 2020).

34. Riahi, K.; Grübler, A.; Nakicenovic, N. Scenarios of long-term socio-economic and environmental development under climate stabilization. Technol. Forecast. Soc. Chang. 2007, 74, 887-935. [CrossRef]

35. Luderer, G.; Pietzcker, R.C.; Bertram, C.; Kriegler, E.; Meinshausen, M.; Edenhofer, O. Economic mitigation challenges: How further delay closes the door for achieving climate targets. Environ. Res. Lett. 2013, 8, 1-8. [CrossRef]

36. Lorenzoni, I.; Nicholson-Cole, S.; Whitmarsh, L. Barriers perceived to engaging with climate change among the UK public and their policy implications. Glob. Environ. Chang. 2007, 17, 445-459. [CrossRef]

37. Pielke, R.A. Misdefining "climate change": Consequences for science and action. Environ. Sci. Policy 2005, 8, 548-561. [CrossRef]

38. IPCC. IPCC Second Assessment Report: Climate Change; Cambridge University Press: Cambridge, UK, 1995.

39. Karl, T.R.; Trenberth, K.E. Modern Global Climate Change. Science 2003, 302, 1719-1723. [CrossRef] [PubMed]

40. McCarthy, J.J.; Canziani, O.F.; Leary, N.A.; Dokken, D.J.; White, K.S. Climate Change 2001: Impacts, Sdaptation, and Vulnerability; Cambridge University Press: Cambridge, UK, 2001.

41. Semenza, J.C.; Hall, D.E.; Wilson, D.J.; Bontempo, B.D.; Sailor, D.J.; George, L.A. Public perception of climate change voluntary mitigation and barriers to behavior change. Am. J. Prev. Med. 2008, 35, 479-487. [CrossRef]

42. Betsill, M.M. Mitigating Climate Change in US Cities: Opportunities and obstacles. Local Environ. 2001, 6, 393-406. [CrossRef]

43. Clarke, J.; Newman, J.; Smith, N.; Vidler, E.; Westmarland, L. Creating Citizen-Consumers: Changing Publics and Changing Public Services; Sage: London, UK, 2007.

44. Seyfang, G. Shopping for sustainability. Environ. Politics 2005, 14, 290-306. [CrossRef]

45. Hoogendoorn, G.; Sütterlin, B.; Siegrist, M. The climate change beliefs fallacy: The influence of climate change beliefs on the perceived consequences of climate change. J. Risk Res. 2020. [CrossRef]

46. de Andalucia, J. Andalucía Innova. Especial Cambio Climático. Available online: http://www. andaluciainvestiga.com/revista/pdf/100PreguntasMedioAmbiente/100medioambiente.pdf (accessed on 7 May 2020).

47. European Environment Agency. Final Energy Consumption by Sector. Available online: http://www.eea. europa.eu/data-and-maps/indicators/final-energy-consumption-by-sector-5/assessment\#toc-1 (accessed on 8 May 2020).

48. Whitmarsh, L. Behavioural responses to climate change: Asymmetry of intentions and impacts. J. Environ. Psychol. 2009, 29, 13-23. [CrossRef]

49. Circular Economy: Definition, Importance and Benefits. Available online: https://www.europarl.europa. eu/news/en/headlines/economy/20151201STO05603/circular-economy-definition-importance-and-benefits (accessed on 9 April 2020). 
50. European Commission. A New Circular Economy Action Plan for a Cleaner and More Competitive Europe. Available online: https://ec.europa.eu/environment/circular-economy (accessed on 10 April 2020).

51. Gifford, R. The dragons of inaction: Psychological barriers that limit climate change mitigation and adaptation. Am. Psychol. 2011, 66, 290-302. [CrossRef] [PubMed]

52. Oreg, S.; Katz-Gerro, T. Predicting proenvironmental behavior cross-nationally: Values, the theory of planned behavior, and value-belief-norm theory. Environ. Behav. 2006, 38, 462-483. [CrossRef]

53. Kollmuss, A.; Agyeman, J. Mind the gap: Why do people act environmentally and what are the barriers to pro-environmental behavior? Environ. Educ. Res. 2002, 8, 239-260. [CrossRef]

54. Franzen, A. Environmental attitudes in international comparison: An analysis of the ISSP surveys 1993 and 2000. Soc. Sci. Q. 2003, 84, 297-308. [CrossRef]

55. Hunter, L.M.; Hatch, A.; Johnson, A. Cross-national gender variation in environmental behaviors. Soc. Sci. Q. 2004, 85, 677-694. [CrossRef]

56. Aoyagi-Usui, M.; Vinken, H.; Kuriyabashi, A. Pro-environmental attitudes and behaviors: An international comparison. Hum. Ecol. Rev. 2003, 10, 23-31.

57. Gelissen, J. Explaining popular support for environmental protection: A multilevel analysis of 50 nations. Environ. Behav. 2007, 39, 392-415. [CrossRef]

58. Guerin, D.; Crete, J.; Mercier, J. A multilevel analysis of the determinants of recycling behavior in the European countries. Soc. Sci. Res. 2001, 30, 195-218. [CrossRef]

59. Gifford, R.; Scannell, L.; Kormos, C.; Smolova, L.; Biel, A. Temporal pessimism and spatial optimism in environmental assessments: An 18-nation study. J. Environ. Psychol. 2009, 29, 1-12. [CrossRef]

60. Kemmelmeier, M.; Król, G.; Kim, Y.H. Values, economics and proenvironmental attitudes in 22 societies. Cross-Cult. Res. 2002, 36, 256-285. [CrossRef]

61. Sarigöllü, E. A cross-country exploration of environmental attitudes. Environ. Behav. 2009, 41, 365-386. [CrossRef]

62. Bord, R.J.; Fisher, A.; O'Connor, R.E. Public perceptions of global warming: United States and international perspectives. Clim. Res. 1998, 11, 75-84. [CrossRef]

63. Brechin, S.R. Comparative public opinion and knowledge on global climatic change and the Kyoto protocol: The, U.S. against the world? Int. J. Sociol. Soc. Pol. 2003, 23, 106-134. [CrossRef]

64. Dunlap, R.E.; Mertig, A.G. Global concern for the environment: Is affluence a prerequisite? J. Soc. 1995, 51, 121-137. [CrossRef]

65. Brechin, S.R.; Kempton, W. Global environmentalism: A challenge to the postmaterialism thesis? Soc. Sci. Q. 1994, 75, 245-269.

66. Inglehart, R. Modernization and Postmodernization: Cultural, Economic, and Political Change in 43 Societies; Princeton University Press: Princeton, NJ, USA, 1997.

67. Franzen, A.; Meyer, R. Environmental attitudes in cross-national perspective: A multilevel analysis of the ISSP 1993 and 2000. Eur. Sociol. Rev. 2010, 26, 219-234. [CrossRef]

68. Diekmann, A.; Franzen, A. The wealth of nations and environmental concern. Environ. Behav. 1999, 31, 540-549. [CrossRef]

69. Schultz, P.W.; Zelezny, L. Values as predictors of environmental attitudes: Evidence for consistency across 14 countries. J. Environ. Psychol. 1999, 19, 255-265. [CrossRef]

70. Washington, H.; Cook, J. Climate Change Denial: Heads in the Sand; Earthscan: London, UK; New York, NY, USA, 2011.

71. Cook, J.; Nuccitelli, D.; Green, S.A.; Richardson, M.; Winkler, B.; Painting, R.; Way, R.; Jacobs, P.; Skuce, A. Quantifying the consensus on anthropogenic global warming in the scientific literature. Environ. Res. Lett. 2013, 8, 024024. [CrossRef]

72. Smith, E.K.; Mayer, A. A social trap for the climate? Collective action, trust and climate change risk perception in 35 countries. Glob. Environ. Chang. 2018, 49, 140-153. [CrossRef]

73. Bain, R.; Cronk, R.; Hossain, R. Global assessment of exposure to faecal contamination through drinking water based on a systematic review. Trop. Med. Int. Health 2014, 19, 917-927. [CrossRef]

74. Tranter, B.; Booth, K. Scepticism in a changing climate: A cross-national study. Glob. Environ. Chang. 2015, 33, 154-164. [CrossRef]

75. Running, K. World citizenship and concern for global warming: Building the case for a strong international civil society. Soc. Forces 2013, 92, 377-399. [CrossRef] 
76. Kvalřy, B.; Finseraas, H.; Listhaug, O. The publics' concern for global warming: A cross-national study of 47 countries. J. Peace Res. 2012, 49, 11-22. [CrossRef]

77. Pew Research Center. Pew Global Attitudes \& Trends Database. 2017. Available online: http://www. pewglobal.org/question-search/?qid=2863\&cntIDs=\&stdIDs (accessed on 11 June 2020).

78. Ding, D.; Maibach, E.; Zhao, X. Support for climate policy and societal action are linked to perceptions about scientific agreement. Nat. Clim. Chang. 2011, 1, 462-466. [CrossRef]

79. Swim, J.; Clayton, S.; Doherty, T.; Gifford, R.; Howard, G.; Reser, J.; Stern, P.; Weber, E. Psychology and global climate change: Addressing a multi-faceted phenomenon and set of challenges. In A Report by the American Psychological Association's Task Force on the Interface between Psychology and Global Climate Change; American Psychological Association: Washington, DC, USA, 2009.

80. Weber, E.U.; Stern, P.C. Public understanding of climate change in the United States. Amer. Psychol. 2011, 66, 315. [CrossRef]

81. Hornsey, M.J.; Harris, E.A.; Fielding, K.S. Relationships among conspiratorial beliefs, conservatism and climate scepticism across nations. Nat. Clim. Chang. 2018, 8, 614-620. [CrossRef]

82. Roppolo, M. Americans More Skeptical of Climate Change Than Others in Global Survey. CBS News 23 July 2014. Available online: https://www.cbsnews.com/news/americans-moreskeptical-of-climate-change-thanothers-in-global-survey (accessed on 12 June 2020).

83. Hamilton, L.C. Public Awareness of the Scientific Consensus on Climate; SAGE: London, UK, 2016; pp. 1-11. [CrossRef]

84. Nisbet, M. The IPCC Report Is a Wake Up Call for Scholars, Advocates, and Philanthropists. Article Adapted from a Lecture Delivered October 11 at the University of Pennsylvania. 2018. Available online: https://medium.com/wealth-of-ideas/the-ipcc-report-isa-wake-up-call-for-scholars-advocates-andphilanthropists-36415d4882f (accessed on 14 June 2020).

85. Scruggs, L.; Benegal, S. Declining public concern about climate change: Can we blame the great recession? Glob. Environ. Chang. 2012, 22, 505-515. [CrossRef]

86. Fairbrother, M.; Sevä, I.J.; Kulin, J. Political trust and the relationship between climate change beliefs and support for fossil fuel taxes: Evidence from a survey of 23 European countries. Glob. Environ. Chang. 2019, 59, 102003. [CrossRef]

87. Lee, S.; Paik, H.S. Korean household waste management and recycling behavior. Build. Environ. 2011, 46, 1159-1166. [CrossRef]

88. Schwartz, S.H. Normative influences on altruism. In Advances in Experimental Social Psychology; Berkowitz, L., Ed.; Academic Press: New York, NY, USA, 1977.

89. Uniting Church. For the Sake of the Planet and All Its People. Uniting Church of Australia Statement. Available online: http://www.unitingjustice.org.au/environment/uca-statements/item/481-for-the-sakeof-theplanet-and-all-its-people (accessed on 11 June 2020).

90. Catholic Earthcare Australia. Climate Change-Our Responsibility to Sustain God's Earth. PositionPaper from Catholic Earthcare Australia. Available online: http://www.catholicearthcare.org.au/POSITION_PAPER. html (accessed on 21 June 2020).

91. Bremer, J.; Linnenluecke, M.K. Determinants of the perceived importance of organisational adaptation to climate change in the Australian energy industry. Aust. J. Manag. 2017, 42, 502-521. [CrossRef]

92. Bockarjova, M.; Steg, L. Can protection motivation theory predict pro-environmental behavior? Explaining the adoption of electric vehicles in the Netherlands. Glob. Environ. Chang. 2014, 28, 276-288. [CrossRef]

93. Bergantino, A.S.; Catalano, M. Individual's psychological traits and urban travel behavior. Int. J. Transp. Econ. 2016, 43, 341-359.

94. De Young, R. Expanding and evaluating motives for environmentally responsible behavior. J. Soc. 2000, 56, 509-526.

95. Frick, J.; Kaiser, F.G.; Wilson, M. Environmental knowledge and conservation behavior: Exploring prevalence and structure in a representative sample. Pers. Individ. Differ. 2004, 37, 1597-1613. [CrossRef]

96. Mobley, C.; Vagias, W.M.; DeWard, S.L. Exploring additional determinants of environmentally responsible behavior: The influence of environmental literature and environmental attitudes. Environ. Behav. 2010, 42, 420-447. [CrossRef]

97. Hines, J.M.; Hungerford, H.P.; Tomera, A.N. Analysis and synthesis of research on responsible environmental behavior: A meta-analysis. J. Environ. Educ. 1986, 18, 1-8. [CrossRef] 
98. Diamantopoulos, A.; Schlegelmilch, B.B.; Sinkovics, R.R.; Bohlen, G.M. Can socio-demographics still play a role in profiling green consumers? A review of the evidence and an empirical investigation. J. Bus. Res. 2003, 56, 465-480. [CrossRef]

99. McCright, A.M.; Dunlap, R.E. Cool dudes: The denial of global climate change among conservative white males in the United States. Glob. Environ. Chang. 2011, 21, 1163-1172. [CrossRef]

100. Whitmarsh, L.; O'Neill, S. Green identity, green living? The role of pro-environmental self-identity in determining consistency across diverse pro-environmental behaviours. J. Environ. Psychol. 2010, 30, 305-314. [CrossRef]

101. Ajzen, I.; Gilbert, N. Attitudes and the prediction of behavior. In Attitudes and Attitude Change; Crano, W.D., Prislin, R., Eds.; Psychology Press: New York, NY, USA, 2008; pp. 289-311.

102. Zelezny, L.C.; Chua, P.; Aldrich, C. Elaborating on gender differences in environmentalism. J. Soc. 2000, 56, 443-457.

103. KatrienVan, A.; Holvoet, N. Intersections of Gender and Marital Status in Accessing Climate Change Adaptation: Evidence from Rural Tanzania. World Dev. 2016, 79, 40-50.

104. Smucker, T.A.; Wisner, B.; Mascarenhas, A.; Munishi, P.; Wangui, E.; Sinha, G. Differentiated livelihoods, local institutions, and the adaptation imperative: Assessing climate change adaptation policy in Tanzania. Geoforum 2015, 59, 39-50. [CrossRef]

105. Mohai, P.; Twight, B.W. Age and environmentalism: An elaboration of the Buttel model using national survey evidence. Soc. Sci. Q. 1987, 68, 798-815.

106. Kaiser, F.G.; Keller, C. Disclosing situational constraints to ecological behavior: A confirmatory application of the mixed Rasch model. Eur. J. Psychol. Assess. 2001, 17, 212-221. [CrossRef]

107. Xiao, C.; McCright, A. Environmental concern and socio-demographic variables: A case study of statistical models. J. Environ. Educ. 2007, 38, 3-13. [CrossRef]

108. Tjernström, E.; Tietenberg, T. Do differences in attitudes explain differences in national climate change policies? Ecol. Econ. 2008, 65, 315-324. [CrossRef]

109. Butler, J. Gender Trouble: Feminism and the Subversion of Identity; Routledge: London, UK, 1990.

110. Dai, J.; Kesternich, M.; Löschel, A.; Ziegler, A. Extreme weather experiences and climate change beliefs in China: An econometric analysis. Ecol. Econ. 2015, 116, 310-321. [CrossRef]

111. Cottrell, S.P. Influence of sociodemographics and environmental attitudes on general responsible environmental behavior among recreational boaters. Environ. Behav. 2003, 35, 347-375. [CrossRef]

112. Dietz, T.; Stern, P.C.; Guagnano, G.A. Social structural and social psychological bases of environmental concern. Environ. Behav. 1998, 30, 450-471. [CrossRef]

113. Zsóka, A.; Szerényi, Z.; Széchy, A.; Kocsis, T. Greening due to environmental education? Environmental knowledge, attitudes, consumer behaviour and everyday proenvironmental activities of Hungarian high school and university students. J. Clean. Prod. 2012, 48, 126-138. [CrossRef]

114. Francis, B. Teaching manfully? Exploring gendered subjectivities and power via analysis of men teachers' gender performance. Gend. Educ. 2008, 20, 109-122. [CrossRef]

115. Nayak, A.; Kehily, M.J. Gender undone: Subversion, regulation and embodiment in the work of Judith Butler. Br. J. Sociol. Educ. 2006, 27, 459-472. [CrossRef]

116. Chant, S. Women-headed households: Poorest of the poor? Perspectives from Mexico, Costa Rica and the Philippines. IDS Bull. 1997, 28, 26-48. [CrossRef]

117. Englert, B. Changing land rights and gendered discourses: Examples from the Uluguru Mountains. In Women's Land Rights and Privatization in Eastern Africa; Tanzania, B., Englert, E., Daley, Eds.; James Currey: Oxford, UK, 2008; pp. 83-100.

118. Boto-García, D.; Bucciol, A. Climate change: Personal responsibility and energy saving. Ecol. Econ. 2020, 169, 106530. [CrossRef]

119. Subaru, K.M.; Bertone, E. From Thoughts to Actions: The Importance of Climate Change Education in Enhancing Students' Self-Efficacy. Aust. J. Environ. Educ. 2019, 35, 123-144.

120. Adger, N.W. Social vulnerability to climate change and extremes in coastal Vietnam. World Dev. 1999, 27, 249-269. [CrossRef]

121. Berman, R.J.; Quinn, C.H.; Paavola, J. Identifying drivers of household coping strategies to multiple climatic hazards in Western Uganda: Implications for adapting to future climate change. Clim. Dev. 2015, 7, 71-84. [CrossRef] 
122. Clark, C.F.; Kotchen, M.J.; Moore, R.M. Internal and external influences on pro-environmental behavior: Participation in a green electricity program. J. Environ. Psychol. 2003, 23, 237-246. [CrossRef]

123. Dimian, G.; Marin, E.; Jablonsky, J. Investigating the long and short-run salary-employment relationship in Romania: A sectorial approach using the ARDL model. Econ. Comput. Econ. Cybern. Stud. Res. 2019, 53, 5-20.

124. Bene, C. Are fishers poor or vulnerable? Assessing economic vulnerability in small-scale fishing communities. J. Dev. Stud. 2009, 45, 911-933. [CrossRef]

125. Domene, E.; Sauri, D. Urbanisation and water consumption: Influencing factors in the metropolitan region of Barcelona. Urban. Stud. 2006, 43, 1605-1623. [CrossRef]

126. Renwick, M.E.; Archibald, S.O. Demand side management policies for residential water use. Land Econ. 1998, 74, 343-359. [CrossRef]

127. Gouldson, A.; Colenbrander, S.; Sudmant, A.; Papargyropoulou, E.; Kerr, N.; McAnulla, F.; Hall, S. Cities and climate change mitigation: Economic opportunities and governance challenges in Asia. Cities 2016, 54, 11-19. [CrossRef]

128. Zhifu, M.; Guan, D.; Liu, Z.; Liu, J.; Viguié, V.; Fromer, N.; Wang, Y. Cities: The core of climate change mitigation. J. Clean. Prod. 2019, 207, 582-589.

129. Rosenzweig, C.; Solecki, W.; Hammer, S.A.; Mehrotra, S. Cities lead the way in climate-change action. Nature 2010, 467, 909-911. [CrossRef]

130. Vermeer, M.; Rahmstorf, S. Global sea level linked to global temperature. Proc. Natl. Acad. Sci. USA 2009, 106, 21527-21532. [CrossRef] [PubMed]

131. Reckien, D.; Salvia, M.; Heidrich, O.; Church, J.M.; Pietrapertosa, F.; De Gregorio-Hurtado, S.; D’Alonzo, V.; Foley, A.; Simoes, V.; Krkoška, V.; et al. How are cities planning to respond to climate change? Assessment of local climate plans from 885 cities in the EU-28. J. Clean. Prod. 2018, 191, 207-219. [CrossRef]

132. Unsworth, K.L.; Fielding, K.S. It's political: How the salience of one's political identity changes climate change beliefs and policy support. Glob. Environ. Chang. 2014, 27, 131-137. [CrossRef]

133. Scott, D.; Willits, F.K. Environmental attitudes and behavior: A Pennsylvania survey. Environ. Behav. 1994, 26, 239-260. [CrossRef]

134. Leiserowitz, A.A.; Maibach, E.; Roser-Renouf, C.; Hmielowski, J.D. Politics \& Global Warming: Democrats, Republicans, Independents, and the Tea Party. Sci. News 2011, 137. [CrossRef]

135. Leviston, Z.; Walker, I. Beliefs and denials about climate change: An Australian perspective. Ecopsychology 2012, 4, 277-285. [CrossRef]

136. Pidgeon, N. Public understanding of, and attitudes to, climate change: UK and international perspectives and policy. Clim. Policy 2012, 12, S85-S108. [CrossRef]

137. Ziegler, A. Political orientation, environmental values, and climate change beliefs and attitudes: An empirical cross country analysis. Energy Econ. 2017, 63, 144-153. [CrossRef]

138. Steg, L. Limiting climate change requires research on climate action. Nat. Clim. Chang. 2018, 8, 754-761. [CrossRef]

139. Harring, N. Understanding the effects of corruption and political trust on willingnessto make economic sacrifices for environmental protection in a cross-national perspective. Soc. Sci. Q. 2013, 94, 660-671. [CrossRef]

140. Kollmann, A.; Reichl, J. How trust in governments influences the acceptance of environmental taxes. In Political Economy and Instruments of Environmental Politics; Schneider, F., Kollman, A., Reichl, J., Eds.; MIT Press: Cambridge, UK, 2015.

141. Klenert, D.; Mattauch, L.; Combet, E.; Edenhofer, O.; Hepburn, C.; Rafaty, R.; Stern, N. Making carbon pricing work for citizens. Nat. Clim. Chang. 2018, 8, 669-677. [CrossRef]

142. Pharr, S.J.; Putnam, R.D.; Dalton, R. A Quarter-Century of Declining Confidence. J. Democr. 2000, 11, 5-25. [CrossRef]

143. Dalton, R. The Social Transformation of Trust in Government. Int. Rev. Sociol. 2005, 15, 133-154. [CrossRef]

144. Lo, A.; Chow, A. The Relationship between Climate Change Concern and National Wealth. Clim. Chang. 2015, 131, 335-348. [CrossRef]

145. Burton-Chellew, M.N.; May, R.M.; West, S.A. Combined inequality in wealth and risk leads to disaster in the climate change game. Clim. Chang. 2013, 120, 815-830. [CrossRef] 
146. Brown, T.C.; Kroll, S. Avoiding an uncertain catastrophe: Climate change mitigation under risk and wealth heterogeneity. Clim. Chang. 2017, 141, 155-166. [CrossRef]

147. Lankao, P.R.; Nychka, D.; Tribbia, J.L. Development and greenhouse gas emissions deviate from the 'modernization'theory and 'convergence'hypothesis. Clim. Res. 2008, 38, 17-29. [CrossRef]

148. Parry, M.; Canziani, O.; Palutikof, J.; van der Linden, P.; Hanson, C. Climate Change 2007: Impacts, Adaptation and Vulnerability. In Contribution of Working Group II to the Fourth Assessment Report of the Intergovernmental Panel on Climate Change; Parry, M.L., Canziani, O.F., Palutikof, J.P., van der Linden, P.J., Hanson, C.E., Eds.; Cambridge University Press: Cambridge, UK, 2007; p. 976.

149. Anderson, K. Talks in the city of light generate more heat. Nature 2015, 528, 437. [CrossRef]

150. Anderson, K.; Le Quéré, C.; Mclachlan, C. Radical emission reductions: The role of demand reductions in accelerating full decarbonization. Carbon Manag. 2014, 5, 321-323. [CrossRef]

151. Lamb, W.F.; Steinberger, J.K. Human well-being and climate change mitigation. Wiley Interdiscip. Rev. Clim. Chang. 2017, 8, e485. [CrossRef]

152. Adua, L.; York, R.; Schuelke-Leech, B.A. The human dimensions of climate change: A micro-level assessment of views from the ecological modernization, political economy and human ecology perspectives. Soc. Sci. Res. 2016, 56, 26-43. [CrossRef]

153. Mol, A.P.J.; Sonnenfeld, D.A.; Spaargaren, G. The Ecological Modernisation Reader: Environmental Reform in Theory and Practice; Routledge: London, UK; New York, NY, USA, 2009.

154. Balogun, A.L.; Marks, D.; Sharma, R.; Shekhar, H.; Balmes, C.; Maheng, D.; Salehi, P. Assessing the Potentials of Digitalization as a Tool for Climate Change Adaptation and Sustainable Development in Urban Centres. Sustain. Cities Soc. 2020, 53, 101888. [CrossRef]

155. United Nations. The Age of Digital Interdependence. Available online: https://www.un.org/en/pdfs/ DigitalCooperation-report-for\%20web.pdf (accessed on 28 June 2020).

156. Kalas, P.P.; Finlay, A. Planting the Knowledge Seed: Adapting to Climate Change Using ICTs; Building Communication Opportunities (BCO) Alliance, 2009; Available online: https:/www.apc.org/sites/default/ files/BCO_ClimateChange.pdf (accessed on 7 May 2020).

157. Vining, J.; Ebreo, A. What makes a recycler? A comparison of recyclers and nonrecyclers. Environ. Behav. 1990, 22, 55-73. [CrossRef]

158. Lawrence, E.K.; Estow, S. Responding to misinformation about climate change. Appl. Environ. Educ. Commun. 2017, 16, 117-128. [CrossRef]

159. Gullberg, A.T.; Aardal, B. Is climate change mitigation compatible with environmental protection? Exploring voter attitudes as expressed through "old" and "new" politics in Norway. Environ. Policy Gov. 2019, 29, 67-80. [CrossRef]

160. Reckien, D.; Flacke, J.; Dawson, R.J.; Heidrich, O.; Olazabal, M.; Foley, A.; Hamann, J.J.-P.; Orru, H.; Salvia, M.; Hurtado, S.D.G.; et al. Climate change response in Europe: What's the reality? Analysis of adaptation and mitigation plans from 200 urban areas in 11 countries. Clim. Chang. 2013, 122, 331-340. [CrossRef]

161. Puppim Oliveira, J.A.; Doll, C.N.H.; Kurniawan, T.A.; Geng, Y.; Kapshe, M. HuisinghPromoting win-win situations in climate change mitigation, local environmental quality and development in Asian cities through co-benefits. J. Clean. Prod. 2013, 58, 1-6. [CrossRef]

162. Bulkeley, H.K. Kern Local government and the governing of climate change in Germany and the UK. Urban. Stud. 2006, 43, 2237-2259. [CrossRef]

163. Heidrich, O.; Tiwary, A. Environmental appraisal of green production systems: Challenges faced by small companies using life cycle assessment. Int. J. Prod. Res. 2013, 51, 5884-5896. [CrossRef]

164. Hunt, A.; Watkiss, P. Climate change impacts and adaptation in cities: A review of the literature. Clim. Chang. 2011, 104, 13-49. [CrossRef]

165. Villarroel, R.; Walker, M.B.; Beck, J.W.; Hall, R.J.; Dawson, O. Identifying key technology and policy strategies for sustainable cities: A case study of London. Environ. Dev. 2017, 21,1-18. [CrossRef]

166. Wende, W.; Bond, A.; Bobylev, N.; Stratmann, L. Climate change mitigation and adaptation in strategic environmental assessment. Environ. Impact Assess. Rev. 2012, 32, 88-93. [CrossRef]

167. Baranzini, A.; Carattini, S. Effectiveness, earmarking and labeling: Testing the acceptability of carbon taxes with survey data. Environ. Econ. Policy Stud. 2017, 19, 197-227. [CrossRef] 
168. Human Development Report 2019 beyond Income, beyond Averages, beyond Today: Inequalities in Human Development in the 21st Century. Available online: http://hdr.undp.org/sites/default/files/hdr2019.pdf (accessed on 12 May 2020).

169. Special Eurobarometer Report 489. Available online: https://op.europa.eu/en/publication-detail/-/publication/ 85980533-adbc-11e9-9d01-01aa75ed71a1 (accessed on 12 June 2020). [CrossRef]

170. Special Eurobarometer Report 490. Available online: https://ec.europa.eu/clima/sites/clima/files/support/ docs/report_2019_en.pdf (accessed on 12 June 2020). [CrossRef]

(c)

(C) 2020 by the authors. Licensee MDPI, Basel, Switzerland. This article is an open access article distributed under the terms and conditions of the Creative Commons Attribution (CC BY) license (http://creativecommons.org/licenses/by/4.0/). 